\title{
Doubly protonated species collision induced dissociation for identification of isocyclosporins
}

Anna A. Baranova ${ }^{\mathrm{a}}$, Alexey A. Chistov ${ }^{\mathrm{b}, \mathrm{c}, \mathrm{d}}$, Maxim V. Shuvalover,e, Anton P. Tyurin ${ }^{\mathrm{a}, \mathrm{d}}$, Mikhail V. Biryukov ${ }^{\mathrm{a}, \mathrm{e}}$, Igor A. Ivanov ${ }^{\mathrm{b}}$, Vera S. Sadykova ${ }^{\mathrm{a}}$, Aleksander V. Kurakov ${ }^{\mathrm{e}}$, Albina I. Sergeeva ${ }^{\mathrm{e}}$, Vladimir A. Korshun ${ }^{\mathrm{a}, \mathrm{b}, \mathrm{d},{ }^{*} \text {, }}$ Vera A. Alferova ${ }^{\mathrm{a}, \mathrm{d}, * *}$

${ }^{\text {a }}$ Gause Institute of New Antibiotics, Bolshaya Pirogovskaya 11, Moscow 119021, Russia

${ }^{\mathrm{b}}$ Shemyakin-Ovchinnikov Institute of Bioorganic Chemistry, Miklukho-Maklaya 16/10, Moscow 117997, Russia

${ }^{\mathrm{c}}$ Orekhovich Research Institute of Biomedical Chemistry, Pogodinskaya 10, Moscow 119121, Russia

${ }^{\mathrm{d}}$ Department of Biology and Biotechnology, National Research University Higher School of Economics, Vavilova 7, Moscow 117312, Russia

${ }^{\mathrm{e}}$ Lomonosov Moscow State University, 1-3 Leninskiye Gory, 119992, Moscow, Russia

Corresponding Authors: Vladimir A. Korshun: Tel./fax: +7-495-725-6715, e-mail: v-korshun@yandex.ru, Shemyakin-Ovchinnikov Institute of Bioorganic Chemistry, Miklukho-Maklaya 16/10, Moscow, 117997, Russia; Vera A. Alferova: Tel./fax: +7-499-246-6983, e-mail: alferovava@gmail.com, Gause Institute of New Antibiotics, Bolshaya Pirogovskaya 11, Moscow 119021, Russia 


\section{Abstract}

Nonribosomal cyclopeptide cyclosporin A (CsA), produced by fungus Tolypocladium inflatum, is an extremely important immunosuppressive drug used in organ transplantations and for therapy of autoimmune diseases. Here we report for the first time production of CsA, along with related cyclosporins B and C, by Tolypocladium inflatum strains of marine origin (White Sea). Cyclosporins A-C contain an unusual amino acid, (4R)-4-((E)-2-butenyl)-4, $N$-dimethyl-L-threonine (MeBmt), and are prone to isomerization to non-active isocyclosporine by $\mathrm{N} \rightarrow \mathrm{O}$ acyl shift of valine connected to $\mathrm{MeBmt}$ in acidic conditions. CsA and isoCsA are not distinguishable in MS analysis of $[\mathrm{M}+\mathrm{H}]^{+}$ions due to the rapid $[\mathrm{CsA}+\mathrm{H}]^{+} \rightarrow[\mathrm{isoCsA}+\mathrm{H}]^{+}$conversion. We found that the $\mathrm{N} \rightarrow \mathrm{O}$ acyl shift is completely suppressed in cyclosporine $[\mathrm{M}+2 \mathrm{H}]^{2+}$ ions, and their MS/MS fragmentation can be used for rapid and unambiguous analysis of cyclosporins and isocylosporins. The fragmentation patterns of $[\mathrm{CyA}+2 \mathrm{H}]^{2+}$ and $[\text { isoCyA }+2 \mathrm{H}]^{2+}$ ions were analyzed and explained. The developed approach could be useful for MS analysis of other peptides containing $\beta$-hydroxy- $\alpha$-amino acids.

\section{Keywords}

Cyclosporin, isocyclosporin, doubly-charged ions, collision-induced dissociation, identification 


\section{Highlights}

- Characteristic $\mathrm{N} \rightarrow \mathrm{O}$ acyl shift in cyclosporins is suppressed in doubly protonated ions

- Analysis of CID spectra of doubly protonated ions reveals unique fragmentation routes

- Double protonation of cyclosporins yields more intense peaks vs. single protonation

- Dereplication techniques can be based on analysis of doubly protonated peptide CID

- High degree of fragmentation is easily achieved for doubly protonated peptides

\section{Graphical abstract}

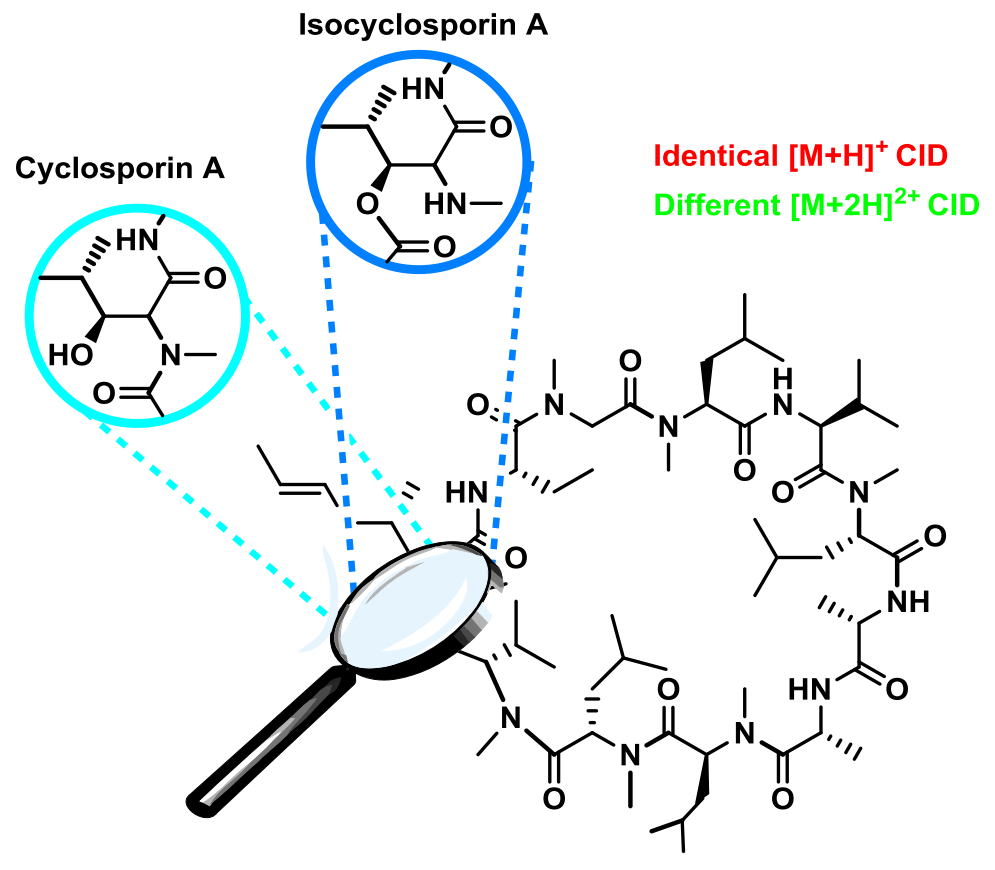




\section{Introduction}

Cyclosporin A (CsA) is a cyclic undecapeptide with a variety of biological activities, and one of the most commonly used immunosuppressive drugs [1]. Seven out of eleven amino acids in CsA are N-methylated, including (4R)-4-((E)-2-butenyl)-4,N-dimethyl-L-threonine (MeBmt). (Fig. 1). Reversible conversion of cyclosporin A into isocyclosporin A (isoCsA) was noticed during structure elucidation of CsA [2]. Acidic conditions facilitate $\mathrm{N} \rightarrow \mathrm{O}$ acyl shift in $\mathrm{MeVal}^{11}-\mathrm{MeBmt}^{1}$ pair of CsA, leading to isoCsA (Fig. 1), whereas in neutral and basic conditions isoCsA is prone to isomerization into CsA [3-6]. IsoCsA completely lacks immunosuppressive properties, thus, its presence in CsA substance is undesirable.
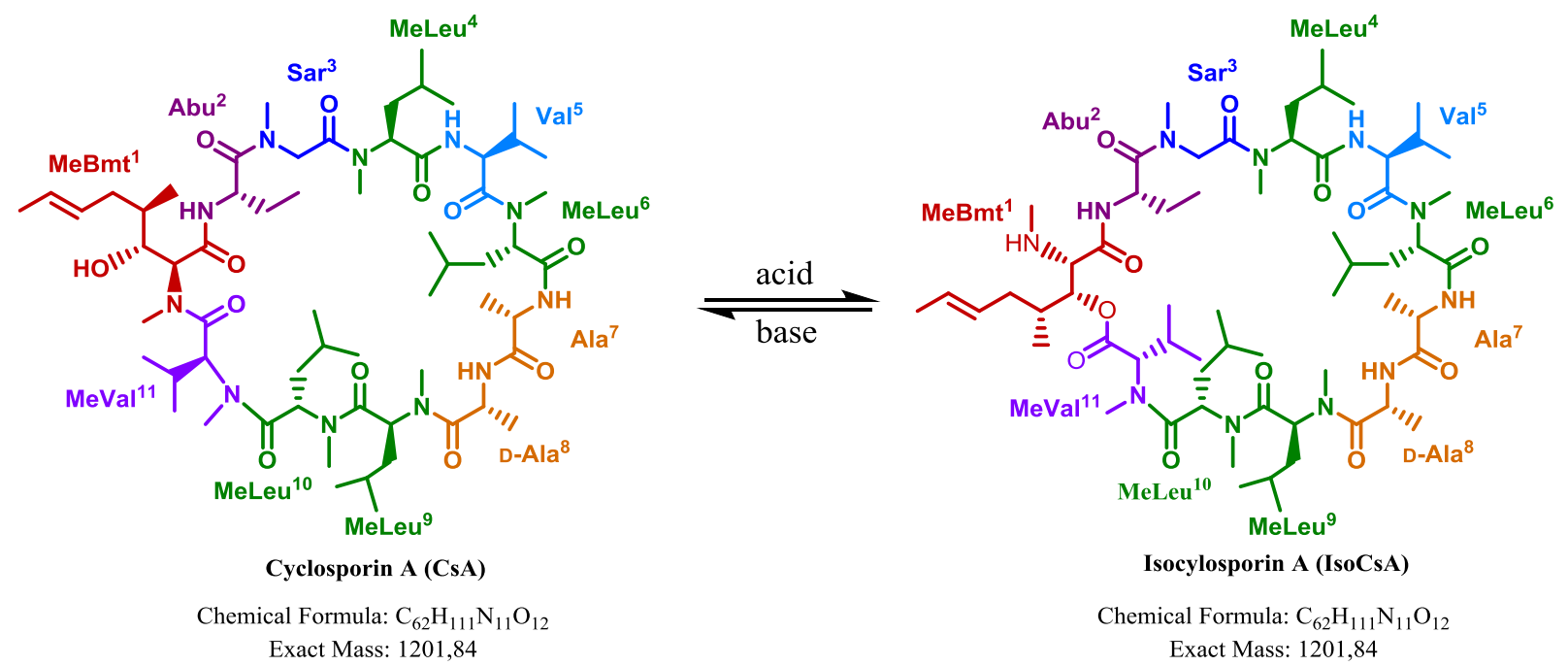

Fig. 1. Structures and interconversions of cyclosporin A and isocyclosporin A.

The enormous importance of CsA as a drug stipulated the development of a number of analytical methods for its detection, identification, and quantificaton. These include HPLC, immunoassay and HPLC-mass spectrometry approaches [7-15]. Methods for analysis of cyclosporins in natural sources also draw significant attention. For example, the $\mathrm{MS}^{\mathrm{n}}$ analytical platform was worked out for CsA congener analysis, including biotransformed analogs [16]. Recently, the MS networking approach allowed to increase the diversity of peptidic natural products, including the chemical space of cyclosporins [17].

CsA and isoCsA are isomers possessing the same molecular mass (Fig. 1), moreover, the $\mathrm{N} \rightarrow \mathrm{O}$ acyl shift in $[\mathrm{M}+\mathrm{H}]^{+}$ions (corresponding to the $[\mathrm{CsA}+\mathrm{H}]^{+} \rightarrow[\text { isoCsA }+\mathrm{H}]^{+}$transformation) was observed in an ion trap [18]. Thus, their straightforward MS-distinguishing is complicated, so special techniques are needed. For example, a specific post-column derivatization technique with divalent metal ions was suggested for differentiation of CsA 
and isoCsA [19]. Here we report specific patterns of fragmentation of $[\mathrm{M}+2 \mathrm{H}]^{2+}$ ions for MeBmt-containing cyclosporins and isocyclosporins, facilitating their rapid and unambiguous distinguishing.

\section{Experimental}

\subsection{Chemicals}

Sorbent: silica gel 60 ("Merck"). Solvents: methanol (MeOH, "Chimmed"); dichloromethane $\left(\mathrm{CH}_{2} \mathrm{Cl}_{2}\right.$ “Chimmed"); ethyl acetate (“Chimmed"), ethanol (EtOH, “Chimmed”), acetonitrile (HPLC grade ("Panreac"), ULC/MS grade acetonitrile ("Biosolve"), trifluoroacetic acid (TFA, "Sigma-Aldrich"); formic acid ( $\mathrm{HCO}_{2} \mathrm{H}$, “Honeywell”). Deionized water for HPLC was produced by a Milli-Q water purifier (Milli-Q ${ }^{\circledR}$ Plus “Millipore”). Cyclosporin A (CsA) was supplied by Sigma-Aldrich. PCR reagent: HS Taq DNA polymerase (“Evrogen”).

\subsection{Instrumentation}

Sequencing was performed using BigDye Terminator v3.1 Cycle Sequencing Kit (“Applied Biosystems”) and Applied Biosystems 3730 xl automatic sequencer. The extracts were concentrated on a rotary evaporator (“Büchi”). Analytical chromatography was performed on a high performance Knauer 2600 liquid chromatograph. Chromatographic separation and on-line mass spectral analyses were performed with an Agilent 6340 Ion Trap equipped with an electrospray ionization source (ESI) (“Agilent Technologies”) coupled to an Agilent 1100 HPLC system (G1379A degasser, G1312A binary gradient pump, G1367B high performance autosampler, G1316A column thermostat and G1314A variable wavelength detector) (“Agilent Technologies”). Experiments with Orbitrap detector were performed using Thermo Scientific LTQ Orbitrap XL hybrid instrument with Waters Alliance 2695 separation module equipped with a YMC Triart C18 column $(1.9 \mu \mathrm{m}, 50 \times 2.1 \mathrm{~mm})$. For time-offlight detection HPLC system (Agilent-1260 Infinity (USA)) consisting of binary pump, thermostat, photometric detector VWD, and the mass spectrometer Agilent 6520 Accurate-Mass quadrupole time-of-flight (Q-TOF) (USA) were used. Chemstation (rev. B.01.03 SR1), 6300 series TrapControl (v 6.2) and Data Analysis (v. 3.4) software was used for data acquisition and qualitative analyses.

\subsection{Screening and identification of marine fungi}

In this study we investigated some of the strains isolated from White Sea bottom soil. Fungal diversity and biological activity screening were described earlier [20]. Preliminary identification was performed according to 
the morphology of spores, colonies and phenotypic characteristics. For further confirmation of morphological identification, the most active strains were subjected to molecular phylogenetic identification based on internal transcribed spacers (ITS) sequence analysis of ribosomal DNA. Total DNA was extracted with CTAB (cetyl trimethyl ammonium bromide) method [21]. ITS regions were amplified using universal primers ITS1 and ITS4 (TCCGTAGGTGAACCTGCGG/TCCTCCGCTTATTGATATGC) with standard PCR protocols [22]. PCR was performed by HS Taq DNA polymerase. DNA fragments were separated by electrophoresis in $1.2 \%$ agarose gel with EtBr, analyzed with UV light $(360 \mathrm{~nm})$, extracted with CleanUp Mini kit. The final PCR products were sequenced by the "Evrogen" company using BigDye Terminator v3.1 Cycle Sequencing Kit with Applied Biosystems $3730 \mathrm{xl}$ automatic sequencer. The resulting sequences were used for GenBank search and species determination by BLASTn software.

\subsection{Cultivation of selected strains, extraction and fractionation}

The strains $T$. inflatum were grown in autoclaved $250 \mathrm{~mL}$ Erlenmeyer flasks containing $100 \mathrm{~mL}$ soluble Czapek medium (3\% glucose, $\left.0.2 \% \mathrm{NaNO}_{3}, 0.1 \% \mathrm{~K}_{2} \mathrm{HPO}_{4}, 0.05 \% \mathrm{KCl}, 0.05 \% \mathrm{MgSO}_{4}, 0.01 \% \mathrm{FeSO}_{4}\right)$ in stationary mode for 14 days at $25^{\circ} \mathrm{C}$.

Fermentation broth was separated by centrifugation and filtration into culture liquid and mycelium; the latter was discarded. The filtrate was extracted with ethylacetate (thrice repeated extraction with $20 \%$ of culture liquid volume). Combined organic layers were concentrated to dryness in vacuo at $42^{\circ} \mathrm{C}$ on a rotary evaporator. The residue was dissolved in $70 \% \mathrm{EtOH}$ and applied to a flash chromatography column. Flash chromatography was performed on silica gel $(40-63 \mu \mathrm{m}$, column size $40 \times 60 \mathrm{~mm})$. The extract was eluted with $\mathrm{CH}_{2} \mathrm{Cl}_{2} / \mathrm{MeOH}$ step gradient (v/v 100:0, 100:1, 50:1, 20:1, 10:1, 5:1, 3:1, each $100 \mathrm{~mL}$ ). Fractions with solvent ratio from 20:1 to 5:1 yielded an antibiotic concentrate. Collected fractions were concentrated to dryness in vacuo on a rotary evaporator. The composition of the fractions was analyzed using TLC and HPLC.

TLC analysis was performed on silica gel plates (Cat. no. 1.05554.0001, "Merck”), eluent $-\mathrm{CH}_{2} \mathrm{Cl}_{2} / \mathrm{MeOH}$ (v/v 5:1).

Further separation was performed with reverse phase HPLC analysis on a $4.6 \times 250 \mathrm{~mm}$ C18 SunFire column (Waters, $5 \mathrm{~mm}, 100 \AA$ ). Eluent A was $0.1 \%$ TFA in deionized water, eluent B was $80 \%$ acetonitrile with $0.1 \%$ 
TFA in deionized water. The column was eluted at a flow rate of $1 \mathrm{~mL} / \mathrm{min}:$ 0-20 $\min$ 60:40 $\rightarrow$ 5:95 (A:B, v/v); 20-40 $\min 60: 40 \rightarrow 60: 40(\mathrm{~A}: \mathrm{B}, \mathrm{v} / \mathrm{v})$. Detection wavelength was $214 \mathrm{~nm}$.

\subsection{Mass-spectrometry}

LC/MS. The compounds were separated on a YMC-Triart C18 (YMC) $(50 \times 2.1 \mathrm{~mm}, 1.9 \mu \mathrm{m}$ particle size) column, maintained at $30^{\circ} \mathrm{C}$. Eluent A was triple-distilled water with LC/MS grade formic acid (0.1\%, v/v), eluent B was ULC/MS grade acetonitrile with the same acid additive. The column was eluted at a flow rate of 0.35 $\mathrm{mL} / \mathrm{min}:$ 0-10 $\min 98: 2 \rightarrow 2: 98(\mathrm{~A}: \mathrm{B}, \mathrm{v} / \mathrm{v}) ; 10-12 \min 2: 98 \rightarrow 98: 2(\mathrm{~A}: \mathrm{B}, \mathrm{v} / \mathrm{v})$. Detection wavelength was 214 nm.

The conditions of electrospray ionization (ESI) source in positive ion mode were as follows: temperature, $335^{\circ} \mathrm{C}$; nebulizer pressure, $30 \mathrm{psi}\left(\mathrm{N}_{2}\right)$; drying gas flow rate, $10 \mathrm{~L} / \mathrm{min}\left(\mathrm{N}_{2}\right)$; capillary voltage, $3500 \mathrm{~V}$. Acquisition parameters were as follows: MS1 scan range, m/z 420-2200 Da (8100 Da/sec). Auto MS2 Parameters were as follows: scan range, m/z 50-2200 Da (8100 Da/sec); number of precursor ions, 3; threshold MS1, 2×106; fragmentation amplitude, $1.00 \mathrm{~V}$. Samples were taken from solution in $200 \mu \mathrm{L}$ of MeOH (HPLC grade). Injection volume was $2 \mu \mathrm{L}$.

Manual MS ${ }^{\mathrm{n}}$ was performed by direct injection (via KDS 100 Legacy syringe pump) as follows: flow rate $5 \mu \mathrm{L} / \mathrm{min}$; temperature $325^{\circ} \mathrm{C}$; nebulizer pressure $15 \mathrm{psi}\left(\mathrm{N}_{2}\right)$; drying gas flow rate $7 \mathrm{~L} / \mathrm{min}\left(\mathrm{N}_{2}\right)$; capillary voltage $3500 \mathrm{~V}$; target mass tune - $602 \mathrm{Da}$. Corresponding masses were subsequently isolated with 2 Da width and fragmentation amplitude $1.00 \mathrm{~V}$. Acquisition time was $1 \mathrm{~min}$ and final mass spectrum was averaged for this time.

\subsection{CsA Rearrangement}

Isocyclosporine A was obtained as described previously [23,24]. CsA $(4 \mu \mathrm{M})$ was mixed with $3 \mathrm{M} \mathrm{HCl}(4$ $\mathrm{mL}$ ) in $15-\mathrm{mL}$ tubes, the solution was stirred and heated for $1 \mathrm{~h}$ at $45^{\circ} \mathrm{C}$.

\section{Results and discussion}

\subsection{Natural isolates investigation}

Marine fungi are a promising source for bioactive secondary metabolites [25]. Recently, we isolated about 200 marine fungi from bottom soils of the White Sea (Fig. 2) [20]. 


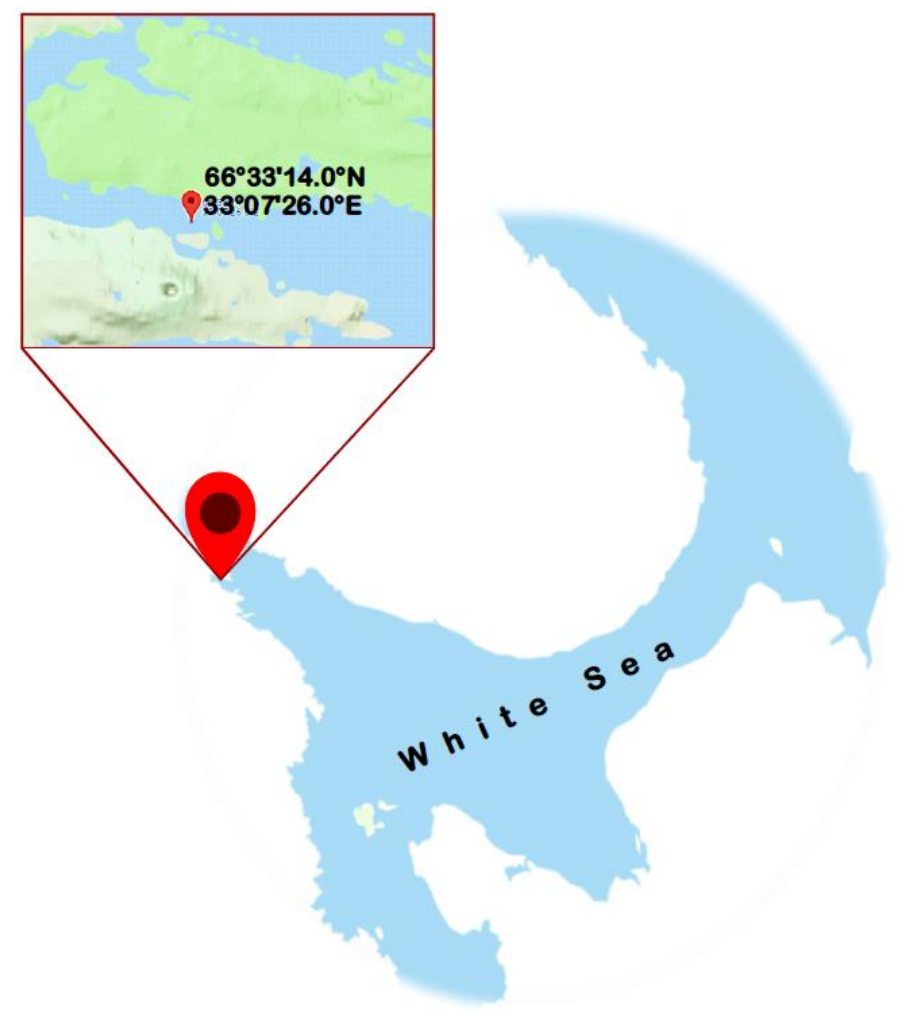

Fig. 2. Location of study area.

Here we investigate secondary metabolites of antifungal strains belonging to the relatively rare genus Tolypocladium. Activity-guided fractionation yielded four Tolypocladium inflatum strains, producing cyclosporins A,B,C. Cyclosporins are common metabolites for terrestrial strains of this taxon, but among marine fungi they have not been hitherto detected.

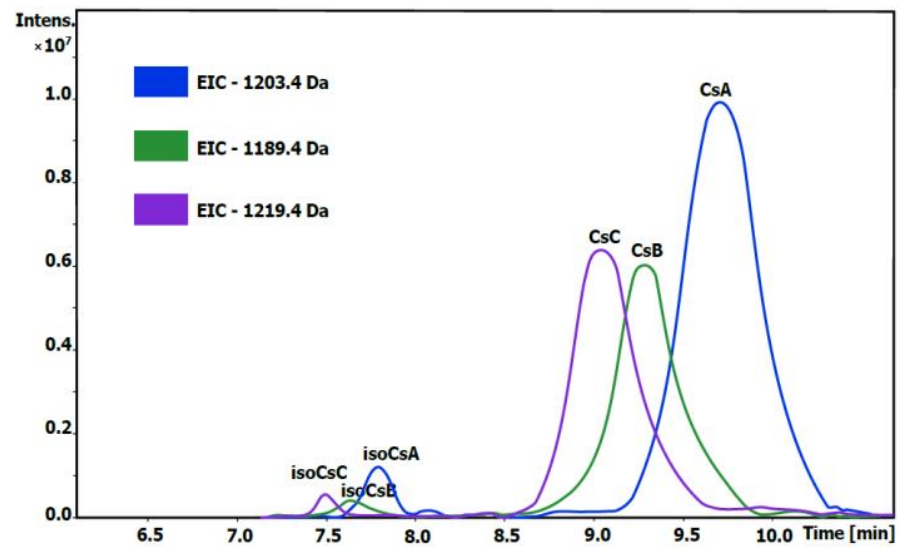

Fig. 3. EIC corresponding to masses of cyclosporins $A, B, C$.

Biosynthesis of cyclosporins was revealed by mass-spectrometric approach. Typical analysis of active fraction LC-MS is represented on Fig. 3. Extracted ion chromatograms (EIC), corresponding to CsA, CsB and $\mathrm{CsC}$, revealed two groups of peaks, having reproducibly different retention times. Nonetheless, composition of 
the minor fraction (retention time about $7.5 \mathrm{~min}$ ) is similar to that of the major fraction (retention time about 9 min), thus suggesting similar structural differences for all isomeric pairs.

Table 1. Composition of marine Tolypocladium inflatum active extracts.

\begin{tabular}{|c|c|c|c|c|}
\hline \multirow{2}{*}{$\begin{array}{c}\text { Strain (GenBank } \\
\text { accession } \\
\text { number) }\end{array}$} & \multirow{2}{*}{$\begin{array}{l}\text { Retention } \\
\text { time, min }\end{array}$} & \multicolumn{2}{|c|}{$\mathbf{m} / \mathbf{z}$} & \multirow{2}{*}{ Compound } \\
\hline & & {$[\mathbf{M}+\mathbf{H}]^{+}$} & {$[\mathbf{M}+2 \mathbf{H}]^{2+}$} & \\
\hline \multirow{6}{*}{13 (MK020176) } & \multirow{3}{*}{$7.3-8.0$} & - & 602.0 & isoCsA \\
\hline & & - & 595.4 & isoCsB \\
\hline & & - & 610.0 & isoCsC \\
\hline & \multirow{3}{*}{$8.5-10.5$} & 1202.9 & 602.0 & $\mathrm{CsA}$ \\
\hline & & 1188.9 & 595.0 & $\mathrm{CsB}$ \\
\hline & & 1218.9 & 610.0 & $\mathrm{CsC}$ \\
\hline \multirow{6}{*}{14 (MH828231) } & \multirow{3}{*}{$7.3-8.0$} & 1202.9 & 602.0 & isoCsA \\
\hline & & - & 595.5 & isoCsB \\
\hline & & - & 610.5 & isoCsC \\
\hline & \multirow{3}{*}{$8.5-10.5$} & 1202.9 & 601.9 & $\mathrm{CsA}$ \\
\hline & & 1188.9 & 595.0 & $\mathrm{CsB}$ \\
\hline & & 1218.9 & 610.0 & $\mathrm{CsC}$ \\
\hline \multirow{4}{*}{$30(\mathrm{MH} 286068)$} & \multirow{3}{*}{$7.3-8.0$} & - & 602.0 & isoCsA \\
\hline & & - & 595.0 & isoCsB \\
\hline & & - & 610.0 & isoCsC \\
\hline & $8.5-10.5$ & 1202.9 & 602.0 & $\mathrm{CsA}$ \\
\hline \multirow{5}{*}{49 (MK020177) } & \multirow{2}{*}{$7.3-8.0$} & - & 602.0 & isoCsA \\
\hline & & - & 595.5 & isoCsB \\
\hline & \multirow{3}{*}{$8.5-10.5$} & 1202.9 & 602.0 & CsA \\
\hline & & - & 595.0 & $\mathrm{CsB}$ \\
\hline & & - & 610.0 & $\mathrm{CsC}$ \\
\hline
\end{tabular}

To understand the nature of the detected compounds, we studied cyclosporin congeners, having the same composition. Because CsA is far more widely described in literature, we decided to focus on it and then expand our conclusions to $\mathrm{CsB}$ and $\mathrm{CsC}$ isomers. There is a number of known natural CsA isomers, including stereoisomeric $\mathrm{CsH}\left(\left[\mathrm{D}-\mathrm{MeVal}^{10}\right] \mathrm{CsA}\right)$ and three compounds with various homologous amino acids CsI $\left(\left[\mathrm{Val}^{2}, \mathrm{Leu}^{10}\right] \mathrm{CsA}\right), \mathrm{CsN}\left(\left[\mathrm{Nva}^{2}, \mathrm{Leu}^{10}\right] \mathrm{CsA}\right), \mathrm{CsX}\left[\mathrm{Nva}^{2}, \mathrm{Leu}^{9}\right] \mathrm{CsA}[26]$. Another compound with the same composition is depsipeptide isocyclosporine $\mathrm{A}$, forming as a result of $\mathrm{N} \rightarrow \mathrm{O}$ acyl shift under acidic conditions [3]. All cyclosporins containing $\beta$-hydroxy amino acid MeBmt undergo the same rearrangement [18]. In order to elucidate the structure of these isomeric minor compounds, we decided to investigate the fragmentation of the detected compounds. 
Cyclosporins can be derived from cyclosporin A by formal substitution of one or two amino acids at a given position, e.g. cyclosporin $\mathrm{C}=\left[\mathrm{Thr}^{2}\right] \mathrm{Cs}$, cyclosporin $\mathrm{B}=\left[\mathrm{Ala}^{2}\right] \mathrm{Cs}$, etc. In this manuscript cyclosporins are referred to both by letters and by formal substitution descriptors.

The nomenclature used in this paper is the updated descriptor system developed previously for sequencing of cyclosporins [18]. A fragment ion is labeled as $\mathrm{x}_{\mathrm{n}}^{\mathrm{e}-\mathrm{f}}$, where $\mathrm{x}$ is the designation of the ion according to traditional nomenclature [27] (lower-case a, b, c). The subscript $n$ represents the number of amino acid residues left in the concerned ion. The $e$ and $f$ (superscript) are the positions of the backbone amide bond, which is cleaved initially. The $e$-amino acid residue stands for the $N$-terminal residue and the $f$-amino acid residue stands for the $C$-terminal residue. For clarity, we used whole numbers for masses in obtained mass spectra. For $N$-methylated amino acids we used the Me prefix (e.g. MeLeu $-N$-methylleucine).

\subsection{Fragmentation of $[\mathrm{M}+\mathrm{H}]^{+}$ions of cyclosporins}

Surprisingly, the fragmentation patterns of major and minor compounds of the same mass were absolutely identical, even relative intensities were practically the same, thus giving no clue to the differences between isomers (Fig. 4). 

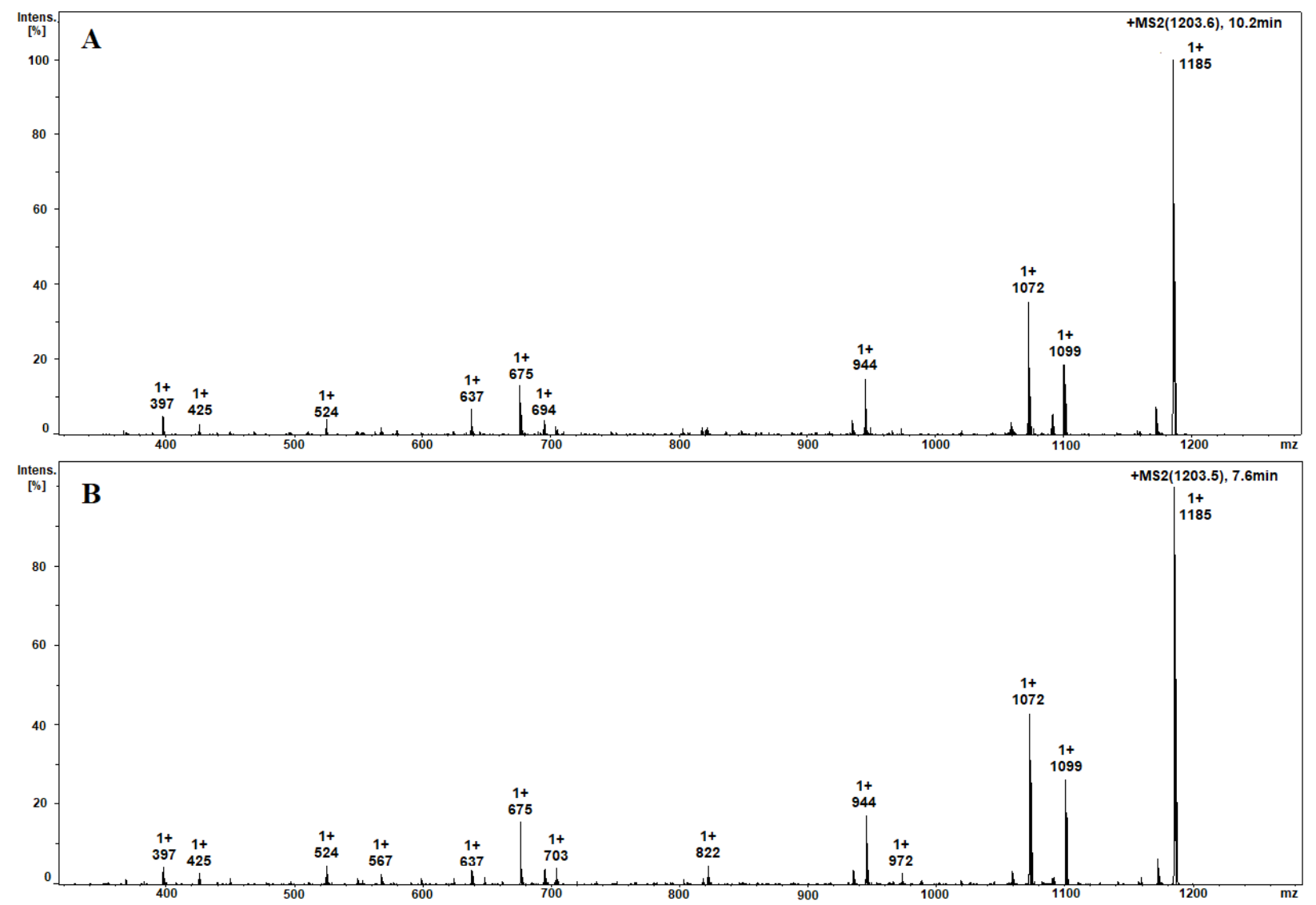

Fig. 4. CID MS2 fragmentation of $[\mathrm{M}+\mathrm{H}]^{+}$ions (m/z 1203) of the major compound (retention time $\left.9.7 \mathrm{~min}\right)(\mathrm{A})$ and the minor compound (retention time $7.8 \mathrm{~min})(\mathrm{B})$.

Fragmentation of protonated molecules of cyclosporins has been thoroughly studied before, mostly for CsA. According to literature, cyclosporins undergo spontaneous rearrangement into isocyclosporins in massspectrometer [18]. CID spectra of both compounds are dominated by $[\mathrm{M}+\mathrm{H}-18]^{+}$and the $\mathrm{b}_{\mathrm{n}}-18^{1-11}$ ion series $(\mathrm{m} / \mathrm{z}$ 1072, 944, 675). Also, both spectra include a diagnostic ion with $\mathrm{m} / \mathrm{z} 1099$, which, according to literature [18], corresponds to elimination of isovaleric acid from isocyclosporin. In several cases CID spectra of cyclosporin A and isocyclosporin A were found to be different on various instruments [18], thus, we registered [M+H] ${ }^{+} \mathrm{CID}$ on TOF and Orbitrap instruments (Figs S7,S8), but found no differences.

\subsection{Fragmentation of $[\mathrm{M}+2 \mathrm{H}]^{2+}$ ions of cyclosporins}

Analyzing MS spectra of isolated compounds (Figs S3, S4, S5), we noticed intense doubly protonated species. CID spectra of these ions (m/z 602 for CsA, 595.5 for CsB and 610 for CsC) exhibited high degree of fragmentation and, more importantly, were significantly different for major and minor compounds. The complete mass spectra for all six natural compounds are presented in Supplementary materials (Figs S9-S17). 
The most important question was to understand the nature of minor isomeric compounds. Thorough investigation of fragmentation of $[\mathrm{M}+2 \mathrm{H}]^{2+}$ ions showed that both spectra contain intense ions of the $b^{6-5}$ series, previously described for cyclosporins. In the case of cyclosporin A and its isomer, observed ions are $637\left(\mathrm{~b}_{6}^{6-5}\right)$, $524\left(b_{5}{ }^{6-5}\right)$ and $397\left(b_{4}{ }^{6-5}\right)$. The same mass and further sequencing of $b_{6}{ }^{6-5}$ ion in both isomers imply no alterations in amino acids included in this ion: $\mathrm{MeVal}^{11}, \mathrm{MeLeu}^{10}, \mathrm{MeLeu}^{9}, \mathrm{D}-\mathrm{Ala}^{8}, \mathrm{Ala}^{7}, \mathrm{MeLeu}^{6}$. While all natural isomers of cyclosporin contain variations in positions 9 or 10, we envisioned that the species detected are isocyclosporins, which have a backbone identical to that of cyclosporins. To confirm our suggestion, we analyzed standard sample of CsA and obtained isocyclosporin A (isoCsA) by acid-catalyzed rearrangement according to known procedure [3,23]. Mass spectra of standard CsA and isoCsA were found to be identical to natural major and minor components, respectively. We further studied the differences in fragmentation for samples of CsA and isoCsA, taking into account the tremendous pharmaceutical importance of CsA vs. other natural cyclosporins.

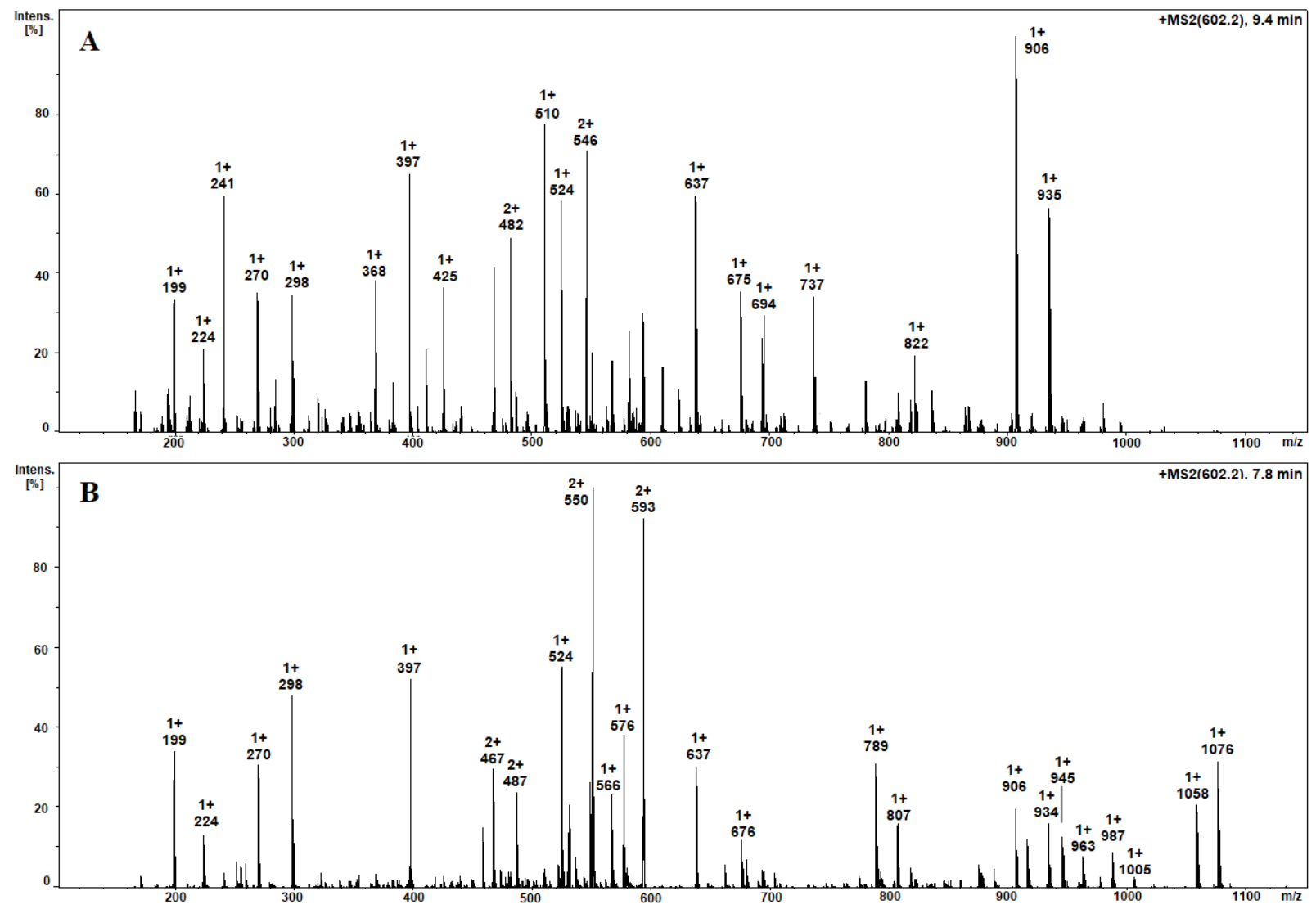

Fig. 5. CID MS2 fragmentation of $[\mathrm{M}+\mathrm{H}]^{+}$ions (m/z 602) of CsA (A) and isoCsA (B).

Interpretation of CID spectra of cyclic peptides is challenging because initial ring opening at different sites leads to superposition of decomposition fragments from various linear peptides [28,29]. Nonetheless, valuable 
biological properties are drawing significant attention to study of cyclosporine A and its congeners, thus, fragmentation of this compound is relatively well studied. Numerous fragmentation patterns were established for CsA in the course of structural study of natural cyclosporins [16,30,31] and specific mass-spectrometric research devoted to unique side chain cleavage in MeBmt [32] and to the role of $N$-amino methylation in initial ring opening process [33]. Identification of isocyclosporin as one of the main hydrolysis products of cyclosporin A has drawn significant attention to differences in their mass-spectra, including MS/MS fragmentation [23,34]. The identical fragmentation of $[\mathrm{M}+\mathrm{H}]^{+}$was explained by spontaneous rearrangement in an ion trap [18]. Recently, the post-column divalent salt addition method was worked out for differentiation of CsA and isoCsA by tandem massspectrometry [19]. We analyzed distinguishable features in $[\mathrm{M}+2 \mathrm{H}]^{2+} \mathrm{CID}$ spectra of these compounds and attempted to attribute observed ions to known fragmentation mechanisms. We performed $\mathrm{MS}^{\mathrm{n}}$ experiments for key ions as previously described for $[\mathrm{M}+\mathrm{H}]^{+}$ions [16] for better understanding of fragmentation of cyclosporins.

\subsubsection{Analysis of $[\mathrm{M}+2 \mathrm{H}]^{2+} \mathrm{CID}$ spectrum of $\mathrm{CsA}$}

First, we compared singly charged ions in $[\mathrm{M}+2 \mathrm{H}]^{2+} \mathrm{CID}$ spectra with previously described cyclosporine fragmentation routes. The 6-5 backbone splitting is typical for CsA fragmentation spectra, but usually this ion series is limited to $b_{4}, b_{5}$ and $b_{6}$ ions [33]. In $[M+2 H]^{2+}$ CID of CsA we additionally register intense $b_{8}{ }^{6-5}(m / z$ 906, $100 \%$ ion) in this ion series. The nature of this ion is corroborated by $\mathrm{MS}^{3}$ experiment (subsequent ions of the series are derived from this one). Moreover, CID $[\mathrm{M}+2 \mathrm{H}]^{2+}$ spectra of CsB (Fig. S14) and CsC (Fig. S20) contain the same ion series $b_{n}{ }^{6-5}$, where only $b_{8}{ }^{6-5}$ includes mass increment (m/z 922 for $\mathrm{CsC}, 893$ for CsB) correlating with plausible ion structure, while $b_{8}{ }^{6-5}$ is the last ion of the series, containing a variable second amino acid. In $\mathrm{MS}^{3}$ spectra of the m/z 906 ion (Fig. S19) there are also peaks, corresponding to far less typical $\mathrm{a}_{\mathrm{n}}{ }^{3-2}$ ion series (e.g. $a_{7}^{3-2} \mathrm{~m} / \mathrm{z} 667$ ), suggesting that this peak could be a superposition of $\mathrm{b}_{8}{ }^{6-5}$ and $\mathrm{a}_{9}{ }^{3-2}$ ions. The mixed nature of this ion can explain its abnormally high intensity.

Another intense ion series, detected in $[\mathrm{M}+2 \mathrm{H}]^{2+} \mathrm{CID}$ spectra of all cyclosporins, is $\mathrm{b}_{\mathrm{n}}{ }^{3-2}$, lacking only the $\mathrm{b}_{10}$ ion. This ion series starts with loss of second amino acid, therefore, ions in the series have equal $\mathrm{m} / \mathrm{z}$ for CsA, $\mathrm{CsB}, \mathrm{CsC}\left(\mathrm{b}_{9}{ }^{3-2}-\mathrm{b}_{2}{ }^{3-2}\right.$ have $\mathrm{m} / \mathrm{z}$ values $935,822,694,567,496,425,298,199$, respectively). Interestingly, the $\mathrm{b}_{\mathrm{n}}{ }^{1-}$

11 ion series, the most abundant in previously described $[\mathrm{M}+\mathrm{H}]^{+}$spectra of cyclosporins corresponding to typical 
1-11 backbone splitting, has very low intensity. Moreover, the $b_{n}{ }^{1-11}-18$ series, usually associated with rearrangement into isocyclosporins, is completely absent (Fig. 6).

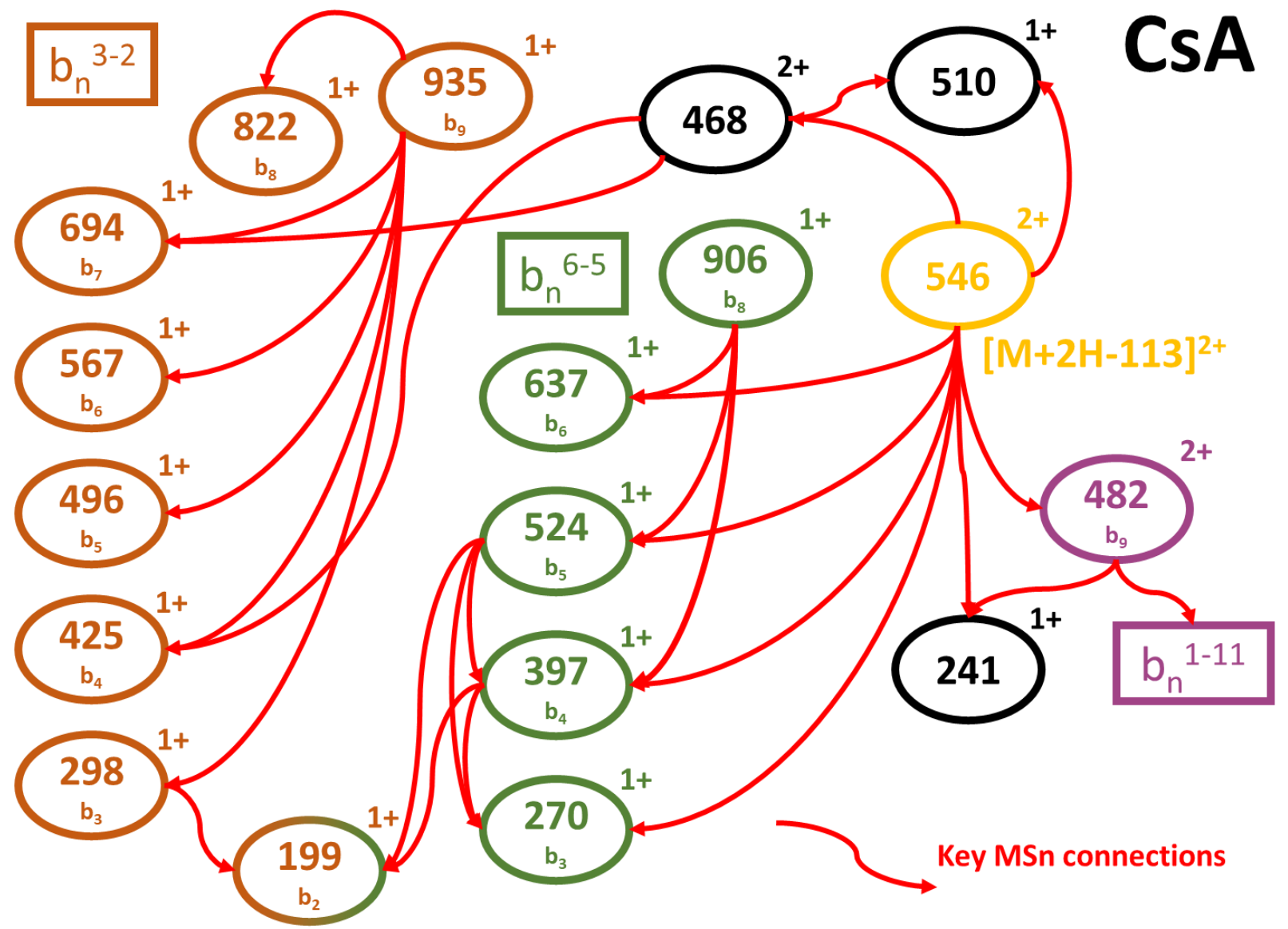

Fig. 6. Analysis of MS/MS splitting of a CsA doubly protonated molecular ion with m/z 602 .

The most interesting part of $[\mathrm{M}+2 \mathrm{H}]^{2+} \mathrm{CID}$ spectra is detection of unique fragment ions, formed exclusively from doubly protonated species. First of all, that would be all doubly charged fragment ions. The most abundant doubly charged ion in CsA fragmentation spectrum is an ion with $\mathrm{m} / \mathrm{z} 546$. We suggest that this ion $[\mathrm{M}+2 \mathrm{H}-$ $113]^{2+}$ is an isobaric mixture of the ion, formed as a result of C-C side chain cleavage in CsA [32], and the $\mathrm{b}_{11}{ }^{1-11}$ ion. The same origin was previously suggested for a singly protonated analogue of this ion, $[\mathrm{M}+\mathrm{H}-113]^{+}$with $\mathrm{m} / \mathrm{z} 1089$ [18]. $\mathrm{MS}^{3}$ spectra of such a mixed ion cannot be unequivocally interpreted, but we observed various fragmentations of this ion leading to formation of the $b_{n}{ }^{3-2}$ ions and a doubly charged ion with $\mathrm{m} / \mathrm{z} 482$, presumably a doubly protonated variant of $b_{9}{ }^{1-11}$, subsequently leading to the $b_{n}{ }^{1-11}$ series (Fig. S20). The $b_{1}{ }^{1-11}$ ion is probably a minor component of the mixture, while the corresponding $b_{n}{ }^{1-11}$ has very low intensity in $\mathrm{MS}^{2}$ spectrum and can be clearly observed only in $\mathrm{MS}^{3}$ fragmentation of doubly charged $\mathrm{b}_{9}^{1-11}(\mathrm{~m} / \mathrm{z} 482)$. Along with 
$\mathrm{b}_{\mathrm{n}}{ }^{1-11}$, fragmentation of this ion includes formation of an ion with $\mathrm{m} / \mathrm{z} 241$, clearly observable in initial MS/MS

either. While this mass has not been detected previously in $[\mathrm{M}+\mathrm{H}]^{+} \mathrm{CID}$ spectra of CsA, we suggest it can be formed only from doubly protonated species via rearrangement or via a charge separation mechanism.

Moreover, we detect a doubly protonated ion with $\mathrm{m} / \mathrm{z} 468$. The latter could be an additionally protonated variant of $b_{9}^{3-2}(m / z 935)$, but $\mathrm{MS}^{3}$ spectra show only rare ions in the succeeding $b_{n}{ }^{3-2}$ series. Furthermore, fragmentation of this ion produces an intense singly charged ion with $\mathrm{m} / \mathrm{z} 510$, also derived from $[\mathrm{M}+2 \mathrm{H}-113]^{2+}$. This species, as well as the previously mentioned ion with $\mathrm{m} / \mathrm{z} 241$, are characteristic of doubly protonated ion fragmentation and are presumably formed via non-sequencing mechanisms.

Thus, the fragmentation pattern of $[\mathrm{M}+2 \mathrm{H}]^{2+} \mathrm{CID}$ spectra incorporates both well-known dissociation mechanisms and unique fragmentation routes. Despite the complexity of these patterns for isobaric mixtures of ions, they are characteristic for structural identification of CsA.

\subsubsection{Analysis of $[\mathrm{M}+2 \mathrm{H}]^{2+} \mathrm{CID}$ spectrum of isoCsA}

Comparing the results of fragmentation experiments for isoCsA (Fig. 5) under the same conditions, we observe significant differences with the CsA case. In the high-mass region of isoCsA fragmentation spectrum we observe an ion corresponding to MeVal loss $1076[\mathrm{M}+\mathrm{H}-127]^{2+}$, which was not observed in CsA fragmentation spectrum. This ion can be formed as a result of a number of initial backbone splittings $\left(b_{10}{ }^{10-9}, b_{10}{ }^{11-10}, b_{10}{ }^{5-4}, b_{10}{ }^{7-}\right.$ ${ }^{6}$ would have $\mathrm{m} / \mathrm{z}$ 1076). There are some ions that can correspond to the $\mathrm{b}_{\mathrm{n}}{ }^{10-9}$ series (e.g. $\mathrm{b}_{7}$ with $\mathrm{m} / \mathrm{z}$ 807, $\mathrm{b}_{8}$ with $\mathrm{m} / \mathrm{z} 934$ and $b_{9}$ with $\left.\mathrm{m} / \mathrm{z} 1005\right)$, but the $\mathrm{MS}^{3}$ spectrum of this ion is not reproducible, thus suggesting that it can be an isobaric mixture of several ions.

Furthermore, the intensity of the $b_{n}{ }^{3-2}$ ion series for isoCsA is rather low compared to CsA, most of the ions $\left(b_{9}, b_{8}, b_{7}, b_{5}, b_{4}\right)$ are barely detectable. In comparison, the ions of the $b_{n}{ }^{6-5}$ series are pronounced in both isoCsA and CsA fragmentation, except for the $b_{7}$ ion series.

The 1-11 backbone splitting leads to $b_{n}{ }^{1-11}$ and $b_{n}{ }^{1-11}-18$ ion series, the latter is associated with elimination of complete $\mathrm{MeVal}^{11}$ from isoCsA. In $[\mathrm{M}+2 \mathrm{H}]^{2+} \mathrm{CID}$ spectrum of isoCsA we observe several ions, corresponding to both of these series, but their intensities are moderate. Analyzing fragmentation of isoCsA, we observe qualitative differences in the fragmentation pattern. First of all, extensive water loss occurs for most of peaks in 
isoCsA spectrum, particularly in the $750-1100 \mathrm{~m} / \mathrm{z}$ range (Fig. 7). Therefore, accompanying water loss counterparts are present not just for the $b_{n}{ }^{1-11}$ series, but for most fragment ions. Likely, the charge-remote water loss mechanism provides an alternative energy dissipation channel for isoCsA, thus leading to a lower degree of fragmentation and more abundant high-mass ions.

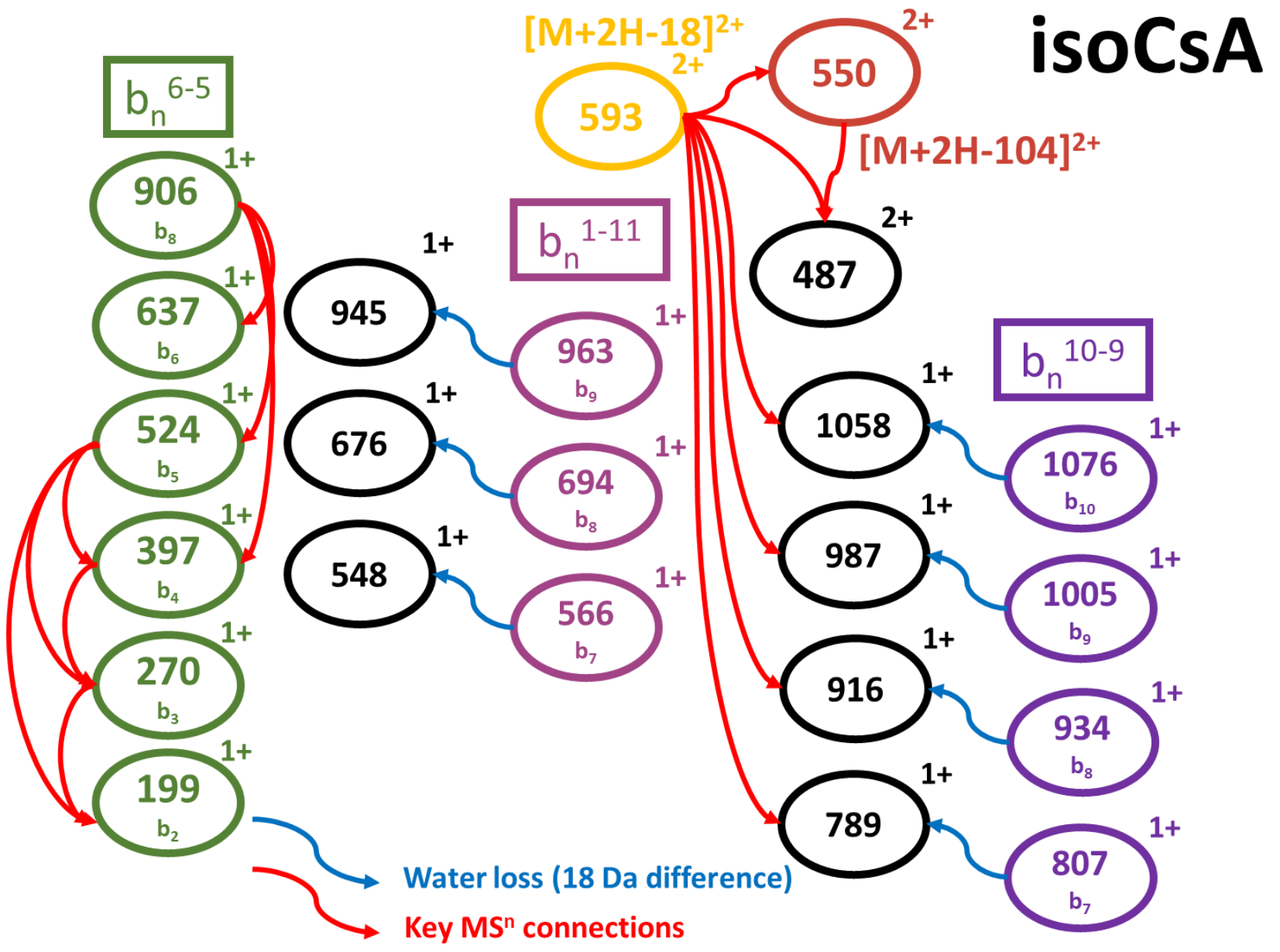

Fig. 7. Analysis MS/MS splitting of a isoCsA doubly protonated molecular ion with m/z 602 .

Analyzing fragment ions formed only from doubly protonated species, we observe the same tendency to lose water, while the most intense doubly charged fragment ion is $\left[\mathrm{M}+2 \mathrm{H}-\mathrm{H}_{2} \mathrm{O}\right]$ with m/z 593 . $\mathrm{MS}^{3}$ spectrum of this ion shows its relation to the dehydrated variant of the $b_{n}{ }^{10-9}$ series (Fig. 6) and with another unique doubly charged ion with $\mathrm{m} / \mathrm{z} 550$. We suppose this ion is $[\mathrm{M}+2 \mathrm{H}-104]-$ a doubly protonated variant of the ion with $\mathrm{m} / \mathrm{z}$ 1099 , characteristic of $[\mathrm{M}+\mathrm{H}]^{+} \mathrm{CID}$ spectra of isoCsA. This ion is assumed to be formed by elimination of isovaleric acid [18]. All these assumptions concerning structures of fragment ions are well supported by comparison with isoCsC and isoCsB datasets (Figs S15, S17). 
Summarizing, we detected a number of unique fragment ions, allowing to distinguish cyclosporins and their $\mathrm{N} \rightarrow \mathrm{O}$ acyl shift products using a relatively accessible MS/MS technique. Due to significant and qualitative differences in observed spectra, low resolution instruments are suitable for effective analysis. Furthermore, the developed approach requires neither chromatographic standards, nor post column derivatization equipment.

The analysis of doubly protonated species can prove useful not just for analysis of CsA samples or natural cyclosporins. It is quite common for peptides to produce doubly protonated ions under ESI ionization conditions. Furthermore, peptides containing basic side-chains usually yield very intense doubly protonated species accompanied by low-intensity protonated molecules. Additionally, the doubly protonated peptide shows a high degree of fragmentation under relatively low CID energies, thus providing more structural information under mild conditions. Therefore, analytical techniques based on doubly charged ions can dramatically improve sensitivity in peptide mass-spectrometry.

\section{Conclusion}

In conclusion, we detected unusual differences in CID mass-spectra of doubly protonated ions in cyclosporins and isocyclosporins, allowing to distinguish between isomers. This method can prove useful since it does not require chromatographic standards and is quite sensitive, while doubly protonated ions are usually very intense for peptides with basic side chains. Furthermore, our results show a high degree of fragmentation and unique degradation patterns in CID of $[\mathrm{M}+2 \mathrm{H}]^{2+}$ ions. In this article, we used this approach for analysis of natural secondary metabolites prodused by Tolypocladium inflatum strains of marine origin (White Sea), however, the approach can be further applied for quality control of pharmaceutical substances and for analysis of other $\beta$ hydroxy- $\alpha$-amino-acid-containing peptides.

\section{Acknowledgements}

The research was supported in part by the Russian Foundation for Basic Research (projects 20-33-70215 and 18-29-25073). 


\section{References}

[1] S.A. Survase, L.D. Kagliwal, U.S. Annapure, R.S. Singhal, Cyclosporin A - A review on fermentative production, downstream processing and pharmacological applications, Biotechnol Adv. 29 (2011) 418-435. https://doi.org/10.1016/j.biotechadv.2011.03.004.

[2] A. Rüegger, M. Kuhn, H. Lichti, H.-R. Loosli, R. Huguenin, C. Quiquerez, A. von Wartburg, Cyclosporin A, ein immunsuppressiv wirksamer Peptidmetabolit aus Trichoderma polysporum (Link ex Pers.) Rifai, Helv. Chim. Acta. 59 (1976) 1075-1092. https://doi.org/10.1002/hlca.19760590412.

[3] R. Oliyai, V.J. Stella, Kinetics and mechanism of isomerization of cyclosporin A, Pharm. Res. 9 (1992) 617-622. https://doi.org/10.1023/A:1015841824760.

[4] G.J. Friis, H. Bundgaard, Kinetics of degradation of cyclosporin A in acidic aqueous solution and its implication in its oral absorption, Int. J. Pharm. 82 (1992) 79-83. https://doi.org/10.1016/03785173(92)90075-D.

[5] H. Bundgaard, G.J. Friis, Prodrugs of peptides. 16. Isocyclosporin A as a potential prodrug of cyclosporin A, Int. J. Pharm. 82 (1992) 85-90. https://doi.org/10.1016/0378-5173(92)90076-E.

[6] R. Oliyai, M. Safadi, P.G. Meier, M.-K. Hu, D.H. Rich, V.J. Stella, Kinetics of acid-catalyzed degradation of cyclosporin A and its analogs in aqueous solution, Int. J. Pept. Prot. Res. 43 (2009) 239-247. https://doi.org/10.1111/j.1399-3011.1994.tb00386.x.

[7] P. Salm, P.J. Taylor, S.V. Lynch, C.R. Warnholtz, P.I. Pillans, A rapid HPLC-mass spectrometry cyclosporin method suitable for current monitoring practices, Clin. Biochem. 38 (2005) 667-673. https://doi.org/10.1016/j.clinbiochem.2005.04.009.

[8] D.J. Andrews, R. Cramb, Cyclosporin: revisions in monitoring guidelines and review of current analytical methods, Ann. Clin. Biochem. 39 (2002) 424-435. https://doi.org/10.1258/000456302320314430.

[9] F.N. Bonifacio, M. Giocanti, J.P. Reynier, B. Lacarelle, A. Nicolay, Development and validation of HPLC method for the determination of Cyclosporin $\mathrm{A}$ and its impurities in Neoral ${ }^{\circledR}$ capsules and its generic versions, J. Pharm. Biomed. Anal. 49 (2009) 540-546. https://doi.org/10.1016/j.jpba.2008.11.027.

[10] C. Alvarez, I.W. Wainer, Development of an automatic solid phase extraction and liquid chromatography mass spectrometry method by using a monolithic column for the analysis of Cyclosporin A in human plasma, Talanta. 79 (2009) 280-283. https://doi.org/10.1016/j.talanta.2009.03.054.

[11] D.C. Muddiman, A.I. Gusev, A. Proctor, D.M. Hercules, R. Venkataraman, W. Diven, Quantitative measurement of cyclosporin A in blood by time-of-flight mass spectrometry, Anal. Chem. 66 (1994) 23622368. https://doi.org/10.1021/ac00086a023. 
[12] B.G. Keevil, D.P. Tierney, D.P. Cooper, M.R. Morris, Rapid liquid chromatography-tandem mass spectrometry method for routine analysis of cyclosporin A over an extended concentration range, Clin. Chem. 48 (2002) 69-76. https://doi.org/10.1093/clinchem/48.1.69.

[13] G. Li, K. Cao, X. Li, X. Dai, L. Yin, J. Ling, Method for controlling impurity of cyclosporin A eye gel, US2019194258 (A1),

https://worldwide.espacenet.com/publicationDetails/biblio?FT=D\&date=20190627\&DB=\&locale=en_EP $\& C C=\mathrm{US} \& \mathrm{NR}=2019194258 \mathrm{~A} 1 \& \mathrm{KC}=\mathrm{A} 1 \& \mathrm{ND}=4$ (accessed May 25, 2020).

[14] R. Gotti, S. Furlanetto, N.A. Santagati, Analysis of cyclosporin A and main degradation impurities by cyclodextrin-modified micellar electrokinetic chromatography, Anal. Lett. 45 (2012) 665-676. https://doi.org/10.1080/00032719.2011.653897.

[15] A. Buchwald, K. Winkler, T. Epting, Validation of an LC-MS/MS method to determine five immunosuppressants with deuterated internal standards including MPA, BMC Clin. Pharmacol. 12 (2012) 2. https://doi.org/10.1186/1472-6904-12-2.

[16] E.Y. Ahn, A. Shrestha, N.H. Hoang, N.L. Huong, Y.J. Yoon, J.W. Park, Structural characterization of cyclosporin A, C and microbial bio-transformed cyclosporin A analog AM6 using HPLC-ESI-ion trapmass spectrometry, Talanta. 123 (2014) 89-94. https://doi.org/10.1016/j.talanta.2014.01.067.

[17] A. Gurevich, A. Mikheenko, A. Shlemov, A. Korobeynikov, H. Mohimani, P.A. Pevzner, Increased diversity of peptidic natural products revealed by modification-tolerant database search of mass spectra, Nature Microbiol. 3 (2018) 319-327. https://doi.org/10.1038/s41564-017-0094-2.

[18] A. Jegorov, V. Havlíček, Spontaneous $\mathrm{N} \rightarrow \mathrm{O}$ acyl shift in the $[\mathrm{M}+\mathrm{H}]^{+}$ions of $\left[\mathrm{MeBmt}{ }^{1}\right]$-cyclosporins in an ion trap, J. Mass Spectrom. 36 (2001) 633-640. https://doi.org/10.1002/jms.163.

[19] A.M. Cirigliano, G.M. Cabrera, Differentiation of cyclosporin A from isocyclosporin A by liquid chromatography/electrospray ionization mass spectrometry with post-column addition of divalent metal salt, Rapid Commun. Mass Spectrom. 28 (2014) 465-470. https://doi.org/10.1002/rcm.6805.

[20] A.I. Khunsnullina, E.N. Bilanenko, A.V. Kurakov, Microscopic fungi of the White Sea sediments, Contemp. Probl. Ecol. (2018) 584-598. https://doi.org/10.15372/SEJ20180507.

[21] S.O. Rogers, A.J. Bendich, Extraction of DNA from milligram amounts of fresh, herbarium and mummified plant tissues, Plant Mol. Biol. 5 (1985) 69-76. https://doi.org/10.1007/BF00020088.

[22] T.J. White, T.D. Bruns, S.B. Lee, J.W. Taylor, Amplification and direct sequencing of fungal ribosomal RNA Genes for phylogenetics, in: PCR - Protocols - A Guide to Methods and Applications, Ed. by M.A. Innis, D.H. Gelfand, J.J. Sninsky, T.J. White, Academic Press, 1990, pp. 315-322. 
[23] F. Magni, L. Arnoldi, M. Del Puppo, M. Galli Kienle, Hydrolysis of cyclosporin A: Identification of 1,11 seco-cyclosporin A and 4,5 seco-isoCyclosporin A by FAB-MS/MS, Peptides. 16 (1995) 1335-1341. https://doi.org/10.1016/0196-9781(95)02025-X.

[24] F. Magni, C. Arcelloni, R. Paroni, I. Fermo, P.A. Bonini, M. Del Puppo, A. Manzocchi, M.G. Kienle, Openchain peptides obtained by acidic hydrolytic cleavage of cyclosporin A, Biol. Mass Spectrom. 23 (1994) 514-518. https://doi.org/10.1002/bms.1200230809.

[25] J. Imhoff, Natural products from marine fungii - still an underrepresented resource, Marine Drugs. 14 (2016) 19. https://doi.org/10.3390/md14010019.

[26] J.R. Jeffery, Cyclosporine analogues, Clin. Biochem. 24 (1991) 15-21. https://doi.org/10.1016/00099120(91)90105-N.

[27] K. Biemann, Mass spectrometry of peptides and proteins, Annu. Rev. Biochem. 61 (1992) 977-1010. https://doi.org/10.1146/annurev.bi.61.070192.004553.

[28] L.C.M. Ngoka, M.L. Gross, Multistep tandem mass spectrometry for sequencing cyclic peptides in an iontrap mass spectrometer, J. Am. Soc. Mass Spectrom. 10 (1999) 732-746. https://doi.org/10.1016/S10440305(99)00049-5.

[29] W.-T. Liu, J. Ng, D. Meluzzi, N. Bandeira, M. Gutierrez, T.L. Simmons, A.W. Schultz, R.G. Linington, B.S. Moore, W.H. Gerwick, P.A. Pevzner, P.C. Dorrestein, Interpretation of tandem mass spectra obtained from cyclic nonribosomal peptides, Anal. Chem. 81 (2009) 4200-4209. https://doi.org/10.1021/ac900114t.

[30] V. Havlíček, A. Jegorov, P. Sedmera, M. Ryska, Sequencing of cyclosporins by fast atom bombardment and linked-scan mass spectrometry, Org. Mass Spectrom. 28 (1993) 1440-1447. https://doi.org/10.1002/oms.1210281214.

[31] M. Kuzma, P. Sedmera, A. Jegorov, V. Havlíček, Cyclosporins from Mycelium sterilae MS 2929, J. Nat. Prod. 72 (2009) 159-163. https://doi.org/10.1021/np8003968.

[32] A. Jegorov, V. Havlíček, P. Sedmera, An unusual side chain C-C cleavage at the MeBmt amino acid in cyclosporin A, Amino Acids. 10 (1996) 145-151. https://doi.org/10.1007/BF00806587.

[33] M. Kuzma, A. Jegorov, A. Hesso, J. Tornaeus, P. Sedmera, V. Havlíček, Role of amino acid $N$-methylation in cyclosporins on ring opening and fragmentation mechanisms during collisionally induced dissociation in an ion trap, J. Mass Spectrom. 37 (2002) 292-298. https://doi.org/10.1002/jms.283.

[34] L. Arnoldi, A. Manzocchi, F. Magni, M. Del Puppo, M. Galli Kienle, ${ }^{1}$ H NMR Analysis of isocyclosporin A prepared in organic solvent and in aqueous solution, Bioorg. Chem. 25 (1997) 110-116. https://doi.org/10.1006/bioo.1997.1058. 


\title{
Doubly protonated species collision induced dissociation for identification of isocyclosporins
}

\section{Supplementary materials}

\author{
Anna A. Baranova ${ }^{\mathrm{a}}$, Alexey A. Chistov ${ }^{\mathrm{b}, \mathrm{c}, \mathrm{d}}$, Maxim V. Shuvalov ${ }^{\mathrm{a}, \mathrm{d}, \mathrm{e}}$, Anton P. Tyurin ${ }^{\mathrm{a}, \mathrm{d}}$, \\ Mikhail V. Biryukov ${ }^{\mathrm{a}, \mathrm{e}}$, Igor A. Ivanov ${ }^{\mathrm{b}}$, Vera S. Sadykova ${ }^{\mathrm{a}}$, Aleksander V. Kurakov \\ Albina I. Sergeeva ${ }^{\mathrm{e}}$, Vladimir A. Korshun ${ }^{\mathrm{a}, \mathrm{b}, \mathrm{d}, *}$, Vera A. Alferova $^{\mathrm{a}, \mathrm{d},{ }^{* *}}$ \\ ${ }^{a}$ Gause Institute of New Antibiotics, Bolshaya Pirogovskaya 11, Moscow 119021, Russia \\ ${ }^{b}$ Shemyakin-Ovchinnikov Institute of Bioorganic Chemistry, Miklukho-Maklaya 16/10, \\ Moscow 117997, Russia \\ c Orekhovich Research Institute of Biomedical Chemistry, Pogodinskaya 10, Moscow 119121, Russia \\ ${ }^{\mathrm{d}}$ Department of Biology and Biotechnology, National Research University Higher School of Economics, \\ Vavilova 7, Moscow 117312, Russia \\ ${ }^{\mathrm{e}}$ Lomonosov Moscow State University, 1-3 Leninskiye Gory, 119992, Moscow, Russia
}




\section{Contents}

Figure S1. Antifungal activity of fungi of bottom soils of the White Sea, belonging to different taxa.

Figure S2. SEM of Tolypocladium inflatum ...............................................................

Figure S3. MS spectra of CsA (A) and isoCsA (B) .................................................

Figure S4. MS spectra of of CsB (A) and isoCsB (B) ................................................

Figure S5. MS spectra of of CsC (A) and isoCsC (B)................................................

Figure S6. CID MS/MS fragmentation of $[\mathrm{M}+\mathrm{H}]^{+}$ions (m/z 1202) of CsA (A) and isoCsA (B) on Triple quadrupole .......................................................................

Figure S7. CID MS/MS fragmentation of $[\mathrm{M}+\mathrm{H}]^{+}$ions (m/z 1202) of CsA (A) and isoCsA (B) on TOF instrument ........................................................................

Figure S8. CID MS/MS fragmentation of $[\mathrm{M}+\mathrm{H}]^{+}$ions $(\mathrm{m} / \mathrm{z}$ 1202) of CsA (A) and isoCsA (B) on Orbitrap instrument................................................................. 10

Figure S9. CID MS/MS fragmentation of $[\mathrm{M}+2 \mathrm{H}]^{+}$ions $(\mathrm{m} / \mathrm{z}$ 602) of CsA (A)

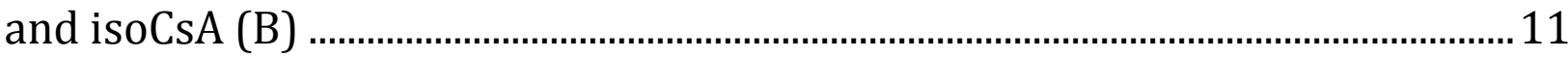

Figure S10. CID MS/MS fragmentation of $[\mathrm{M}+2 \mathrm{H}]^{2+}$ ions $(\mathrm{m} / \mathrm{z} 595)$ of CsB (A)

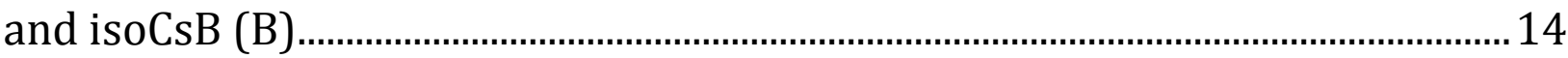

Figure S11. CID MS/MS fragmentation of $[\mathrm{M}+2 \mathrm{H}]^{2+}$ ions $(\mathrm{m} / \mathrm{z} 610)$ of CsC $(\mathrm{A})$

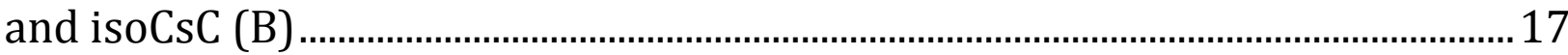

Figure S12. CID MS/MS fragmentation of $[\mathrm{M}+2 \mathrm{H}]^{2+}$ ions $(\mathrm{m} / \mathrm{z} 602)$ of CsA.....20 Figure S13. CID MS/MS fragmentation of $[\mathrm{M}+2 \mathrm{H}]^{2+}$ ions $(\mathrm{m} / \mathrm{z} 602)$ of isoCsA23 Figure S14. CID MS/MS fragmentation of $[\mathrm{M}+2 \mathrm{H}]^{2+}$ ions $(\mathrm{m} / \mathrm{z} 595)$ of CsB .....26 Figure S15. CID MS/MS fragmentation of $[\mathrm{M}+2 \mathrm{H}]^{2+}$ ions $(\mathrm{m} / \mathrm{z} 595)$ of isoCsB29 Figure S16. CID MS/MS fragmentation of $[\mathrm{M}+2 \mathrm{H}]^{2+}$ ions $(\mathrm{m} / \mathrm{z} 611)$ of $\mathrm{CsC}$.....32 Figure S17. CID MS/MS fragmentation of $[\mathrm{M}+2 \mathrm{H}]^{2+}$ ions $(\mathrm{m} / \mathrm{z} 610)$ of isoCsC35 Figure S18. CID MS3 fragmentation of ion (m/z 935) of CsA................................38

Figure S19. CID MS3 fragmentation of ion ( $\mathrm{m} / \mathrm{z}$ 906) of CsA................................39

Figure S20. CID MS3 fragmentation of ion (m/z 546) of CsA............................... 40

Figure S21. CID MS3 fragmentation of ion (m/z 468) of CsA................................ 41

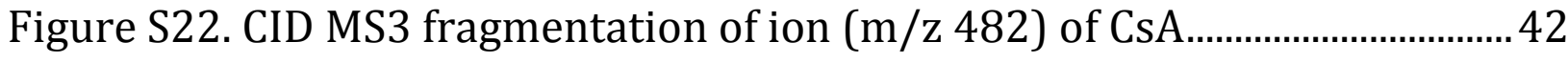

Figure S23. CID MS3 fragmentation of ion ( $\mathrm{m} / \mathrm{z}$ 1076) of isoCsA ........................ 43

Figure S24. CID MS3 fragmentation of ion (m/z 593) of isoCsA........................... 44

Figure S25. CID MS3 fragmentation of ion ( $\mathrm{m} / \mathrm{z} 550$ ) of isoCsA........................... 45

Figure S26. CID MS3 fragmentation of ion (m/z 487) of isoCsA ........................... 46 
Figure S1. Antifungal activity of fungi of bottom soils of the White Sea, belonging to different taxa

Order Eurotiales

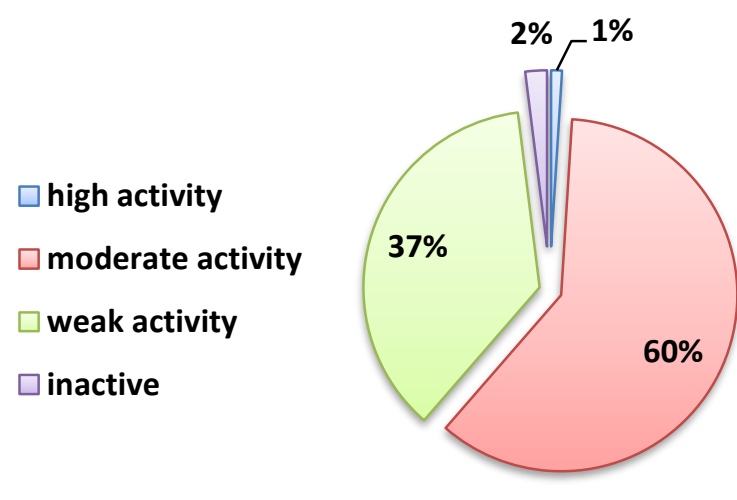

Order Mucorales and

Umbelopsidales

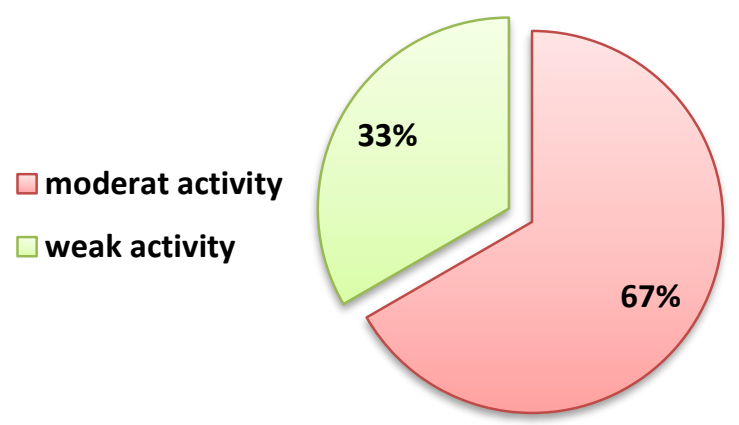

$\square$ high activity

$\square$ moderate activity

$\square$ weak activity

\section{Other orders}

high activity

$\square$ moderate activity

$\square$ weak activity

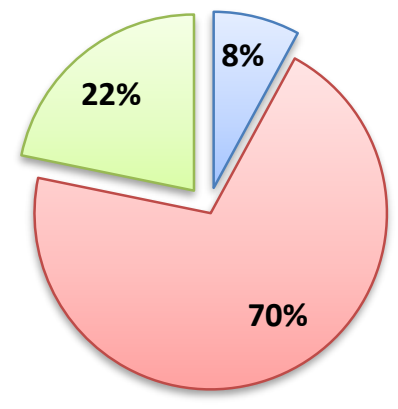

Tolypocladium inflatum W. Gams

$\square$ cyclosporine

$\square$ no cyclosporine

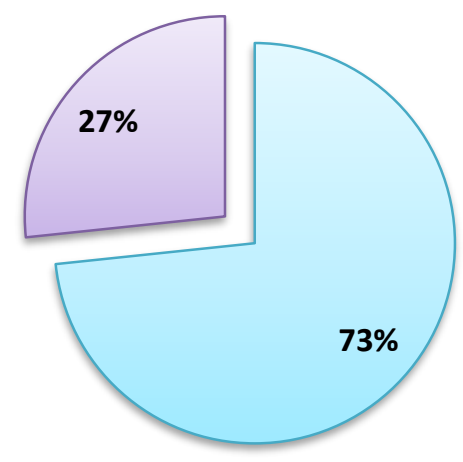


Antifungal activity of isolated strains.

\begin{tabular}{|c|c|c|c|c|c|c|c|}
\hline Division & Order & Genera & №n/n & inactive & $\begin{array}{c}\text { weak } \\
\text { activity }\end{array}$ & $\begin{array}{c}\text { moderate } \\
\text { activity }\end{array}$ & $\begin{array}{c}\text { high } \\
\text { activity }\end{array}$ \\
\hline \multirow{18}{*}{ 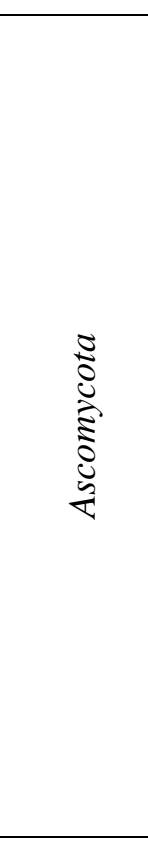 } & \multirow{3}{*}{ Eurotiales } & Penicillium & 109 & \multirow{3}{*}{2} & \multirow{3}{*}{47} & \multirow{3}{*}{78} & \multirow{3}{*}{1} \\
\hline & & Aspergillus & 5 & & & & \\
\hline & & Talaromyces & 14 & & & & \\
\hline & \multirow{8}{*}{ Hypocreales } & Tolypocladium & 27 & \multirow{8}{*}{0} & \multirow{8}{*}{10} & \multirow{8}{*}{34} & \multirow{8}{*}{4} \\
\hline & & Trichoderma & 12 & & & & \\
\hline & & Lecanicillium & 1 & & & & \\
\hline & & Stachybotrys & 1 & & & & \\
\hline & & Acremonium & 3 & & & & \\
\hline & & Gibberella & 1 & & & & \\
\hline & & Fusarium & 2 & & & & \\
\hline & & Simplicillium & 1 & & & & \\
\hline & Microascales & Rhizopus & 1 & \multirow{7}{*}{0} & \multirow{7}{*}{9} & \multirow{7}{*}{4} & \multirow{7}{*}{1} \\
\hline & Capnodiales & Cladosporium & 1 & & & & \\
\hline & Pleosporales & Paradendryphiella & 1 & & & & \\
\hline & Saccharomycetales & Meyerozyma & 1 & & & & \\
\hline & \multirow{2}{*}{ Incertae sedis } & Pseudeurotium & 2 & & & & \\
\hline & & Pseudogymnoascus & 7 & & & & \\
\hline & Onygenales & Chrysosporium & 1 & & & & \\
\hline \multirow{3}{*}{ 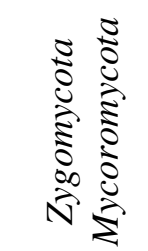 } & \multirow{2}{*}{ Mucorales } & Mucor & 2 & 0 & 1 & 1 & 0 \\
\hline & & Absidia & 2 & & 1 & 1 & 0 \\
\hline & Umbelopsidales & Umbelopsis & 4 & 0 & 2 & 2 & 0 \\
\hline
\end{tabular}

\section{Figure S2. SEM of Tolypocladium inflatum}

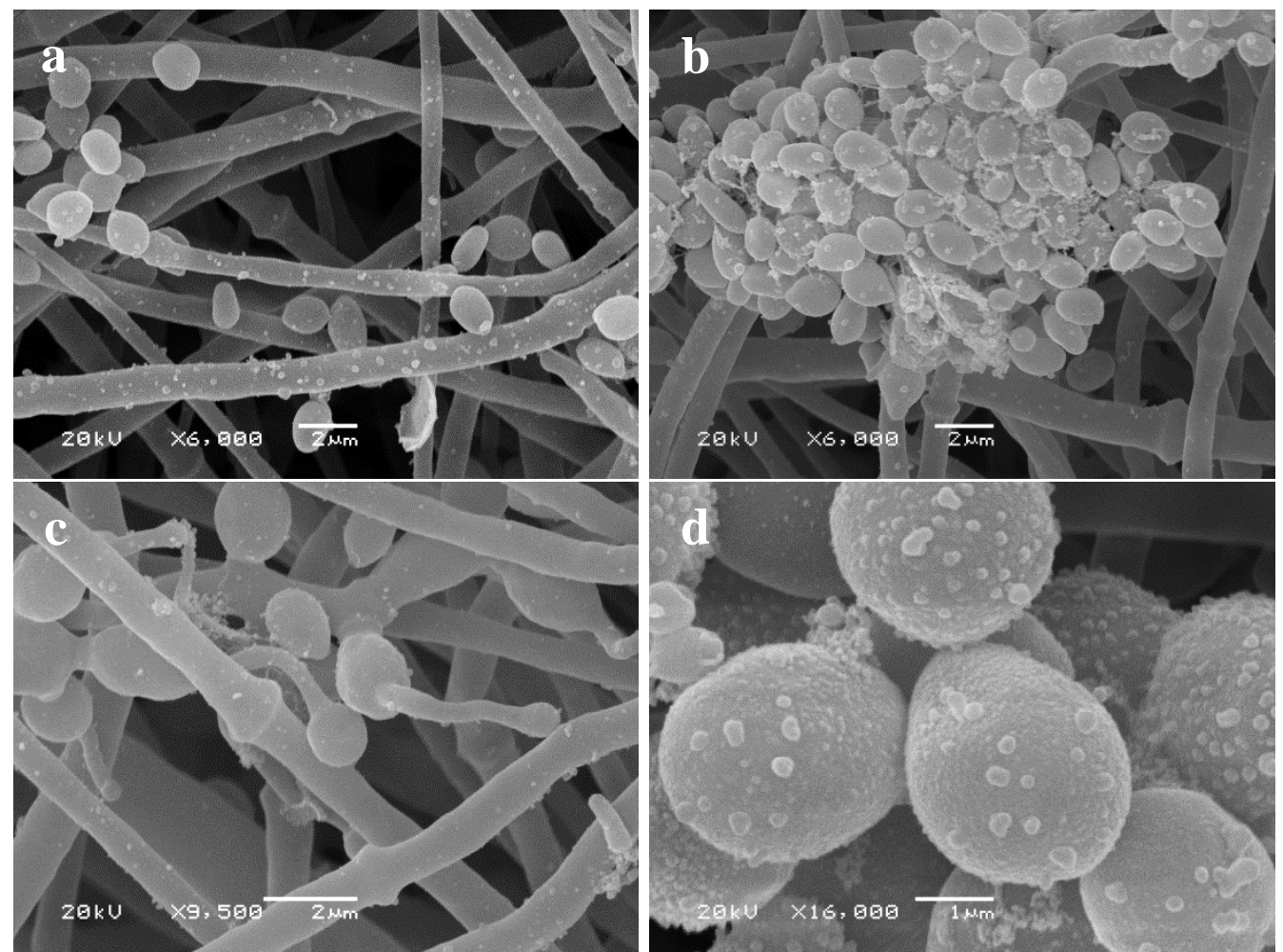

$\mathrm{a}, \mathrm{b}$ - hyphal view of fungus with spores; $\mathrm{c}-$ conidiophores with phialides and conidia; $\mathrm{d}$ - spores. 
Figure S3. MS spectra of CsA (A) and isoCsA (B)

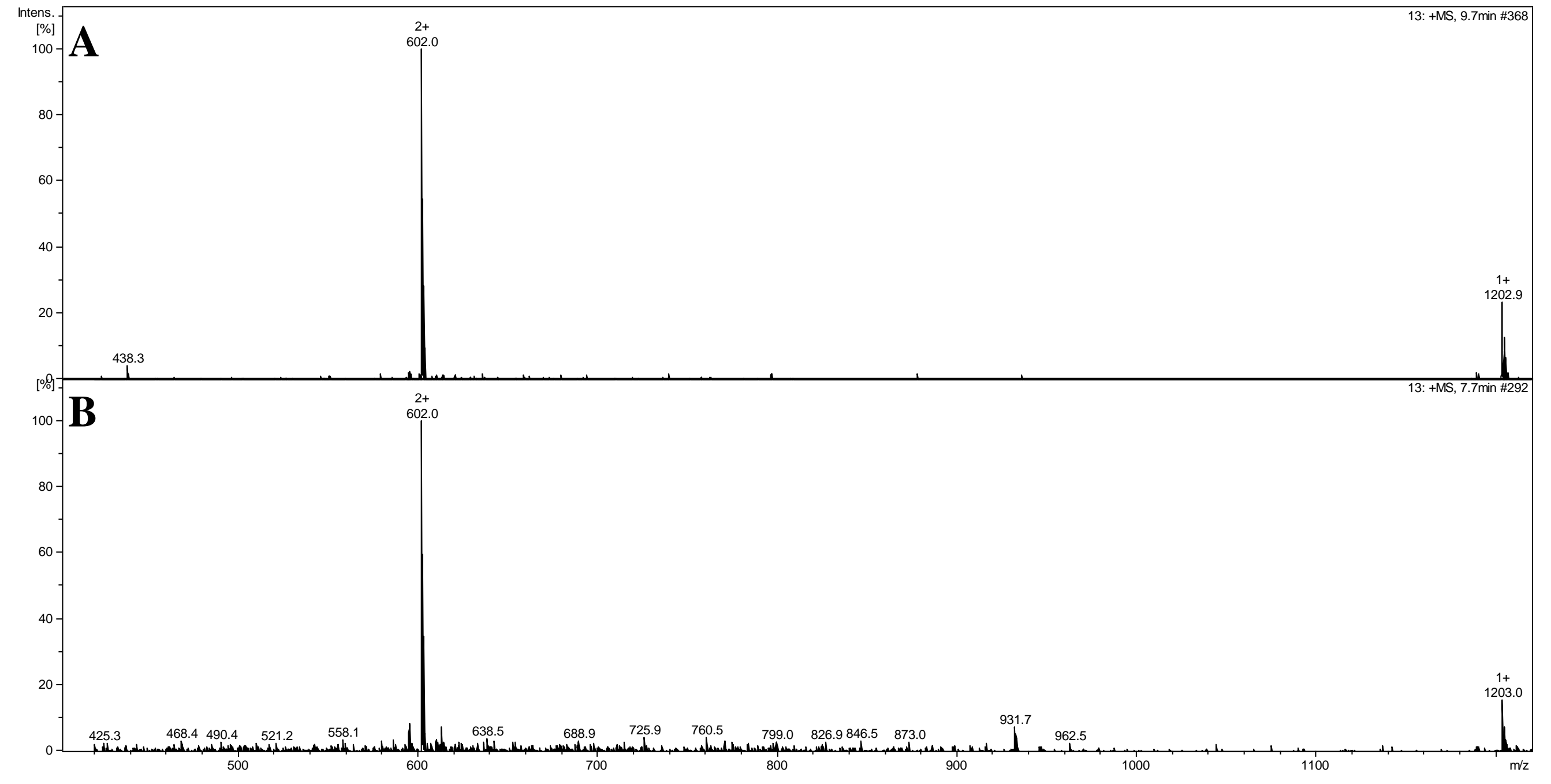


Figure S4. MS spectra of of CsB (A) and isoCsB (B)

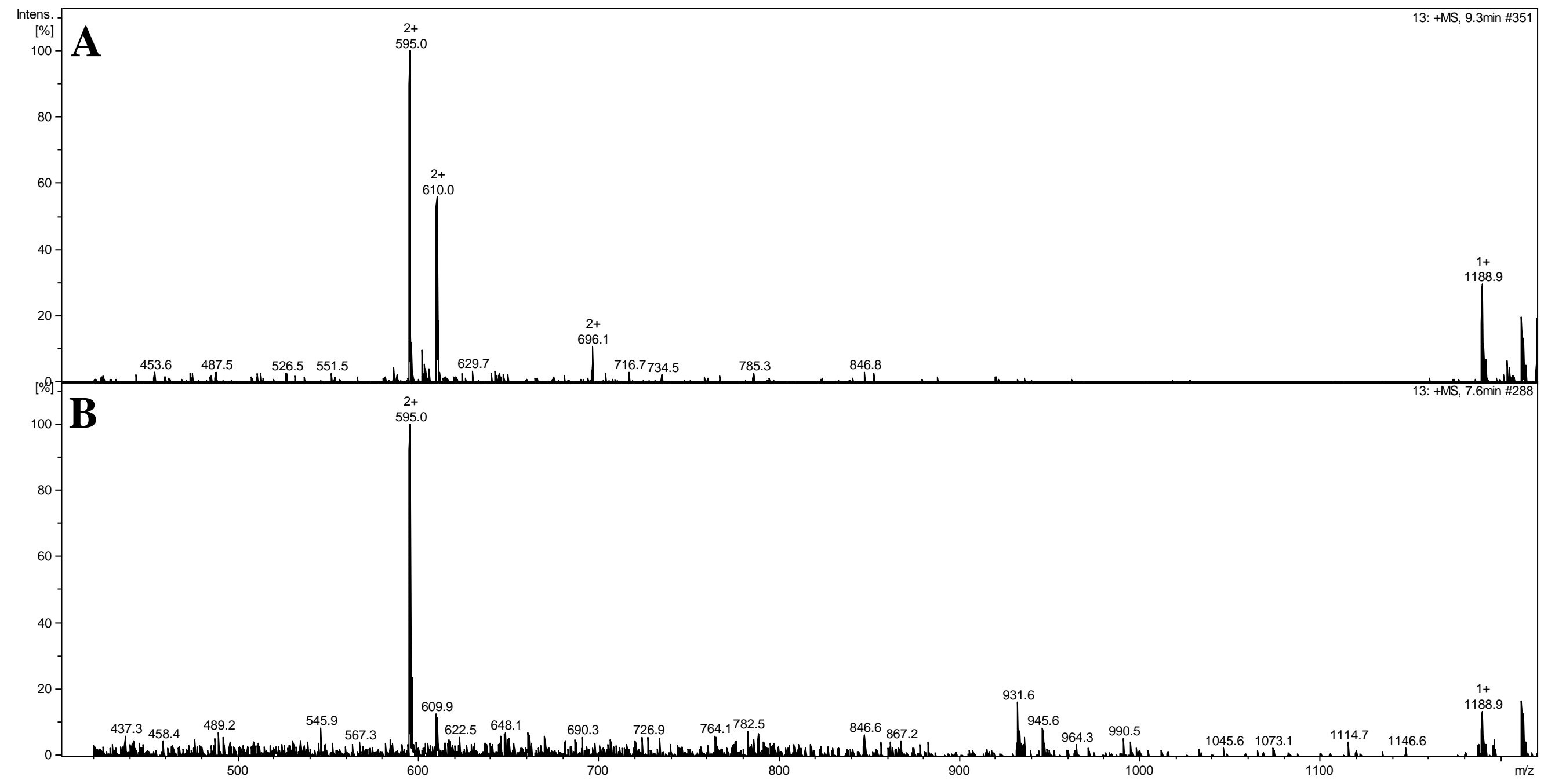


Figure S5. MS spectra of of CsC (A) and isoCsC (B)

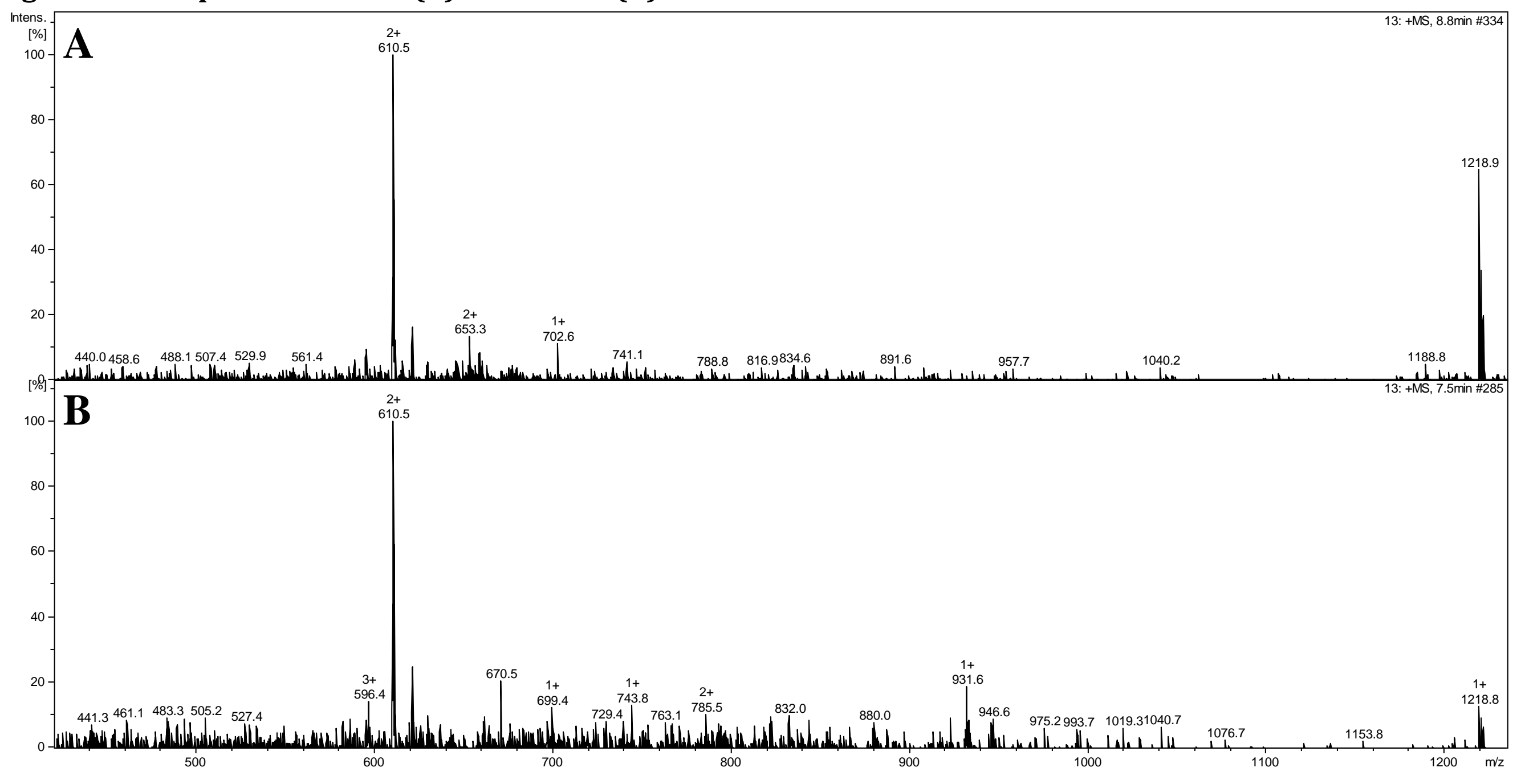


Figure S6. CID MS/MS fragmentation of $[\mathrm{M}+\mathrm{H}]^{+}$ions (m/z 1202) of CsA (A) and isoCsA (B) on Triple quadrupole

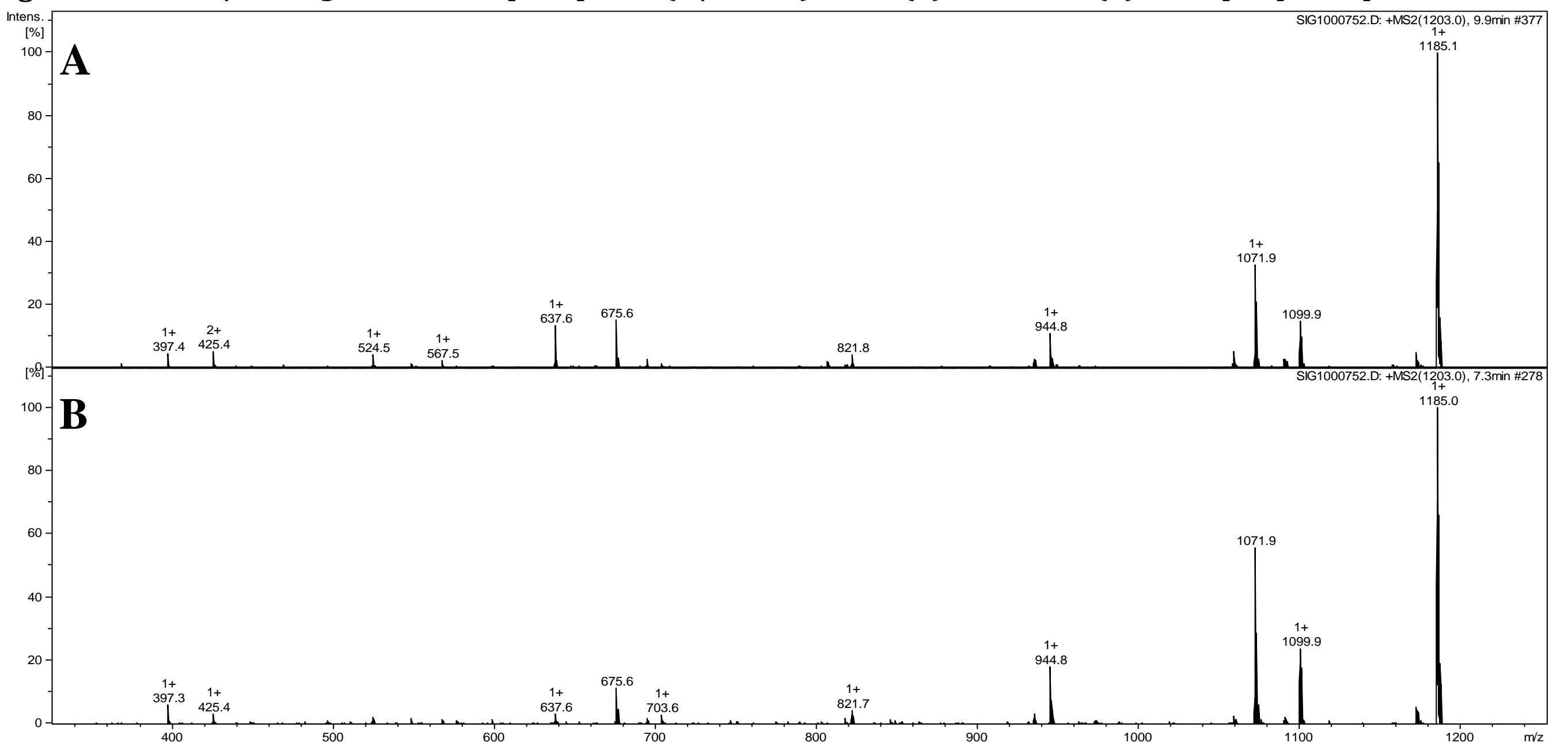


Figure S7. CID MS/MS fragmentation of $[\mathrm{M}+\mathrm{H}]^{+}$ions (m/z 1202) of CsA (A) and isoCsA (B) on TOF instrument
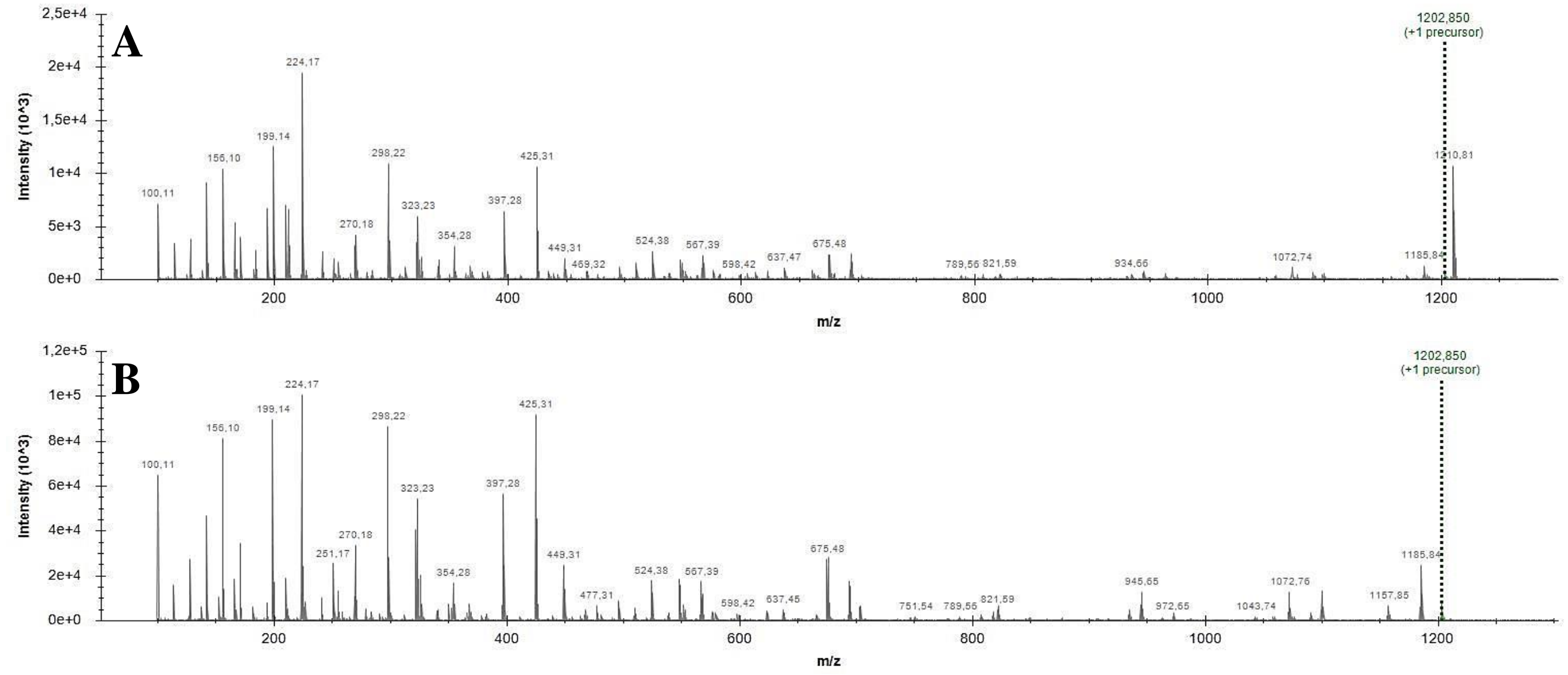
Figure S8. CID MS/MS fragmentation of $[\mathrm{M}+\mathrm{H}]^{+}$ions (m/z 1202) of CsA (A) and isoCsA (B) on Orbitrap instrument
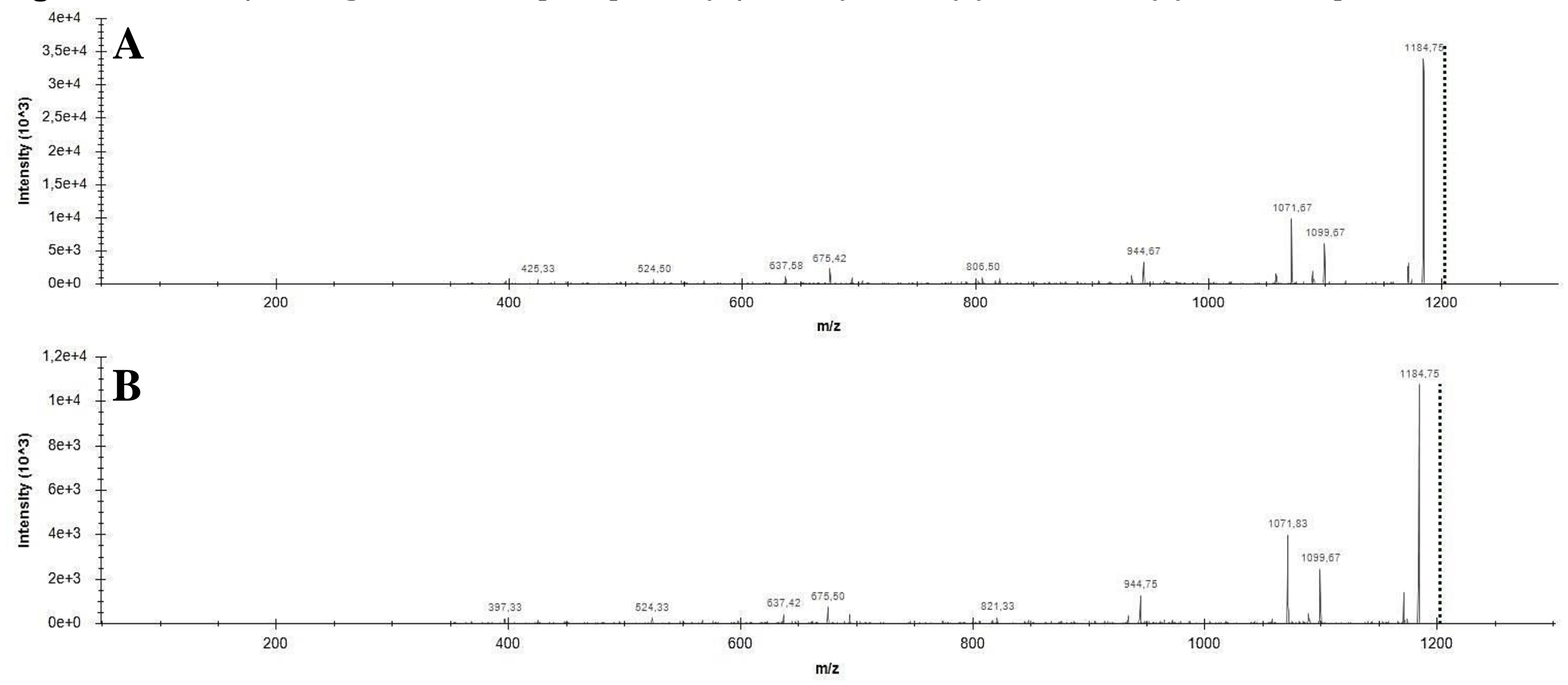
Figure S9. CID MS/MS fragmentation of $[\mathrm{M}+2 \mathrm{H}]^{+}$ions $(\mathrm{m} / \mathrm{z} 602)$ of CsA (A) and isoCsA (B)

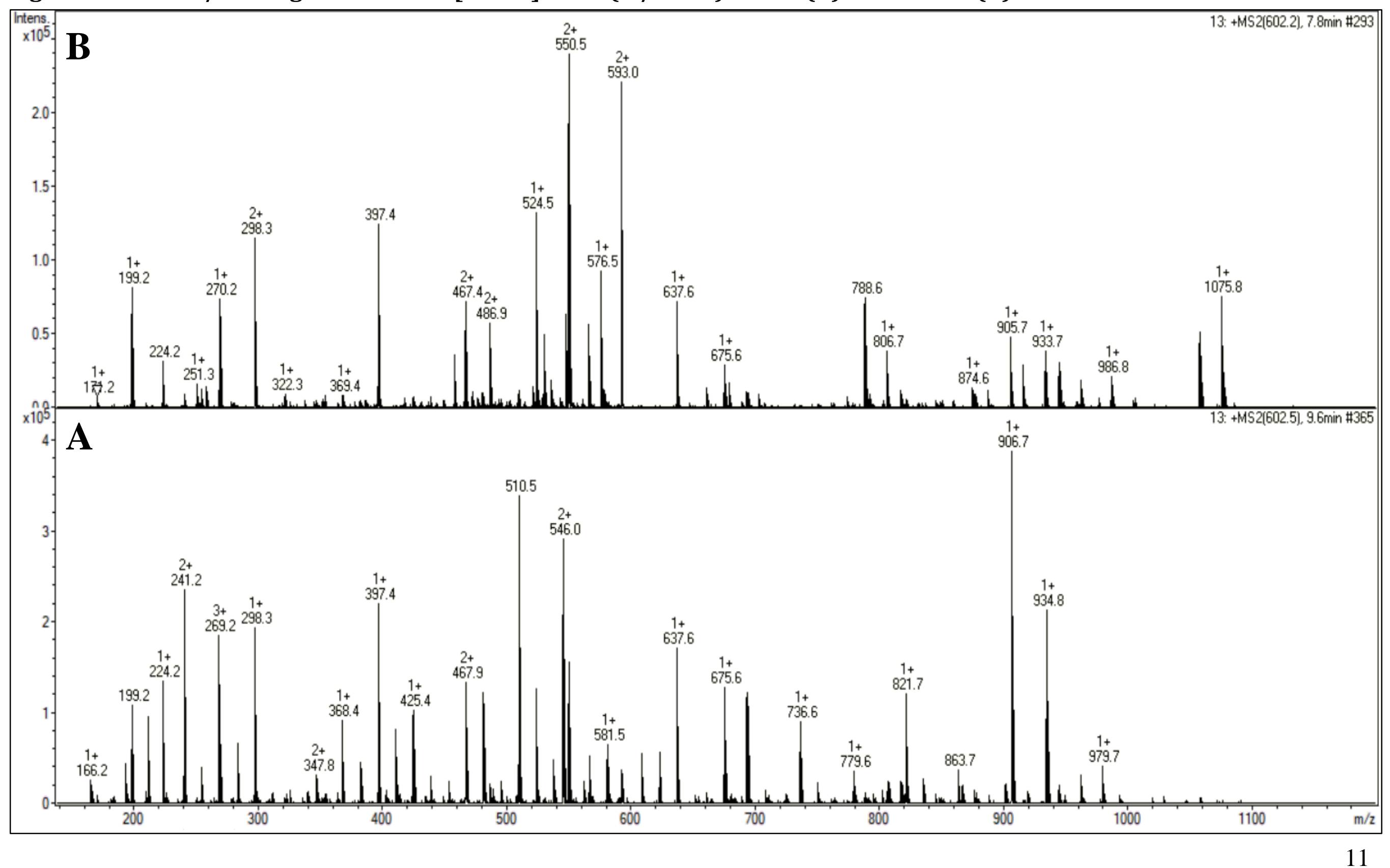

$\underline{\text { Back to Contents }}$ 
CID MS/MS fragmentation of [M+2H]+ ions ( $\mathrm{m} / \mathrm{z}$ 602) of CsA (A) and isoCsA (B), region 130-600

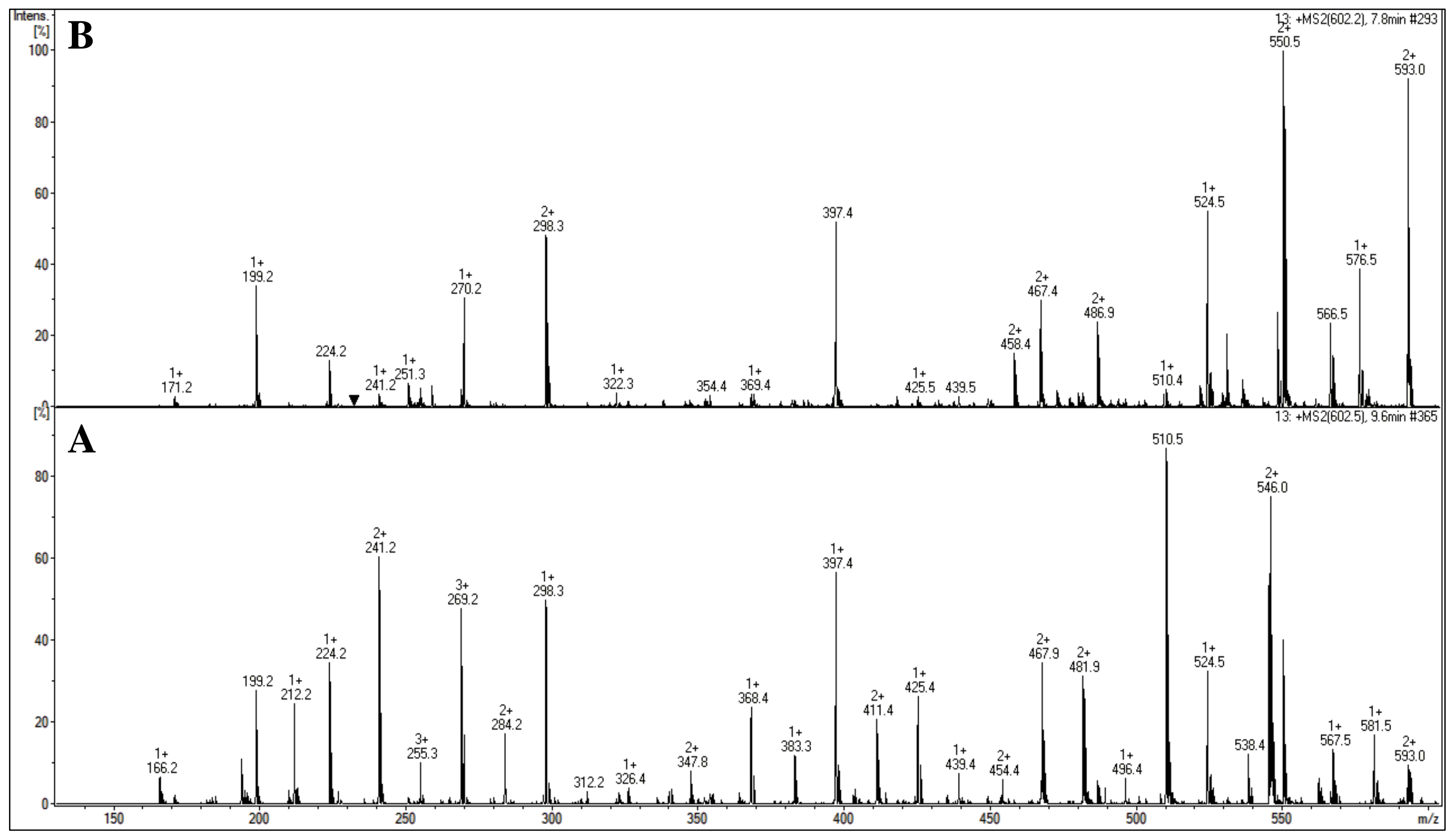

$\underline{\text { Back to Contents }}$ 
CID MS/MS fragmentation of $[\mathrm{M}+2 \mathrm{H}]^{+}$ions (m/z 602) of CsA (A) and isoCsA (B), region 600-1200

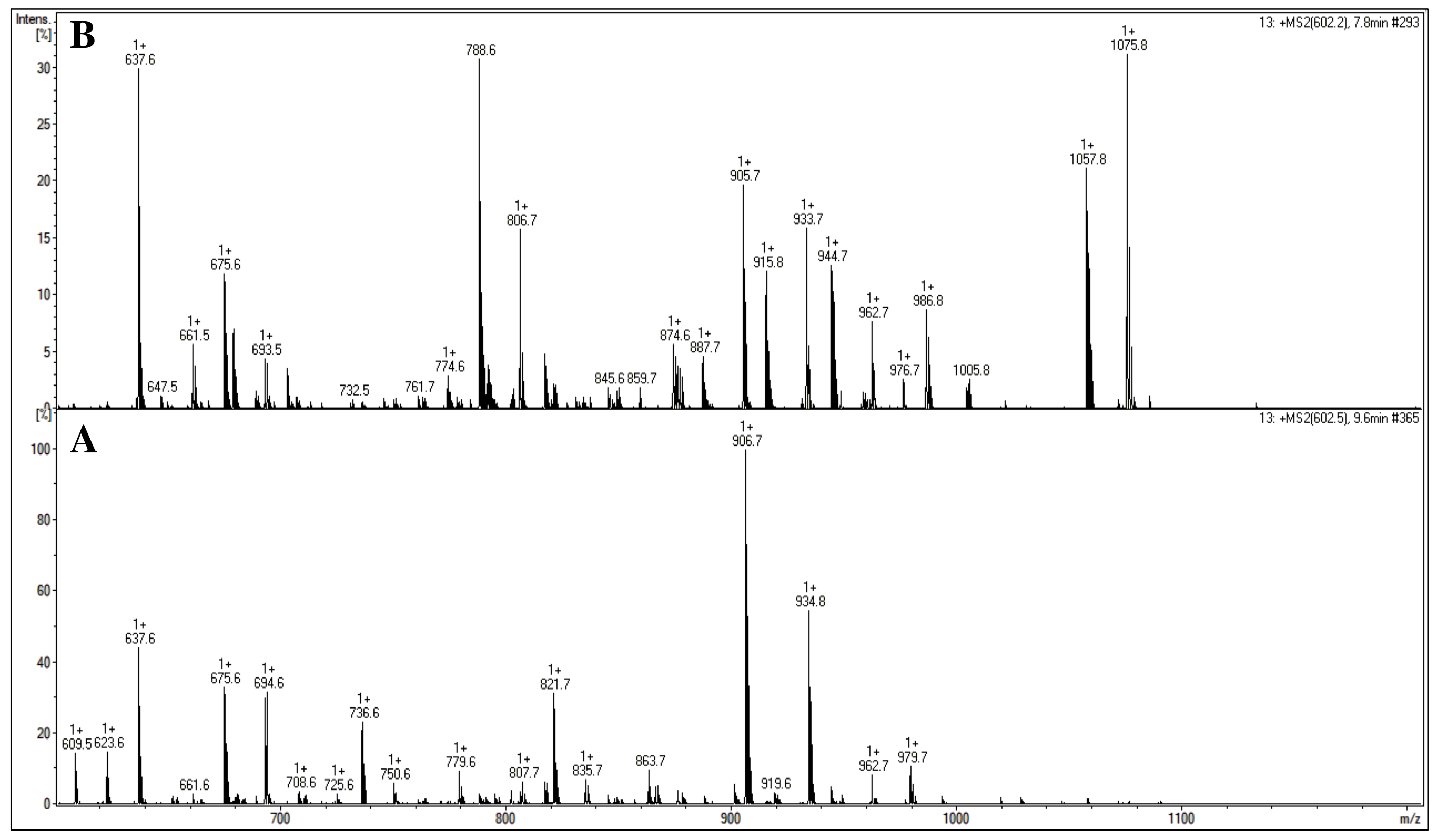

$\underline{\text { Back to Contents }}$ 
Figure S10. CID MS/MS fragmentation of $[\mathrm{M}+2 \mathrm{H}]^{2+}$ ions $(\mathrm{m} / \mathrm{z} 595)$ of $\mathrm{CsB}(\mathrm{A})$ and isoCsB (B)

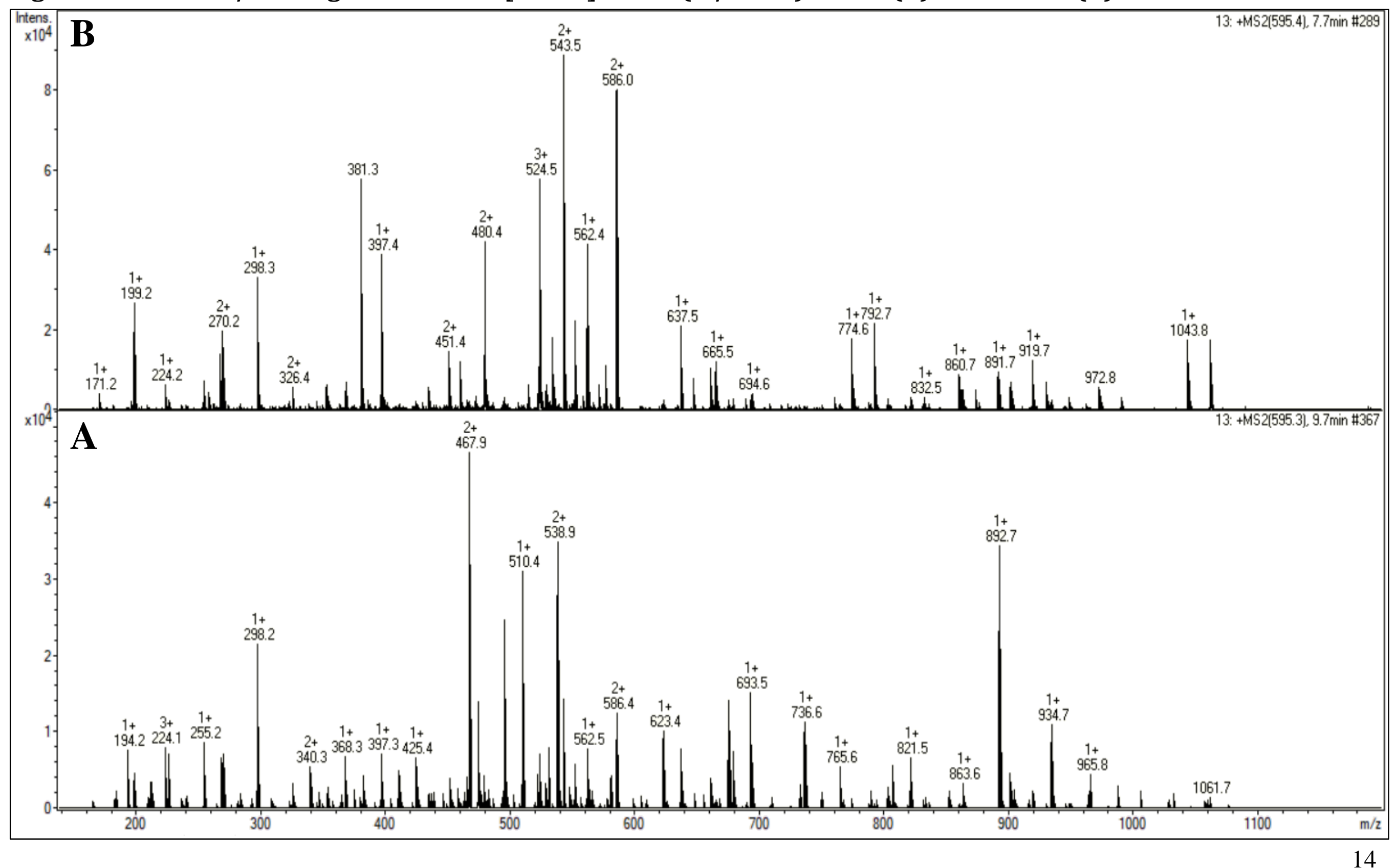

$\underline{\text { Back to Contents }}$ 
CID MS/MS fragmentation of $[\mathrm{M}+2 \mathrm{H}]^{2+}$ ions (m/z 595) of CsB (A) and isoCsB (B), region 140-600

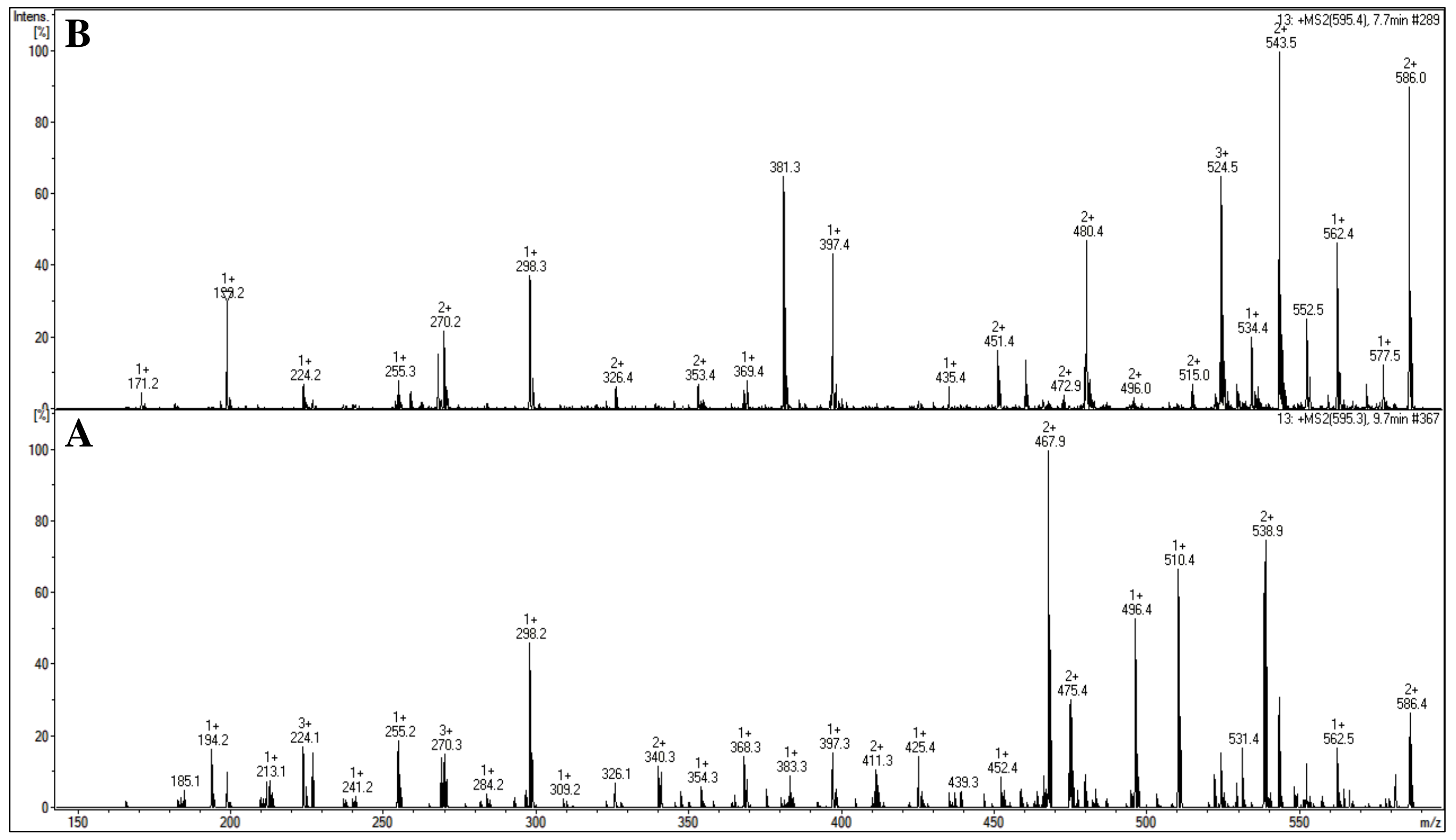

$\underline{\text { Back to Contents }}$ 
CID MS/MS fragmentation of $[\mathrm{M}+2 \mathrm{H}]^{2+}$ ions (m/z 595) of CsB (A) and isoCsB (B), region 600-1200

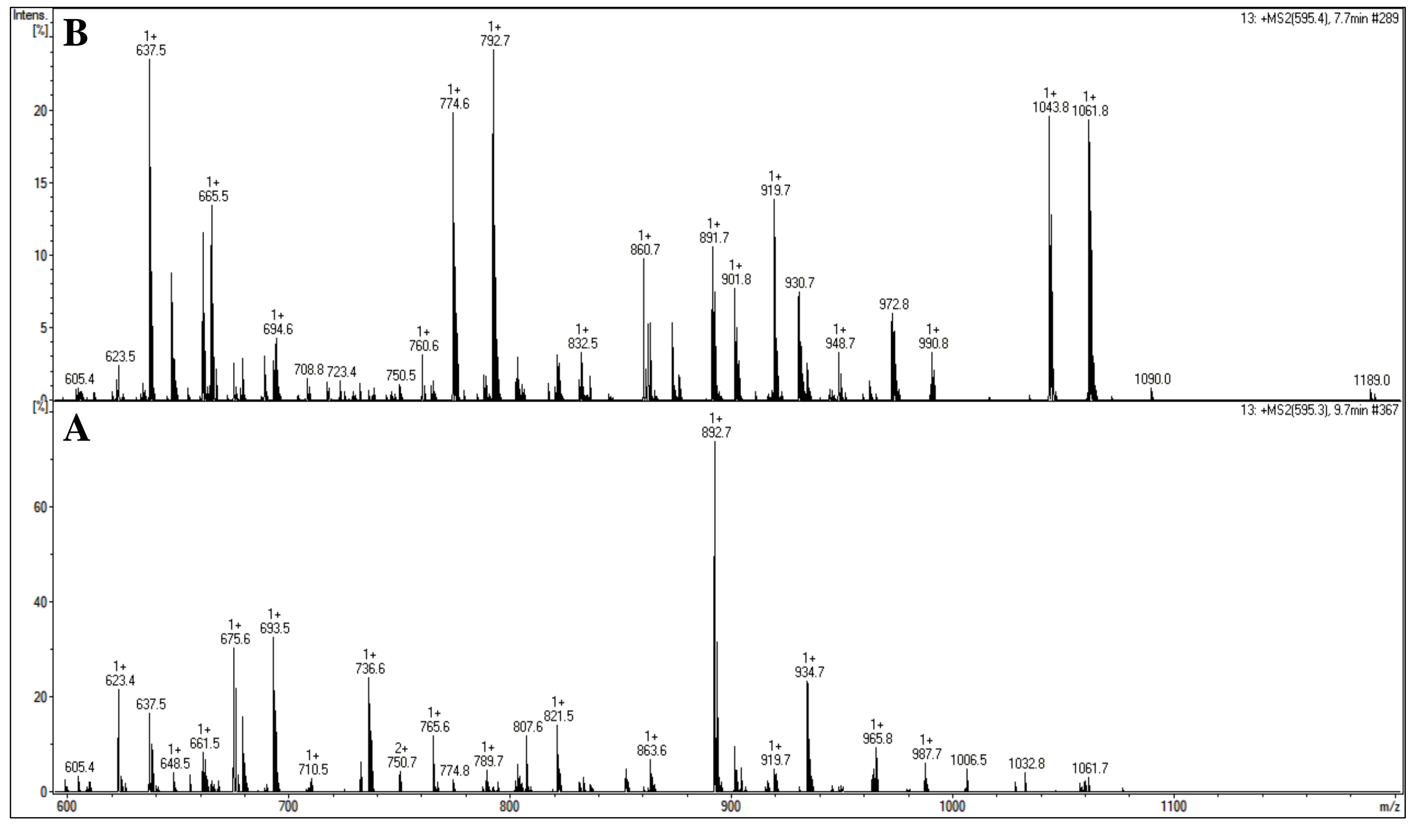

$\underline{\text { Back to Contents }}$ 
Figure S11. CID MS/MS fragmentation of $[\mathrm{M}+2 \mathrm{H}]^{2+}$ ions $(\mathrm{m} / \mathrm{z} 610)$ of $\mathrm{CsC}(\mathrm{A})$ and isoCsC (B)

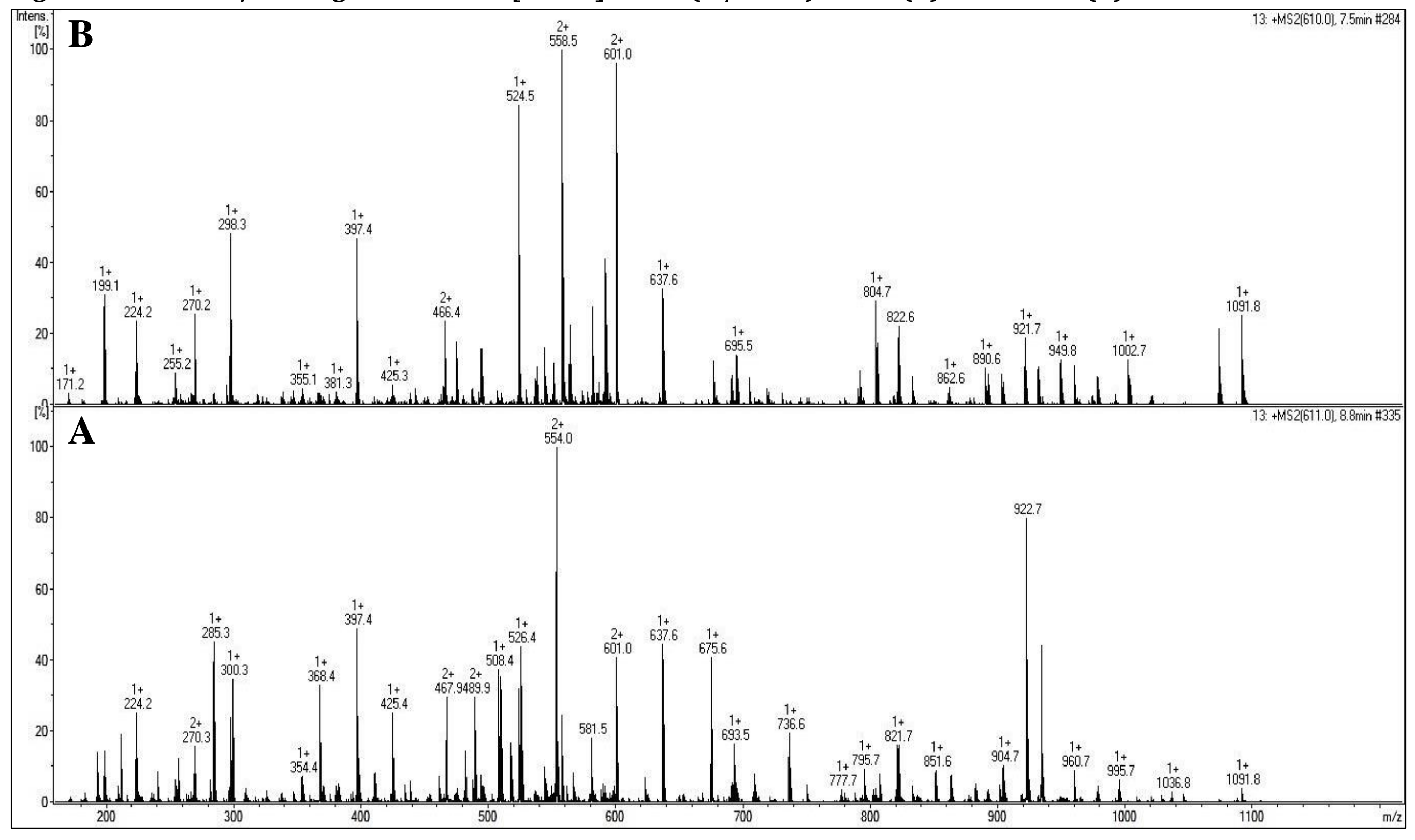

$\underline{\text { Back to Contents }}$ 
CID MS/MS fragmentation of $[\mathrm{M}+2 \mathrm{H}]^{2+}$ ions $(\mathrm{m} / \mathrm{z} 610)$ of $\mathrm{CsC}(\mathrm{A})$ and isoCsC $(\mathrm{B})$, region 0-623

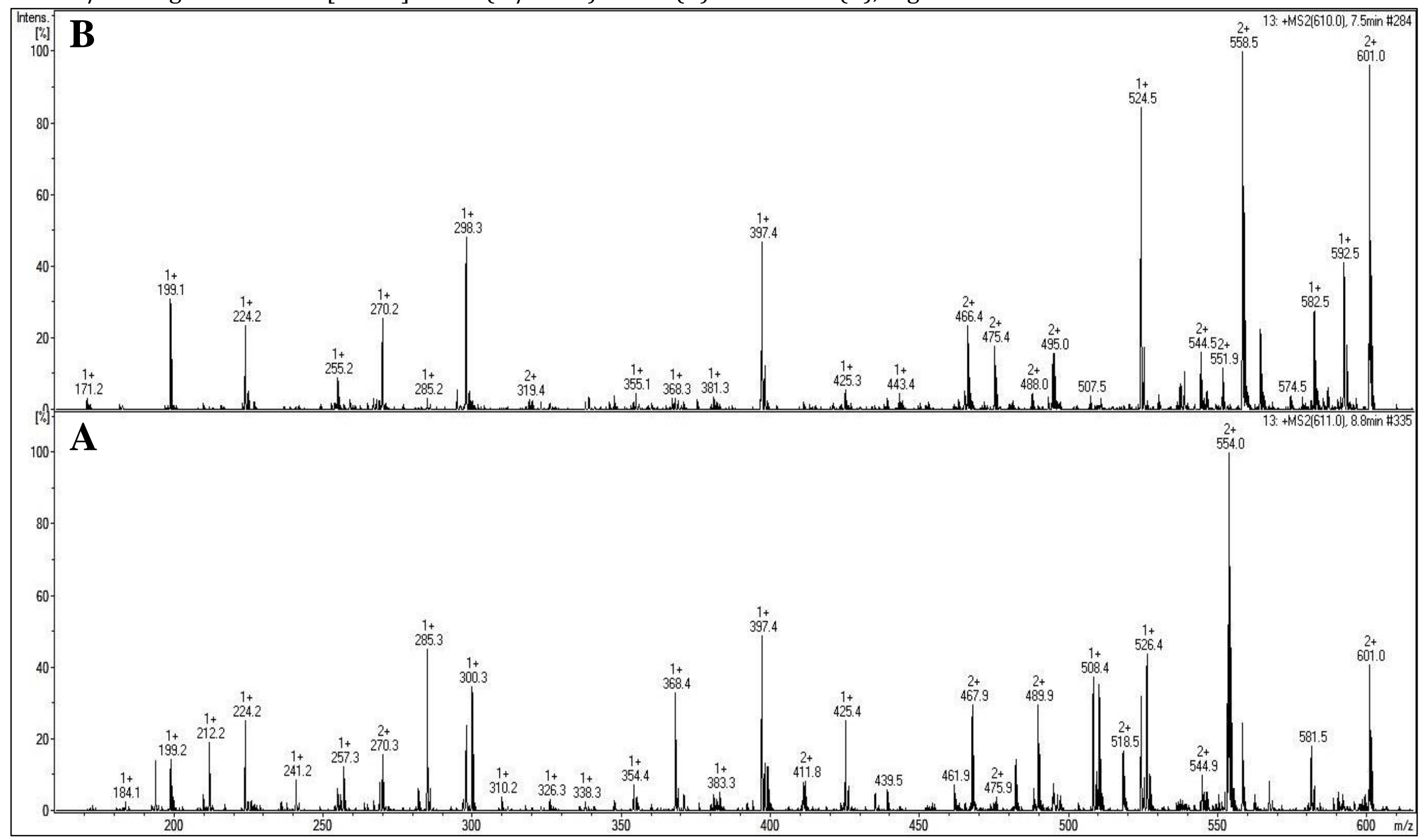

$\underline{\text { Back to Contents }}$ 
CID MS/MS fragmentation of $[\mathrm{M}+2 \mathrm{H}]^{2+}$ ions (m/z 610) of CsC $(\mathrm{A})$ and isoCsC $(\mathrm{B})$, region 623-1220

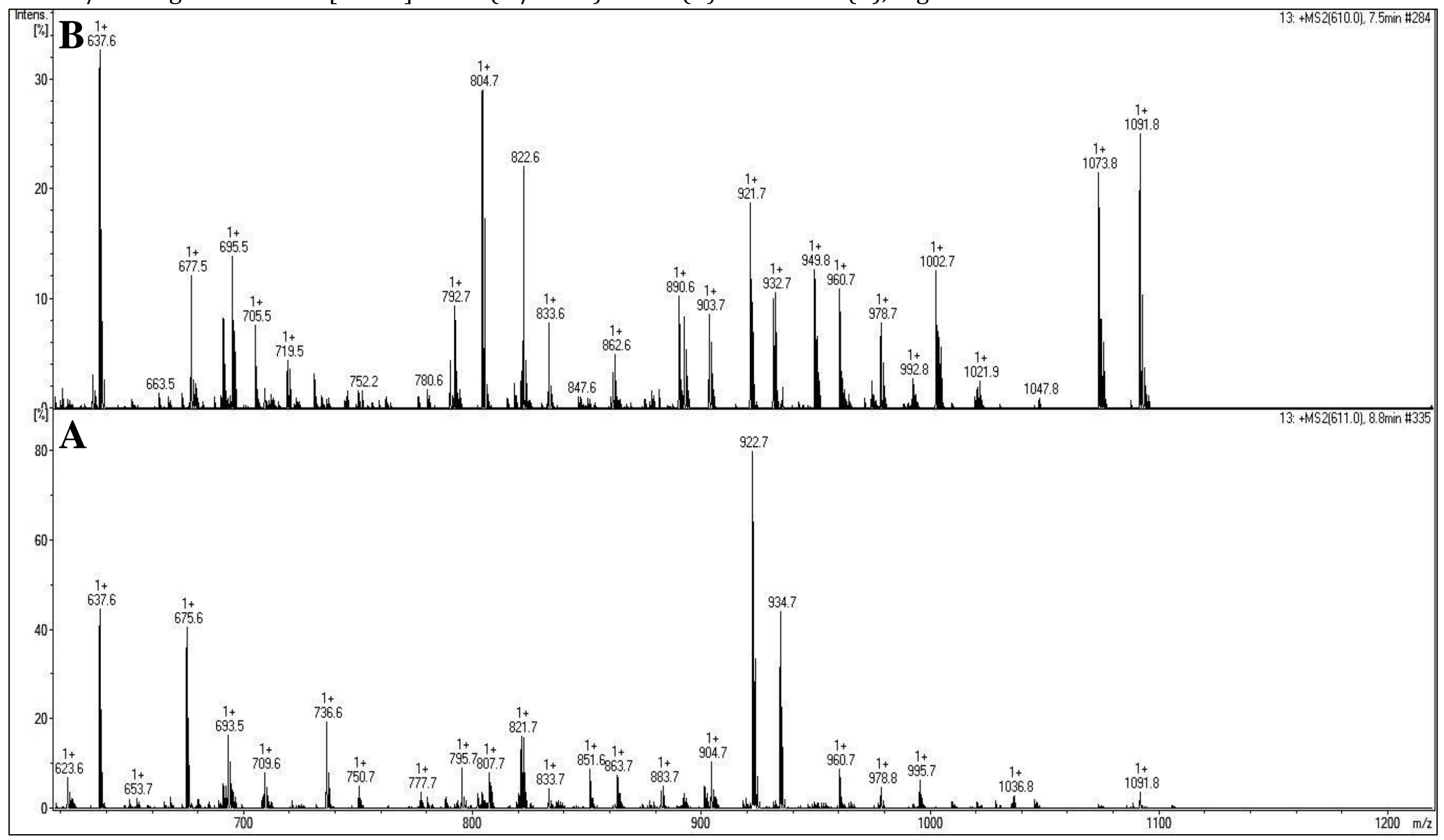

$\underline{\text { Back to Contents }}$ 
Figure S12. CID MS/MS fragmentation of $[M+2 H]^{2+}$ ions $(\mathrm{m} / \mathrm{z} 602)$ of CsA

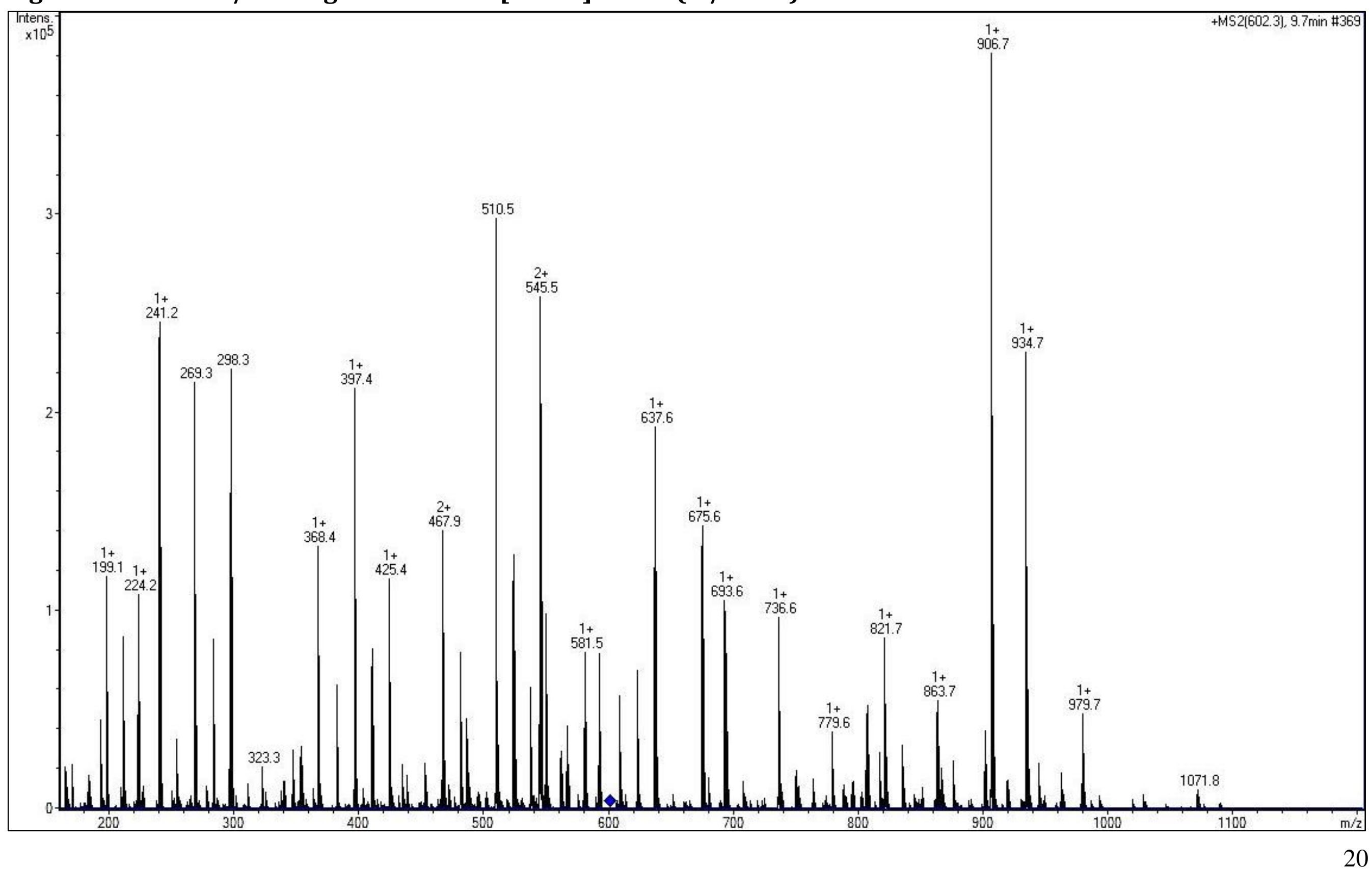

$\underline{\text { Back to Contents }}$ 
CID MS/MS fragmentation of $[\mathrm{M}+2 \mathrm{H}]^{2+}$ ions $(\mathrm{m} / \mathrm{z}$ 602) of CsA, region 166-605

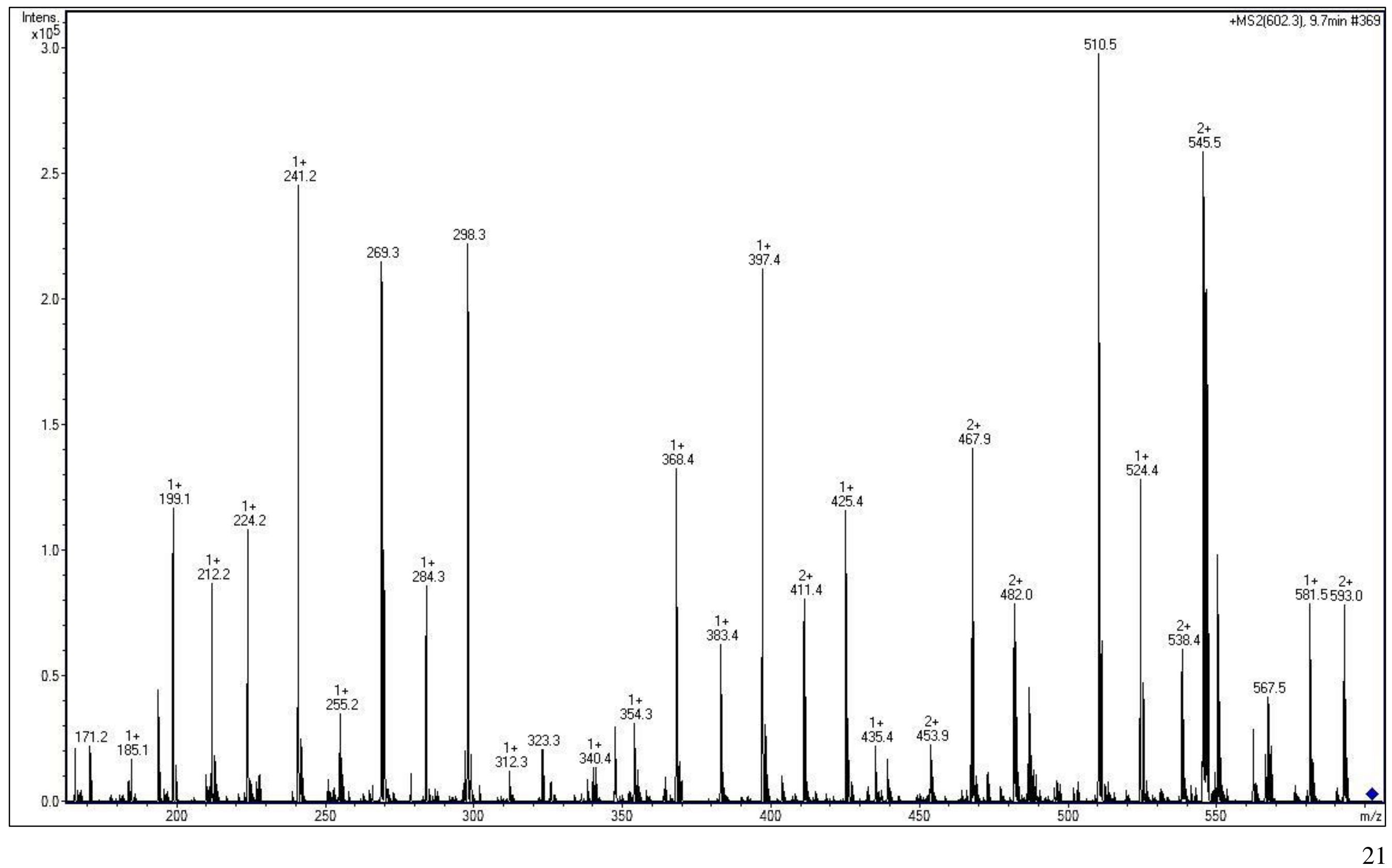

$\underline{\text { Back to Contents }}$ 
CID MS/MS fragmentation of $[\mathrm{M}+2 \mathrm{H}]^{2+}$ ions $(\mathrm{m} / \mathrm{z}$ 602) of CsA, region 605-1205

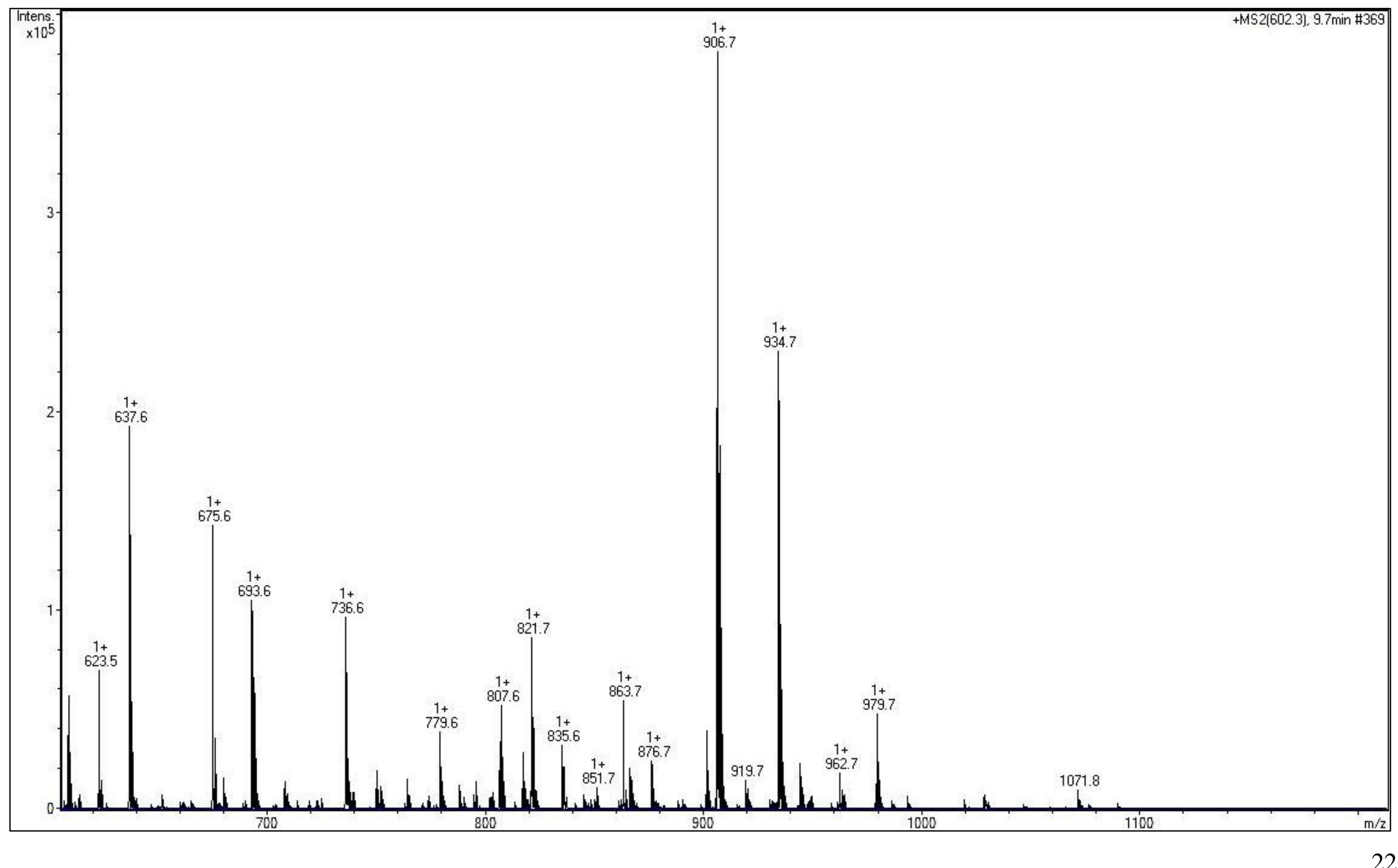

$\underline{\text { Back to Contents }}$ 
Figure S13. CID MS/MS fragmentation of $[\mathrm{M}+2 \mathrm{H}]^{2+}$ ions $(\mathrm{m} / \mathrm{z} 602)$ of isoCsA

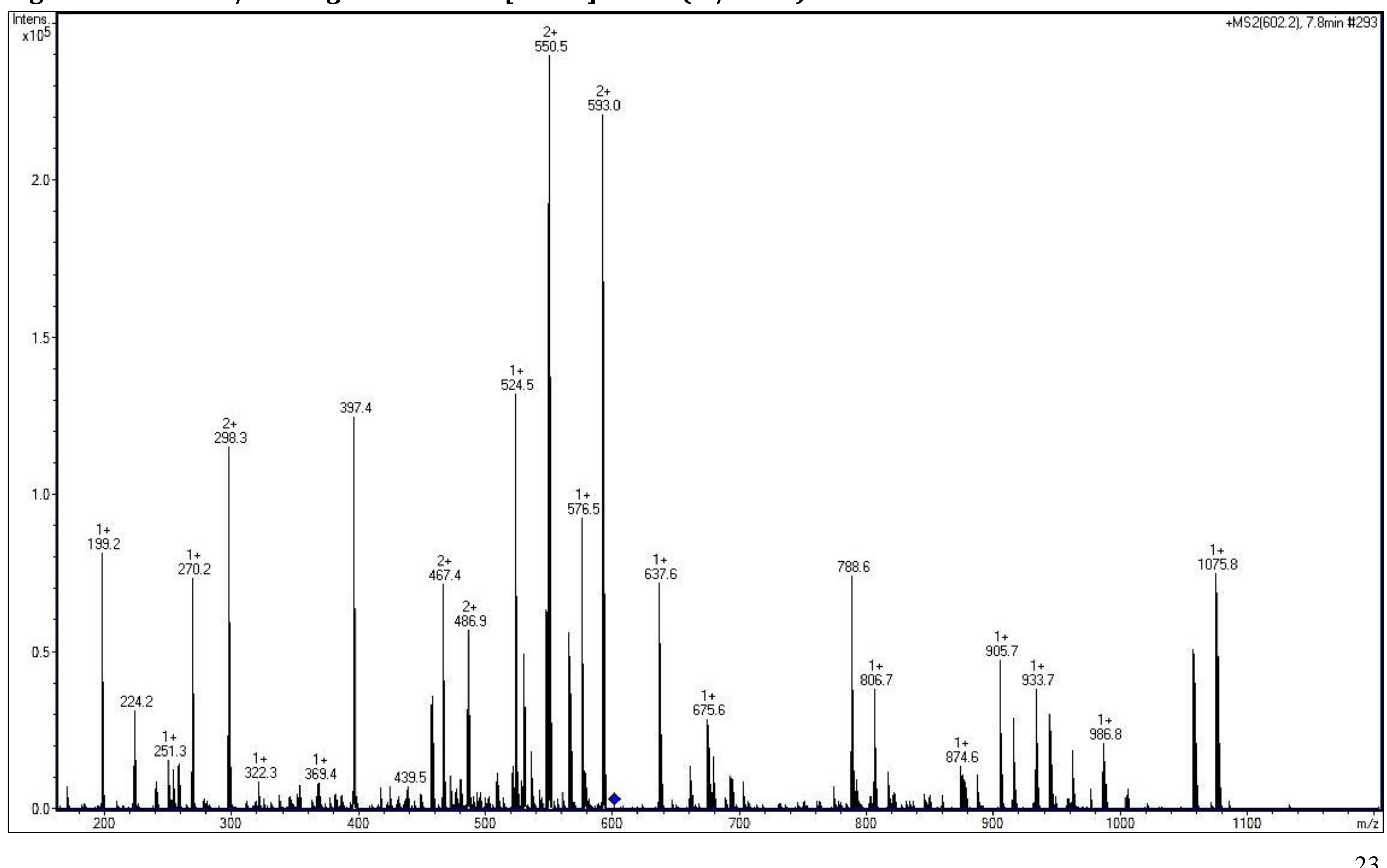

$\underline{\text { Back to Contents }}$ 
CID MS/MS fragmentation of $[\mathrm{M}+2 \mathrm{H}]^{2+}$ ions (m/z 602) of isoCsA, region 166-606

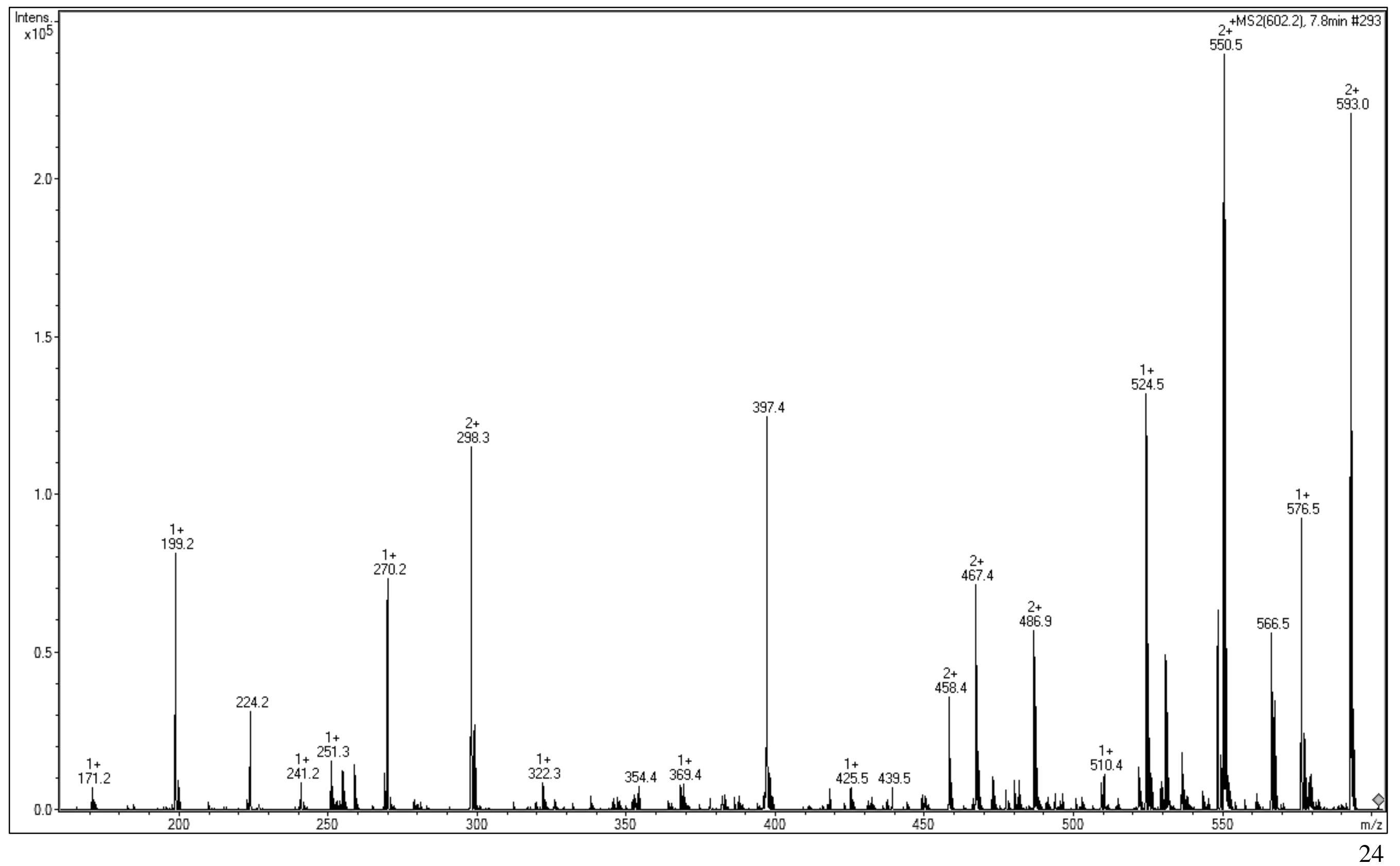

$\underline{\text { Back to Contents }}$ 
CID MS/MS fragmentation of $[\mathrm{M}+2 \mathrm{H}]^{2+}$ ions $(\mathrm{m} / \mathrm{z}$ 602) of isoCsA, region 606-1205

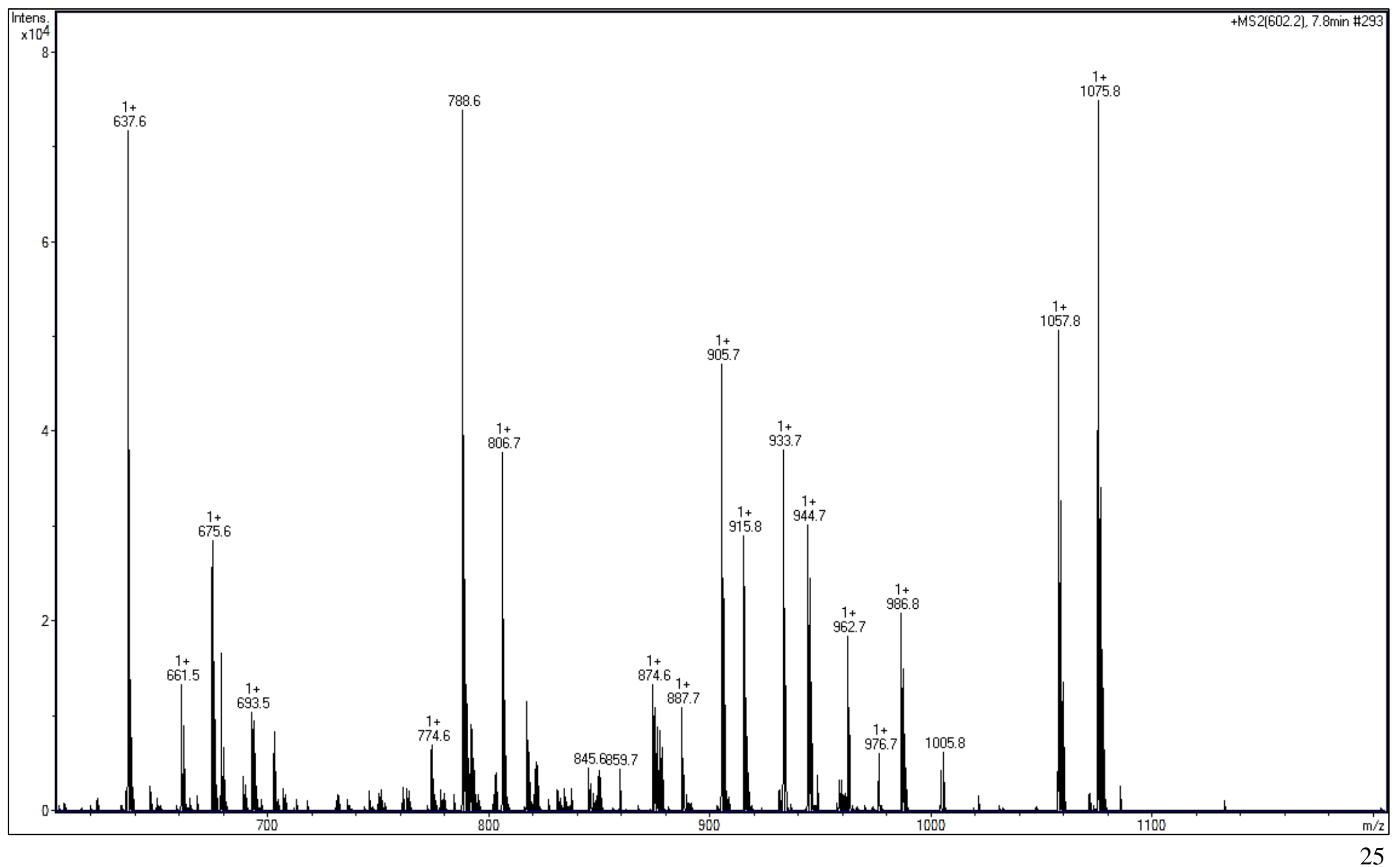

$\underline{\text { Back to Contents }}$ 
Figure S14. CID MS/MS fragmentation of $[M+2 H]^{2+}$ ions $(\mathrm{m} / \mathrm{z} 595)$ of CsB

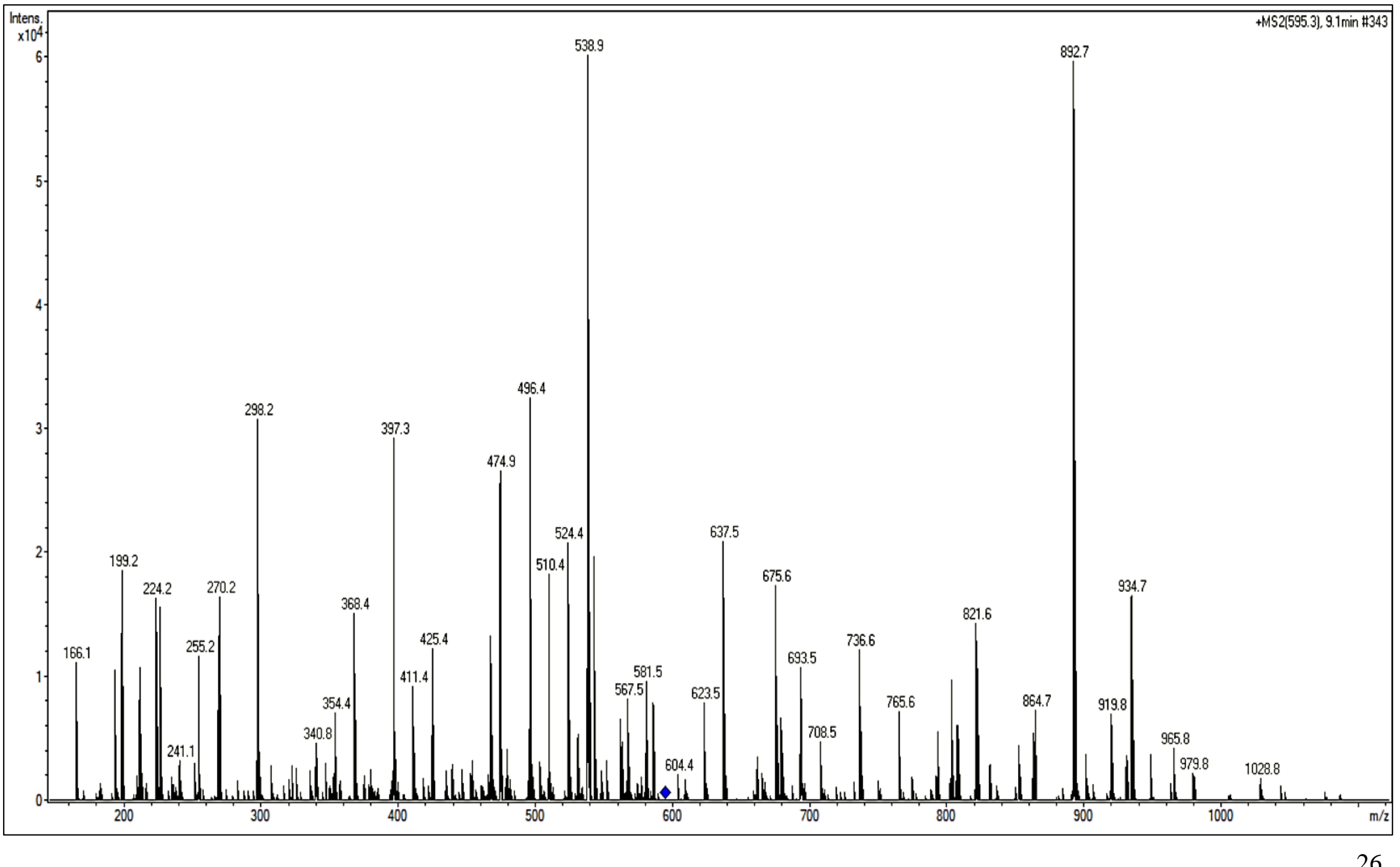

$\underline{\text { Back to Contents }}$ 
CID MS/MS fragmentation of $[\mathrm{M}+2 \mathrm{H}]^{2+}$ ions (m/z 595) of CsB, region 166-620

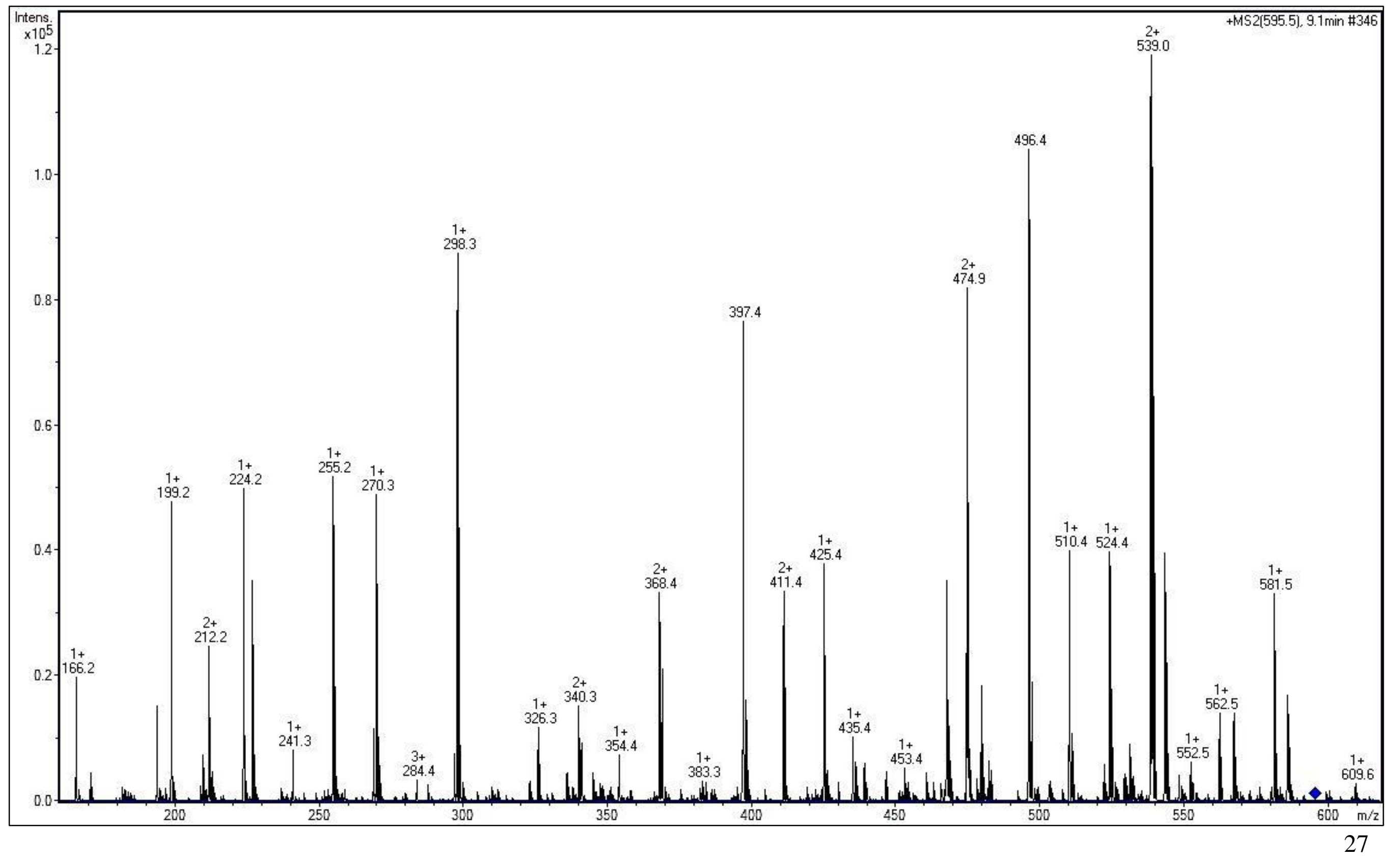

$\underline{\text { Back to Contents }}$ 
CID MS/MS fragmentation of $[\mathrm{M}+2 \mathrm{H}]^{2+}$ ions $(\mathrm{m} / \mathrm{z}$ 595) of CsB, region 620-1990

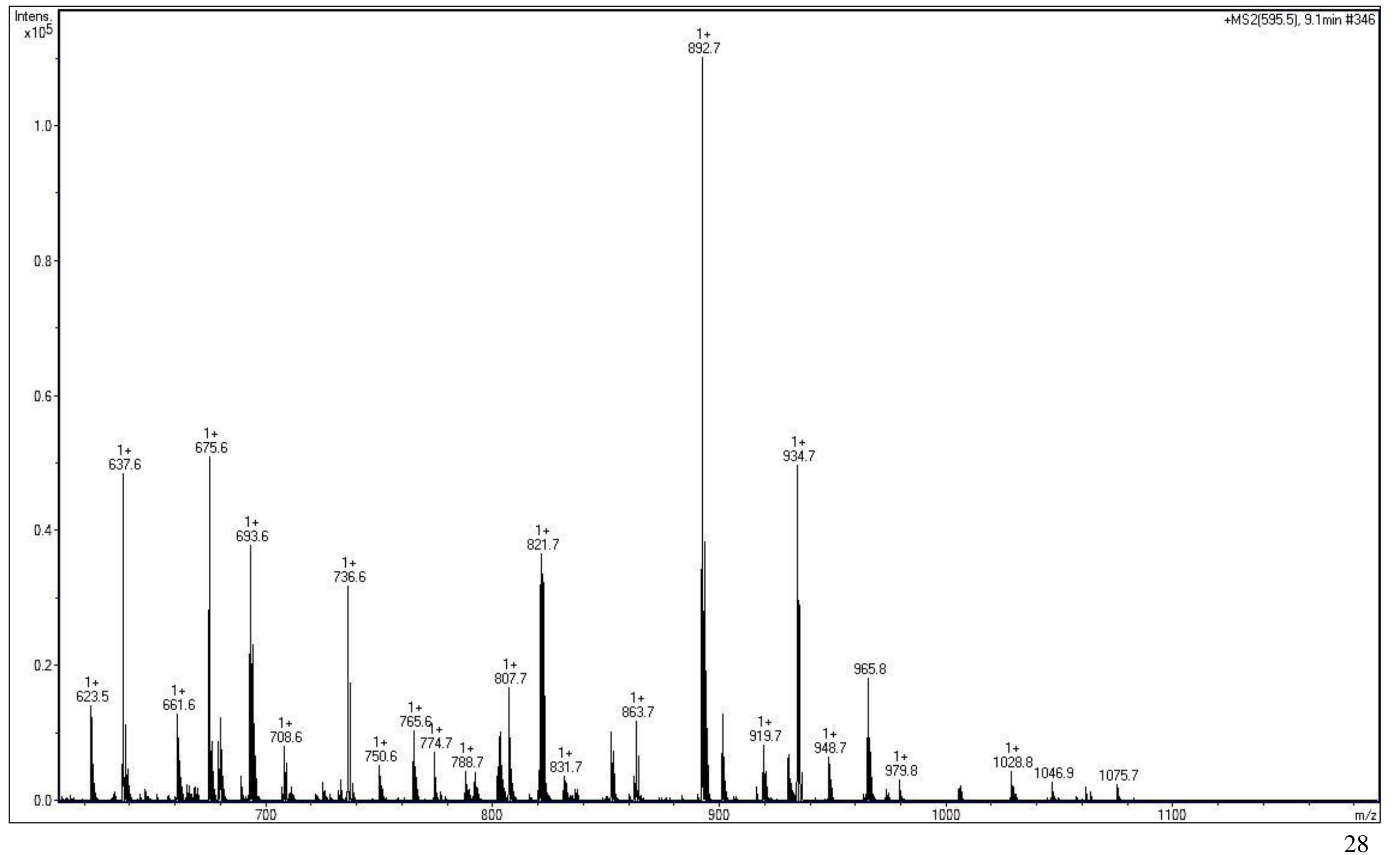

$\underline{\text { Back to Contents }}$ 
Figure S15. CID MS/MS fragmentation of $[\mathrm{M}+2 \mathrm{H}]^{2+}$ ions $(\mathrm{m} / \mathrm{z} 595)$ of isoCsB

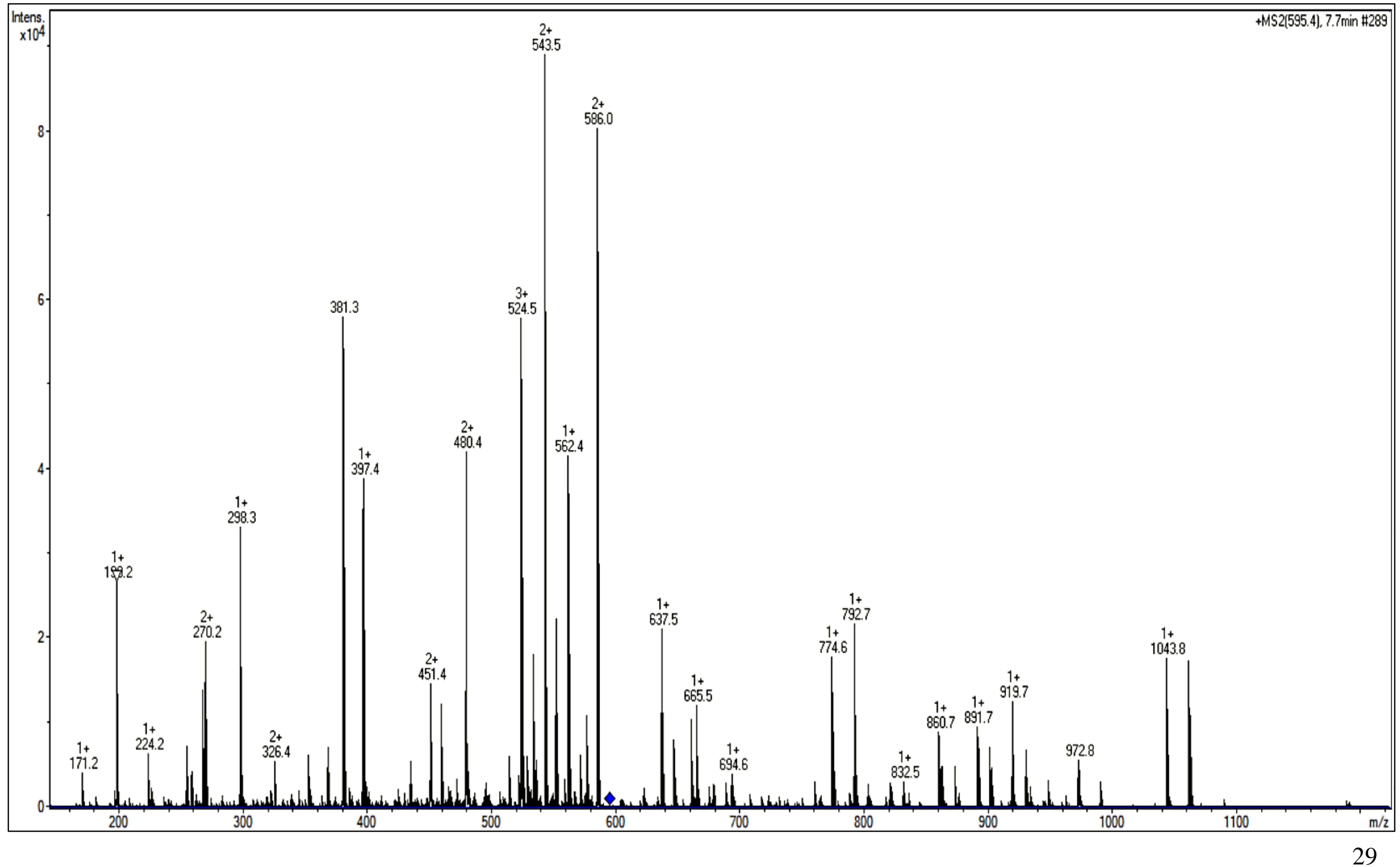

$\underline{\text { Back to Contents }}$ 
CID MS/MS fragmentation of $[\mathrm{M}+2 \mathrm{H}]^{2+}$ ions ( $\mathrm{m} / \mathrm{z}$ 595) of isoCsB, region 166-620

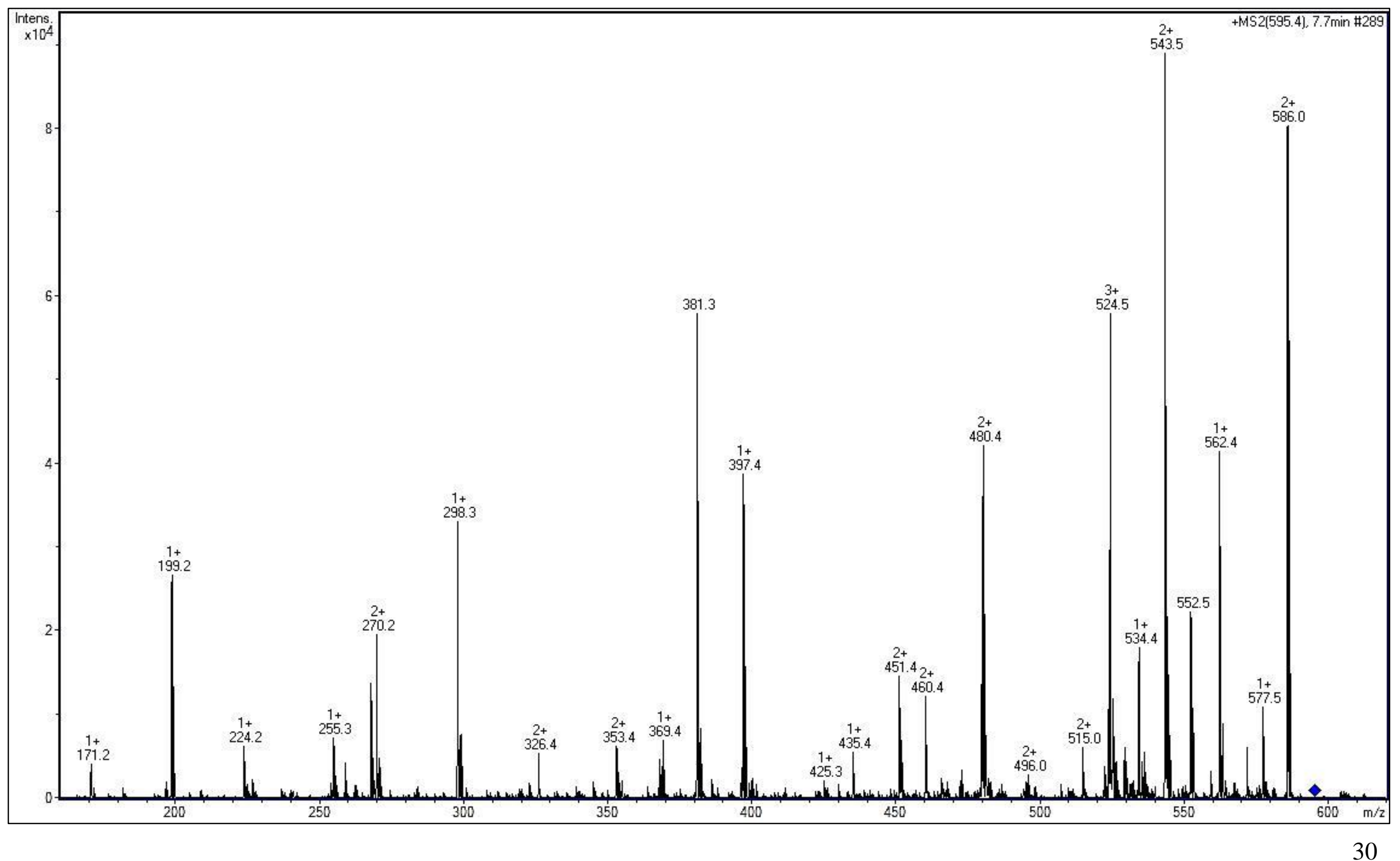

$\underline{\text { Back to Contents }}$ 
CID MS/MS fragmentation of $[\mathrm{M}+2 \mathrm{H}]^{2+}$ ions $(\mathrm{m} / \mathrm{z}$ 595) of isoCsB, region 620-1190

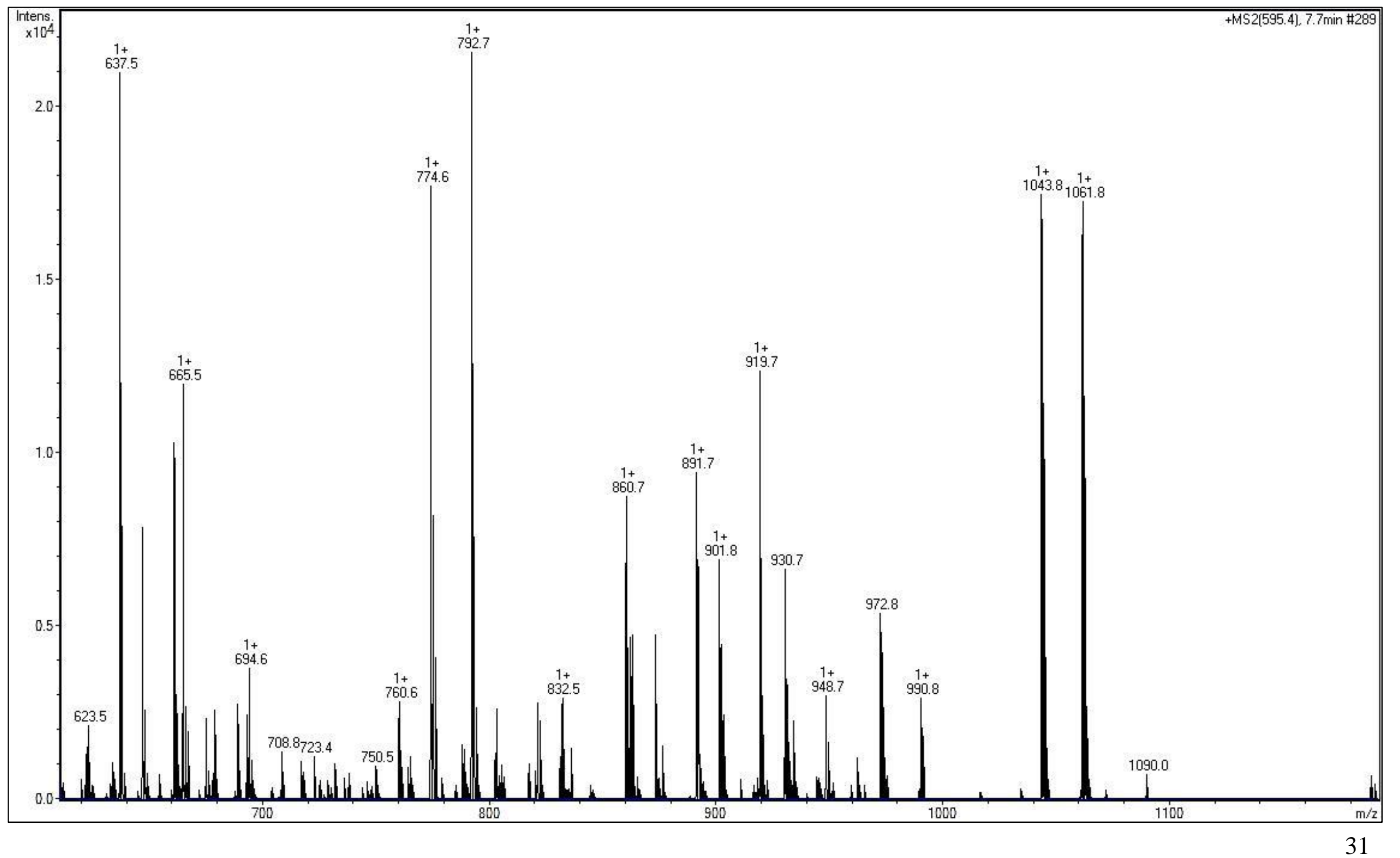

$\underline{\text { Back to Contents }}$ 
Figure S16. CID MS/MS fragmentation of $[M+2 H]^{2+}$ ions $(\mathrm{m} / \mathrm{z} 611)$ of CsC

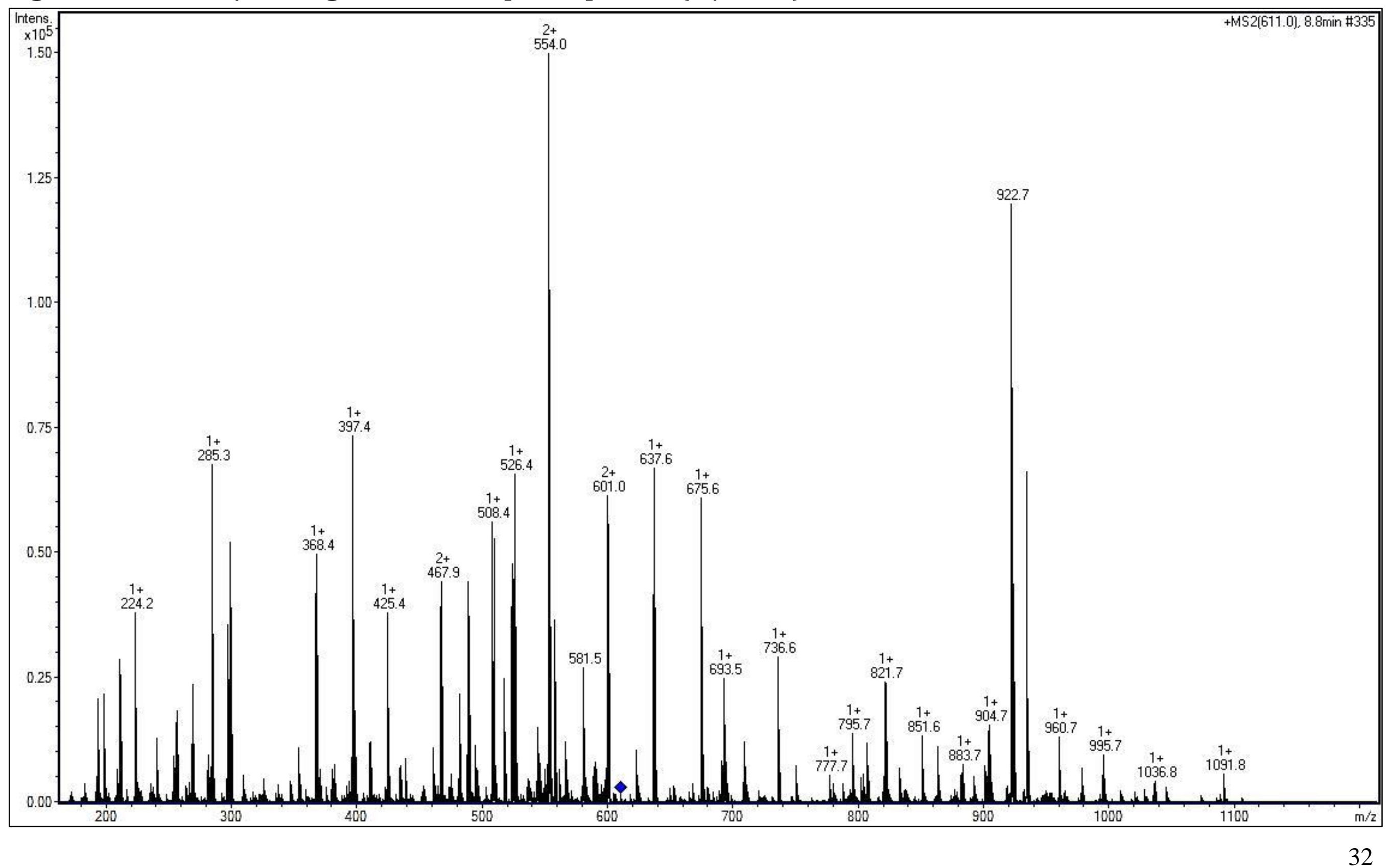

$\underline{\text { Back to Contents }}$ 
CID MS/MS fragmentation of $[\mathrm{M}+2 \mathrm{H}]^{2+}$ ions $(\mathrm{m} / \mathrm{z}$ 611) of $\mathrm{CsC}$, region 166-620

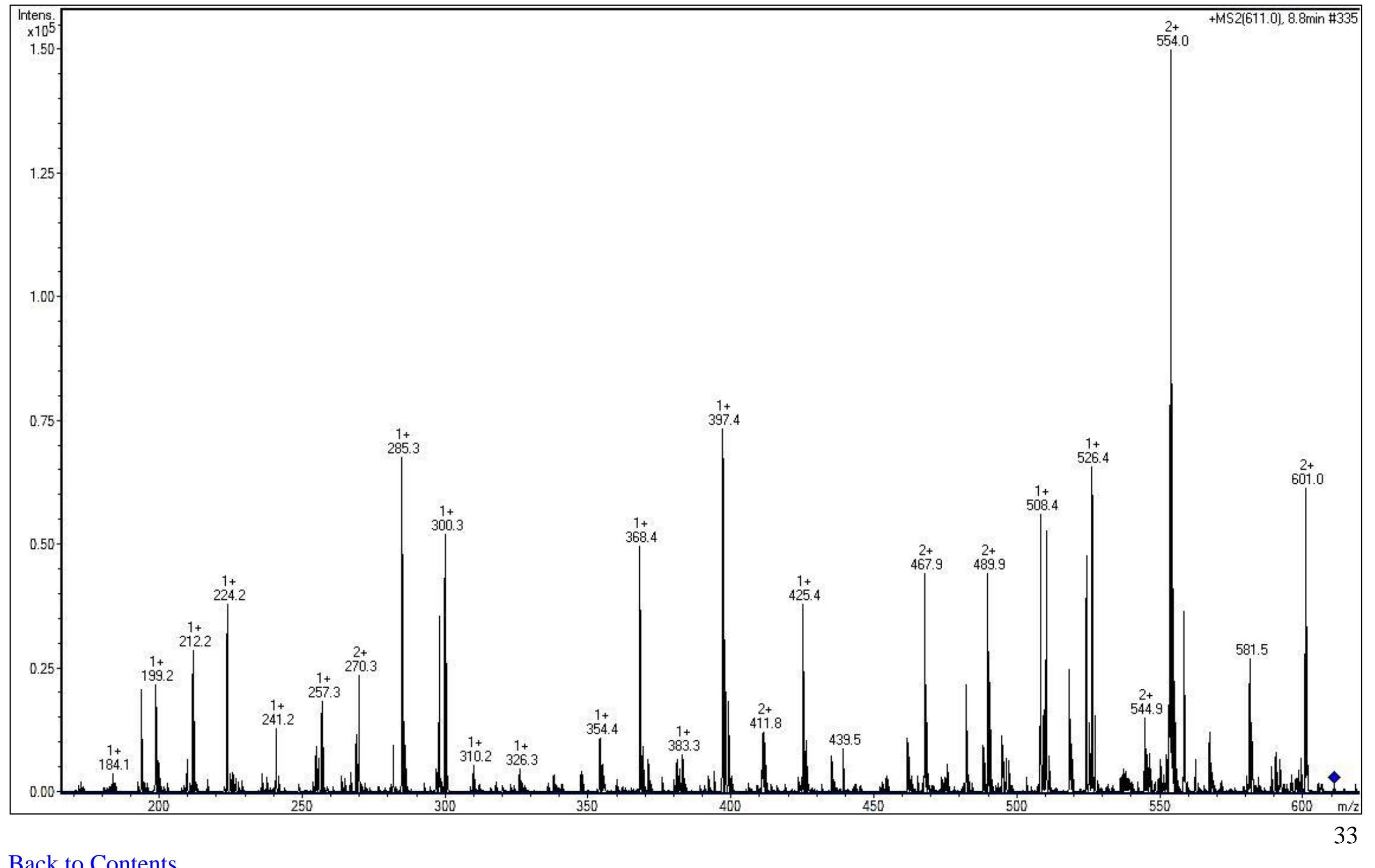

$\underline{\text { Back to Contents }}$ 
CID MS/MS fragmentation of $[\mathrm{M}+2 \mathrm{H}]^{2+}$ ions $(\mathrm{m} / \mathrm{z}$ 611) of $\mathrm{CsC}$, region 620-1225

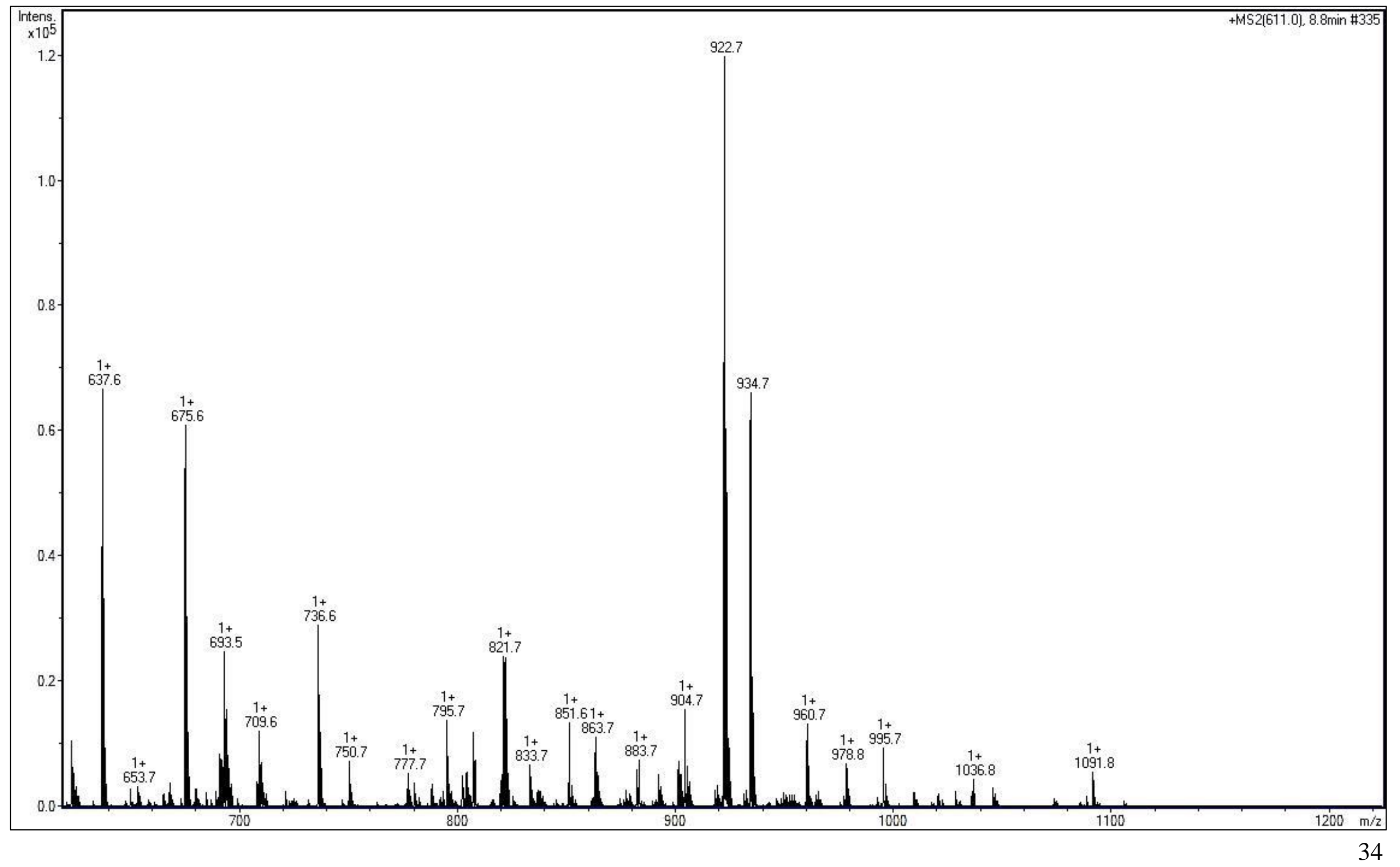

$\underline{\text { Back to Contents }}$ 
Figure S17. CID MS/MS fragmentation of $[\mathrm{M}+2 \mathrm{H}]^{2+}$ ions $(\mathrm{m} / \mathrm{z} 610)$ of isoCsC

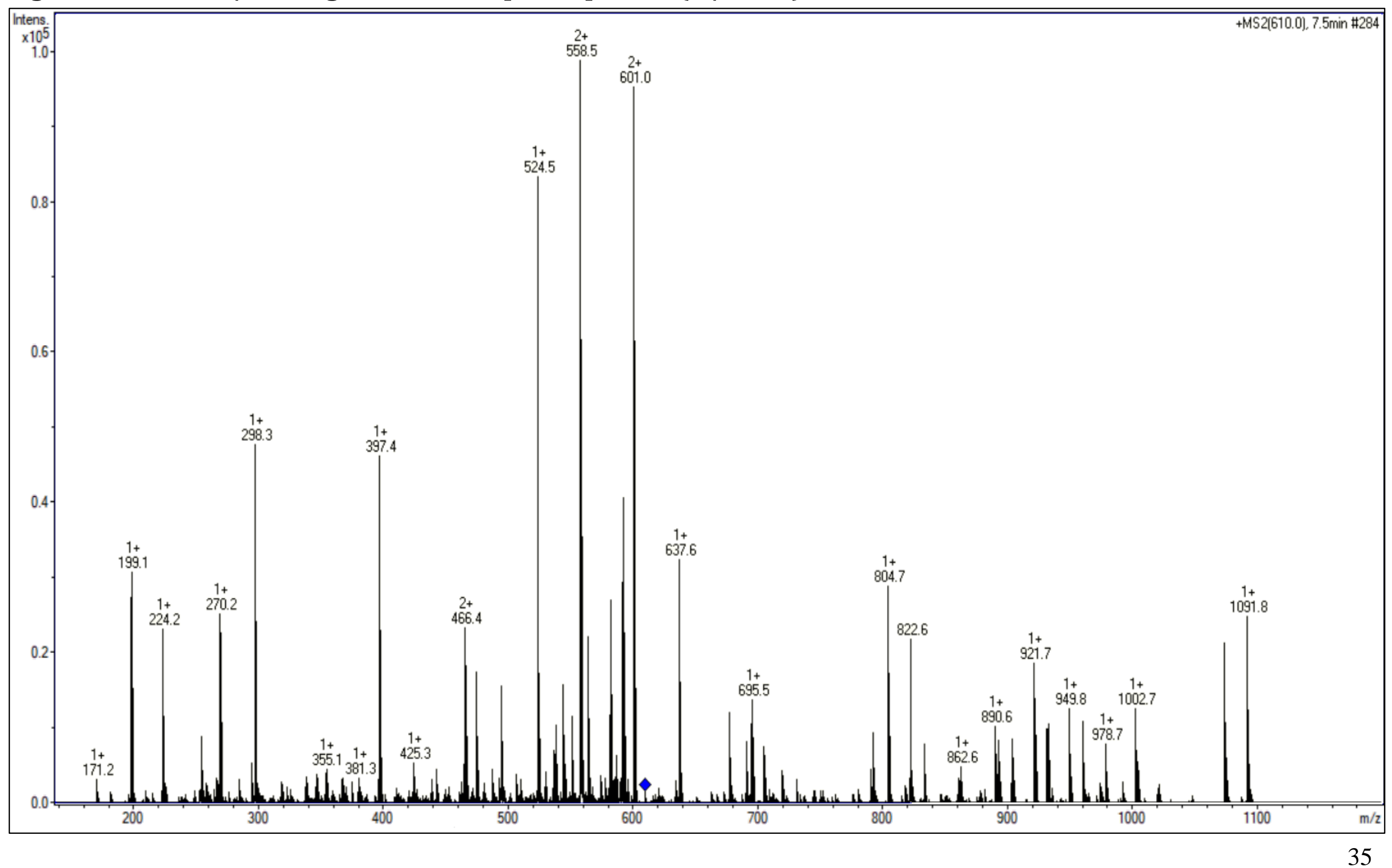

$\underline{\text { Back to Contents }}$ 
CID MS/MS fragmentation of $[\mathrm{M}+2 \mathrm{H}]^{2+}$ ions $(\mathrm{m} / \mathrm{z} 610)$ of isoCsC, region 161-621

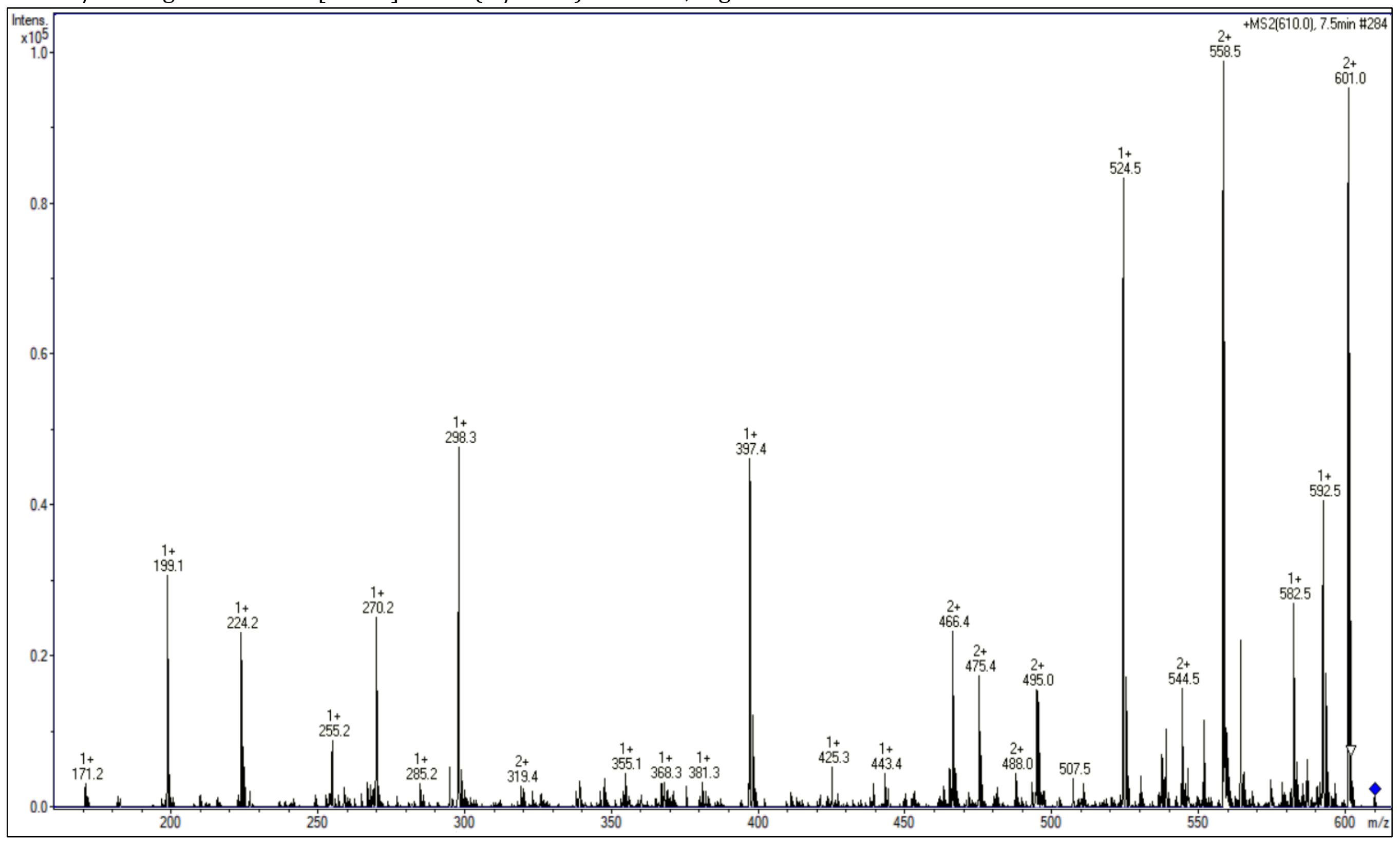

$\underline{\text { Back to Contents }}$ 
CID MS/MS fragmentation of $[\mathrm{M}+2 \mathrm{H}]^{2+}$ ions $(\mathrm{m} / \mathrm{z}$ 610) of isoCsC, region 621-1220

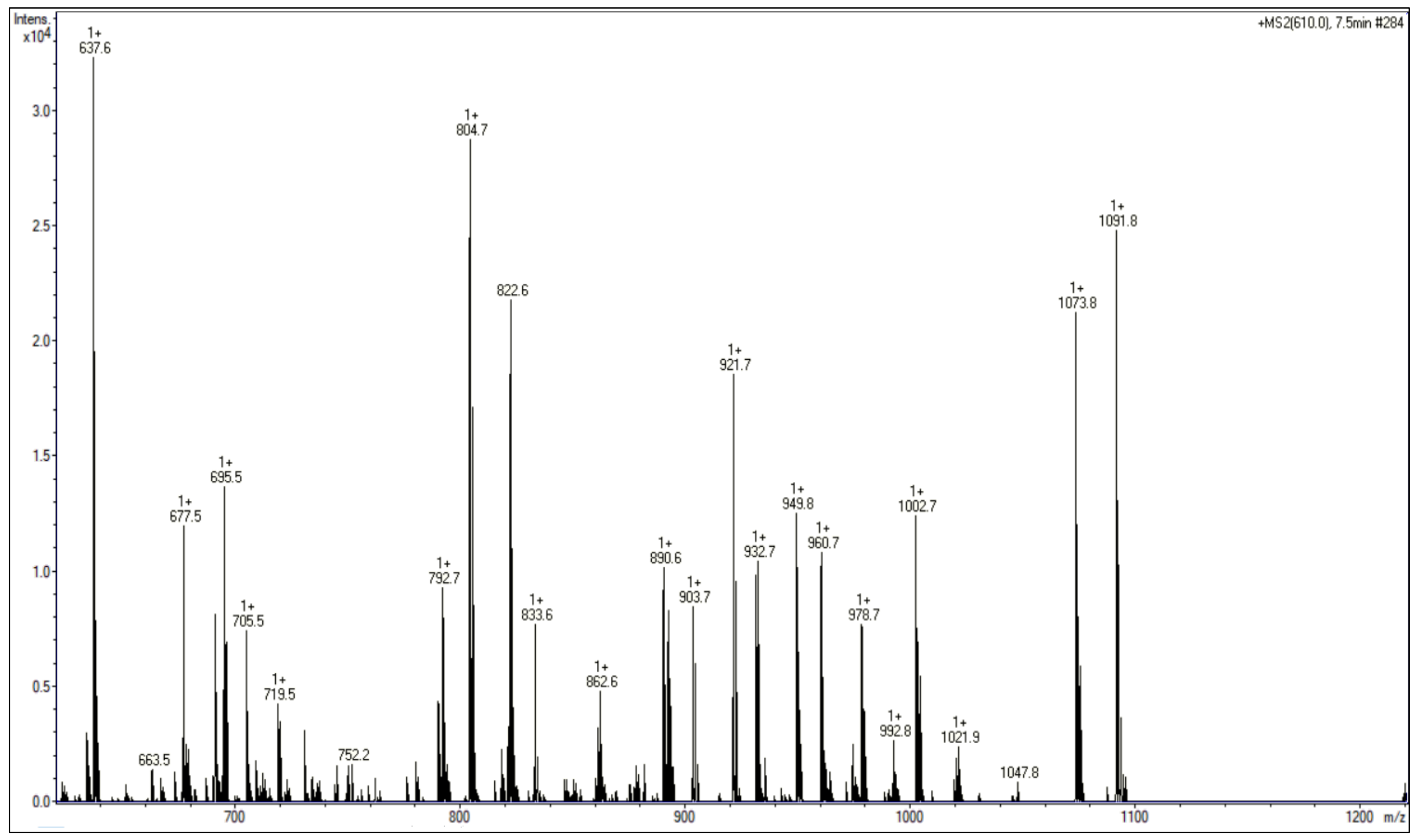

$\underline{\text { Back to Contents }}$ 
Figure S18. CID MS3 fragmentation of ion (m/z 935) of CsA

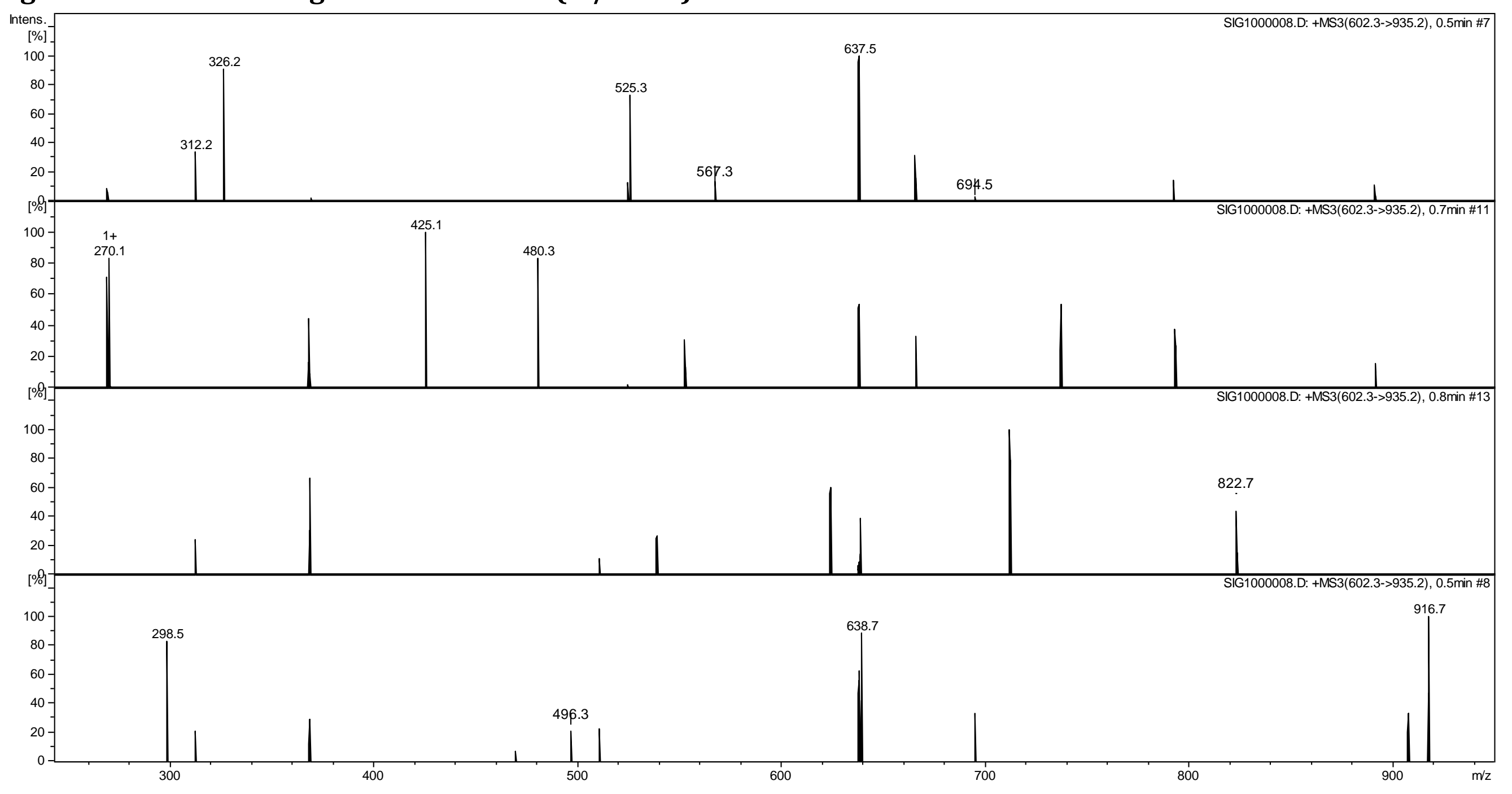


Figure S19. CID MS3 fragmentation of ion (m/z 906) of CsA

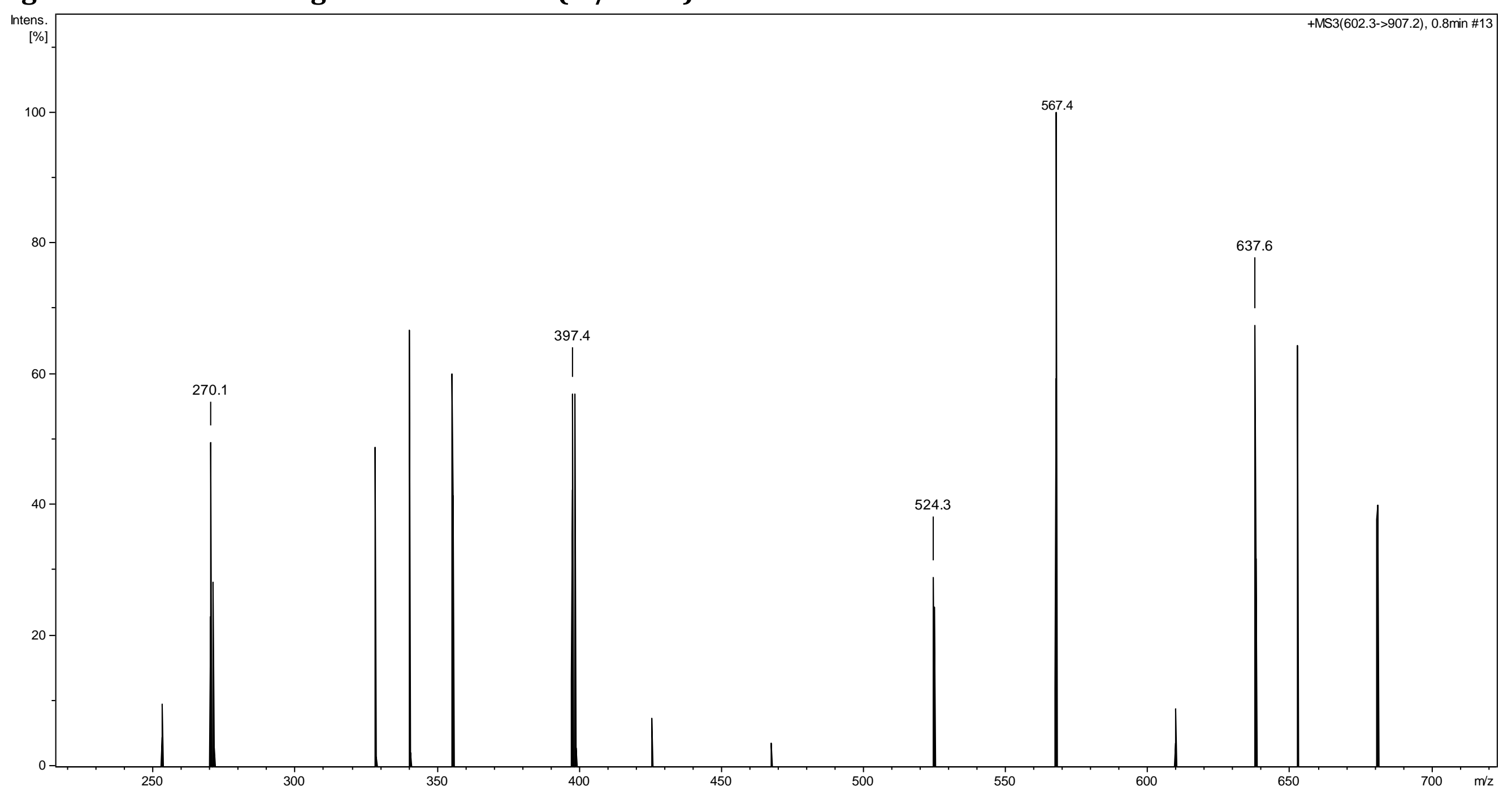


Figure S20. CID MS3 fragmentation of ion (m/z 546) of CsA

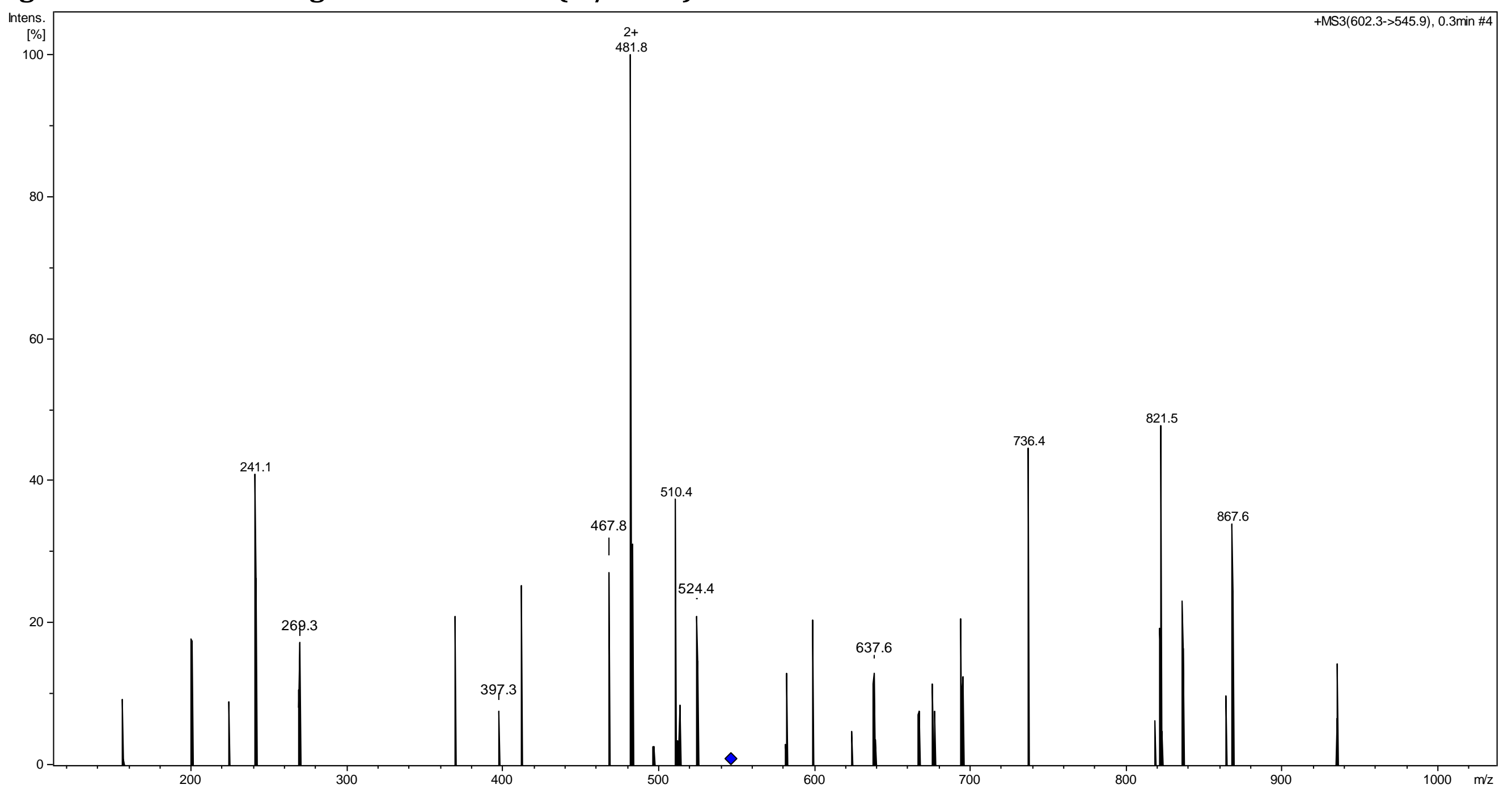


Figure S21. CID MS3 fragmentation of ion (m/z 468) of CsA

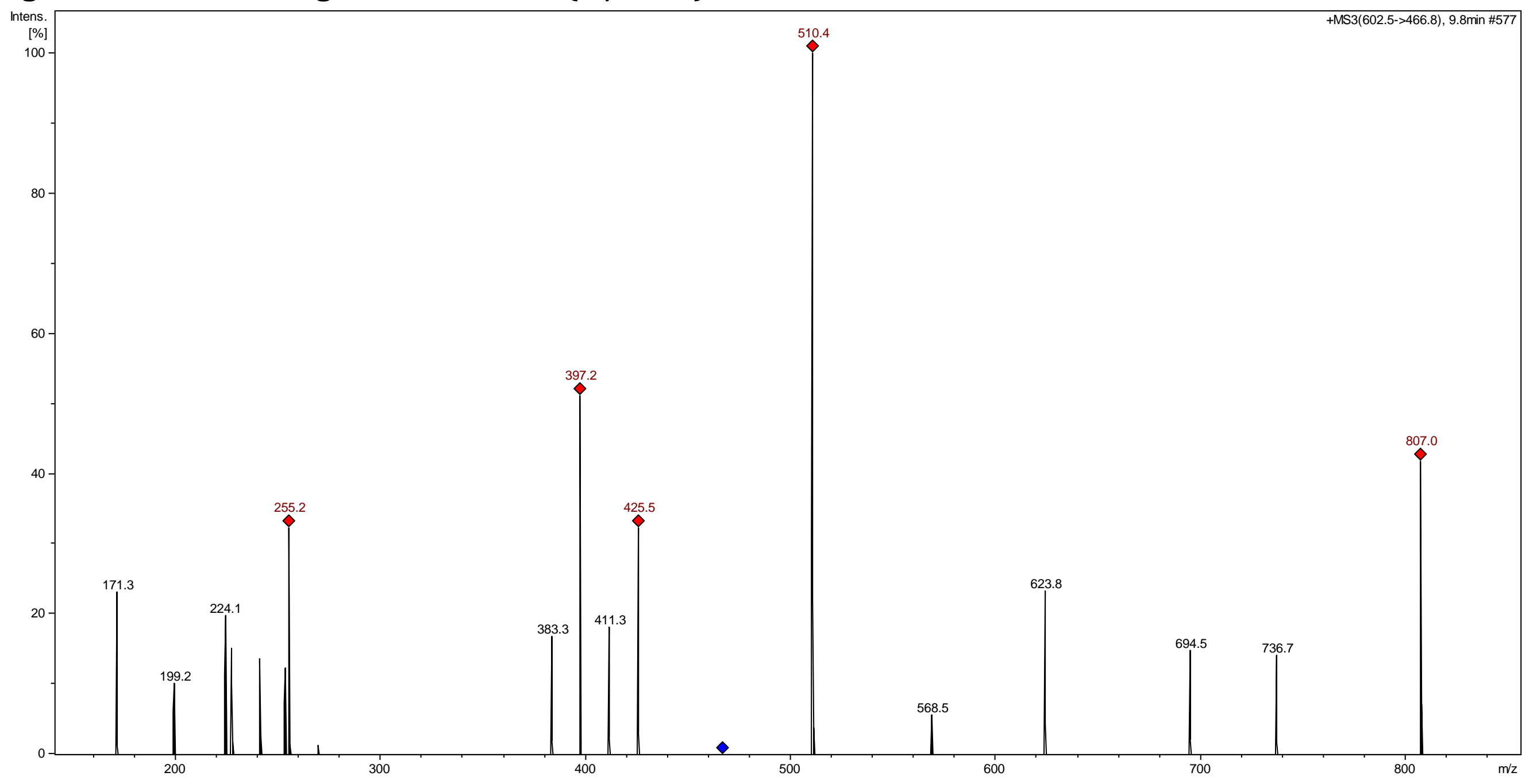


Figure S22. CID MS3 fragmentation of ion (m/z 482) of CsA

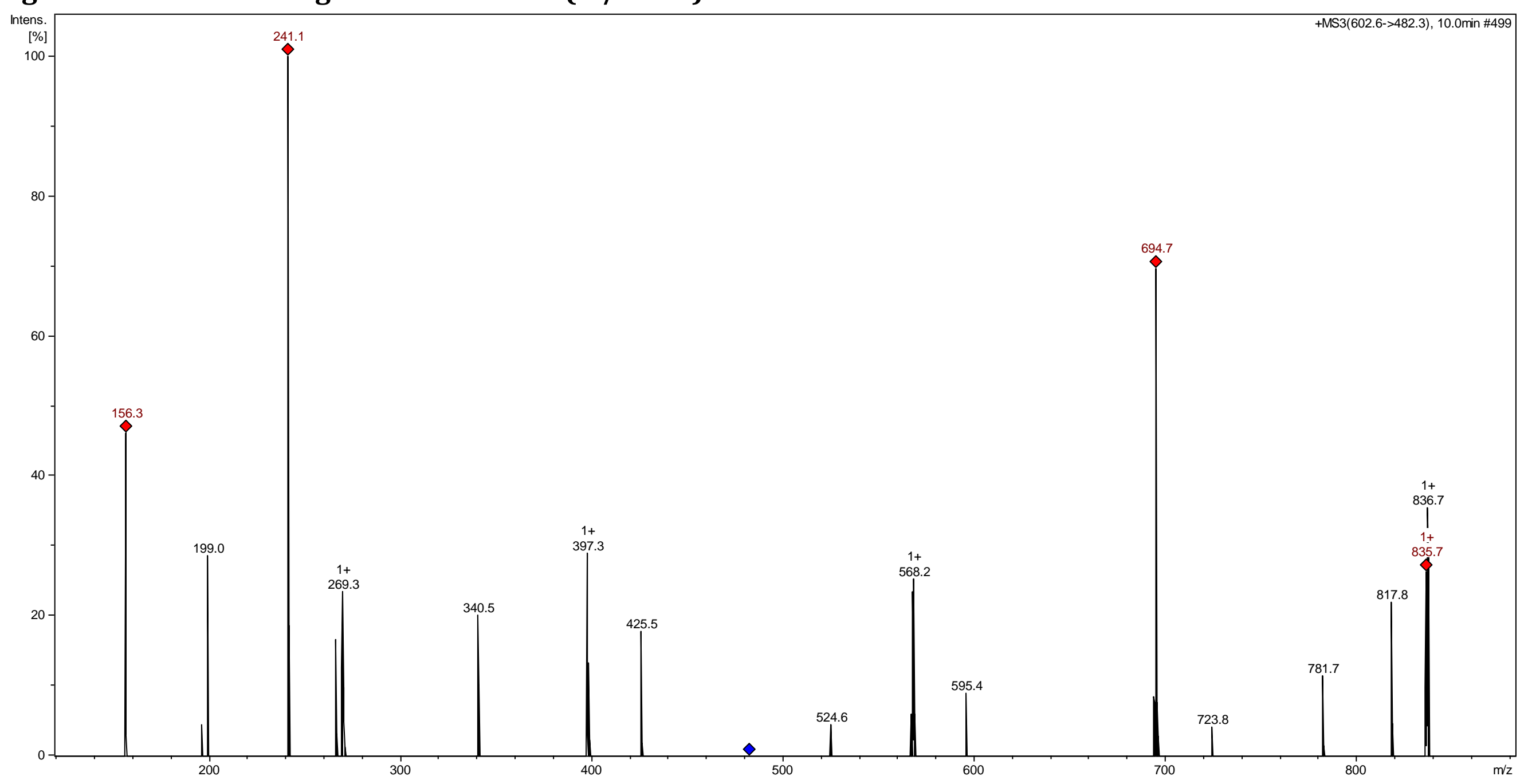


Figure S23. CID MS3 fragmentation of ion ( $\mathrm{m} / \mathrm{z} 1076)$ of isoCsA

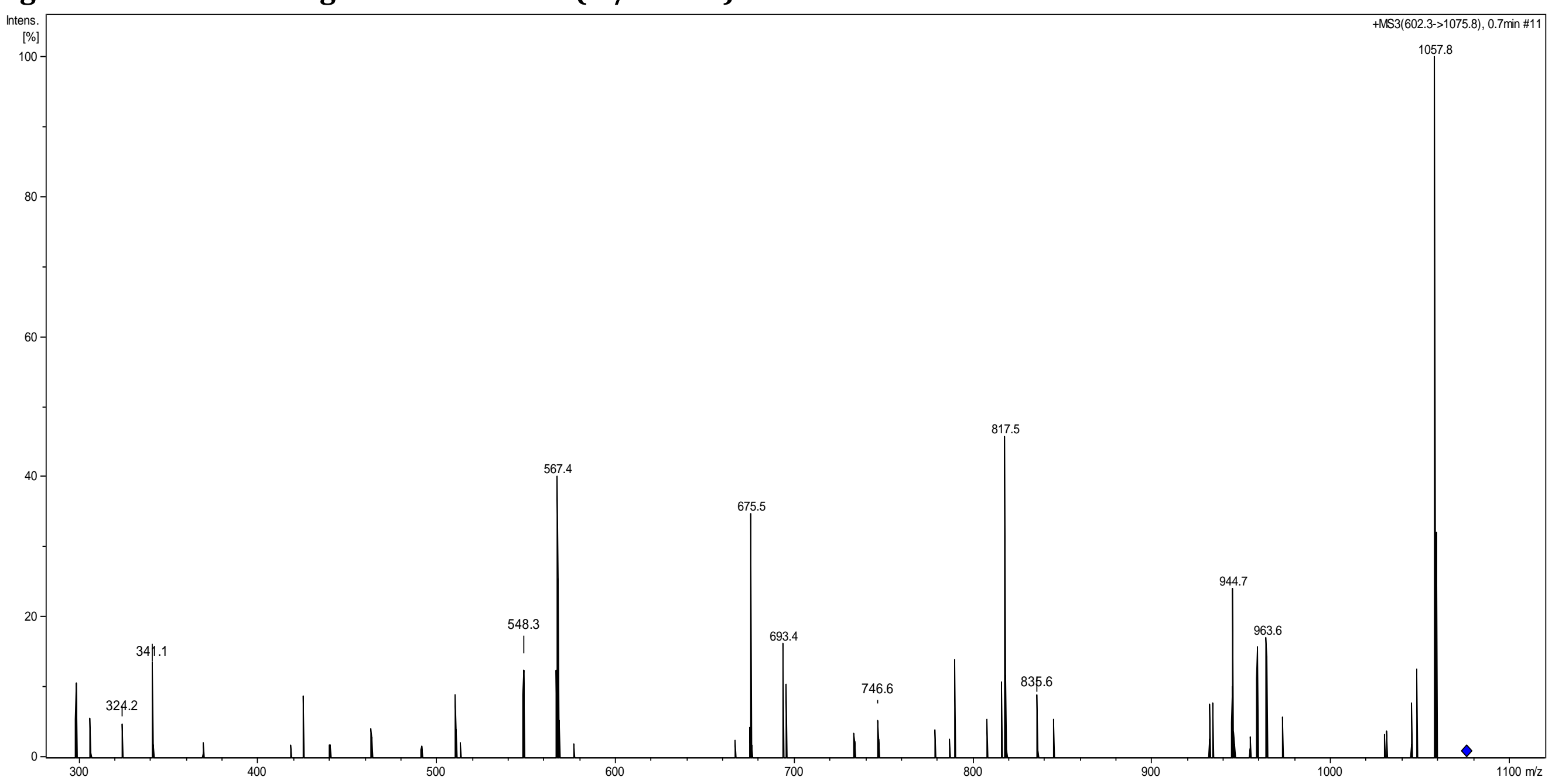


Figure S24. CID MS3 fragmentation of ion (m/z 593) of isoCsA

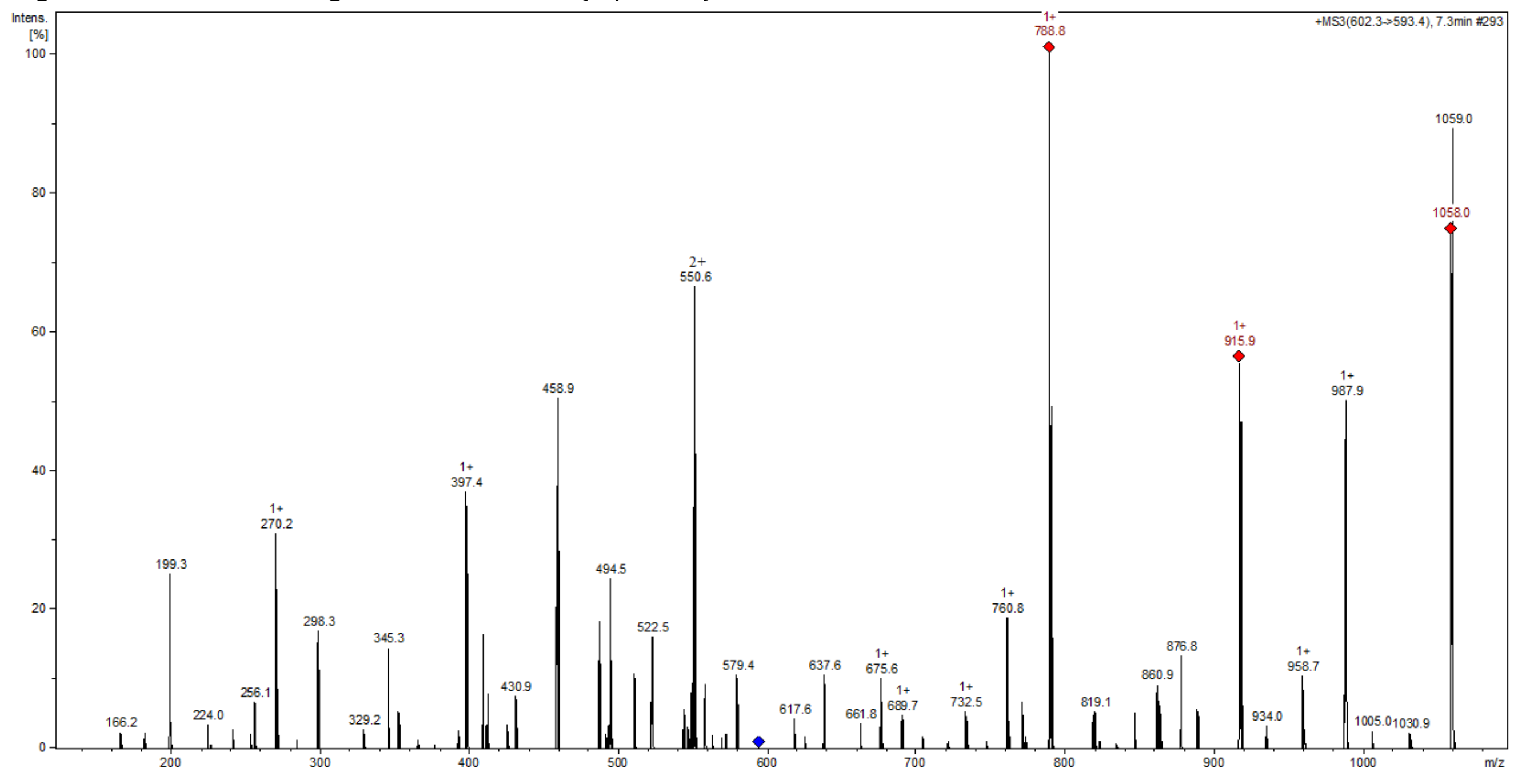


Figure S25. CID MS3 fragmentation of ion (m/z 550) of isoCsA

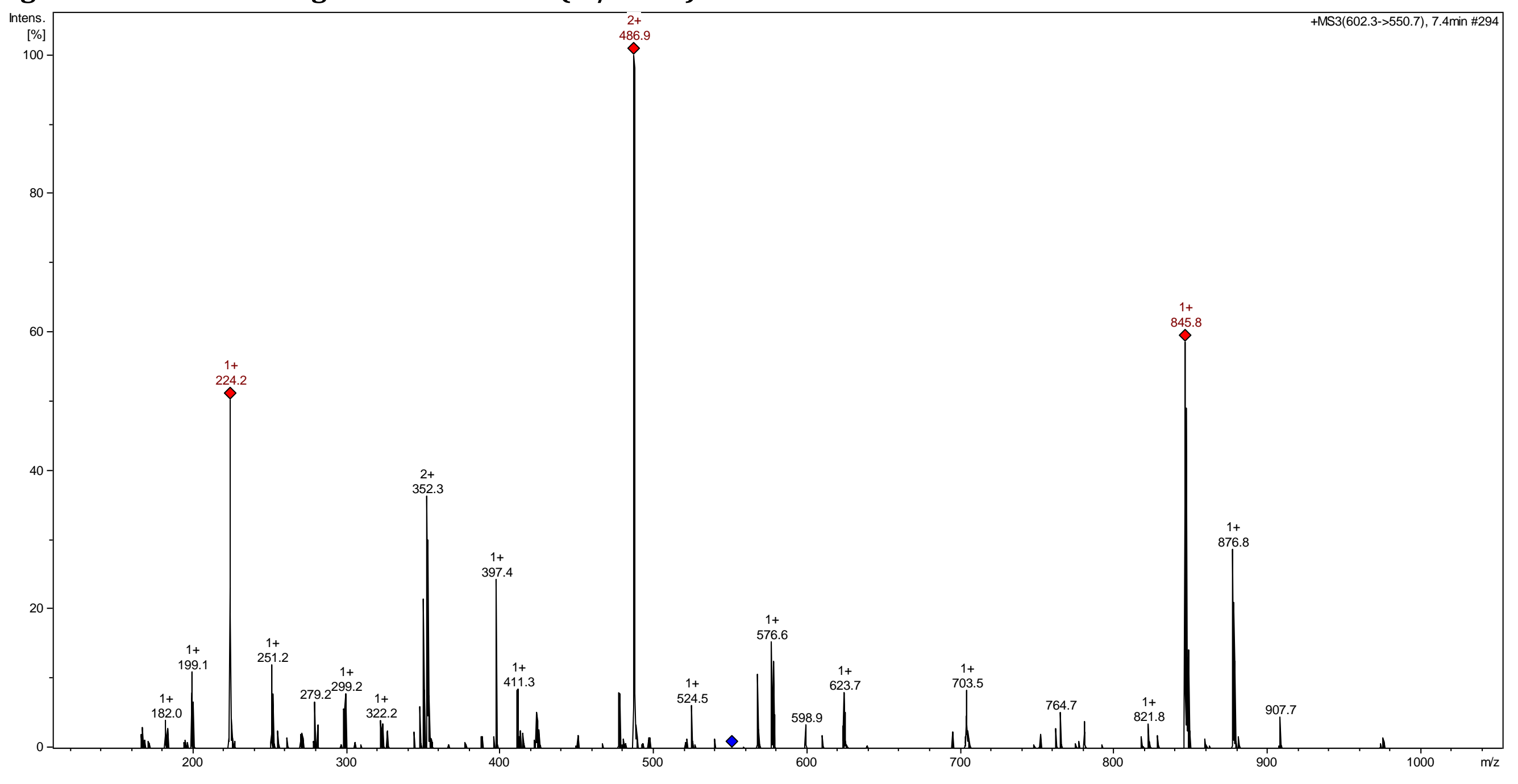


Figure S26. CID MS3 fragmentation of ion (m/z 487) of isoCsA

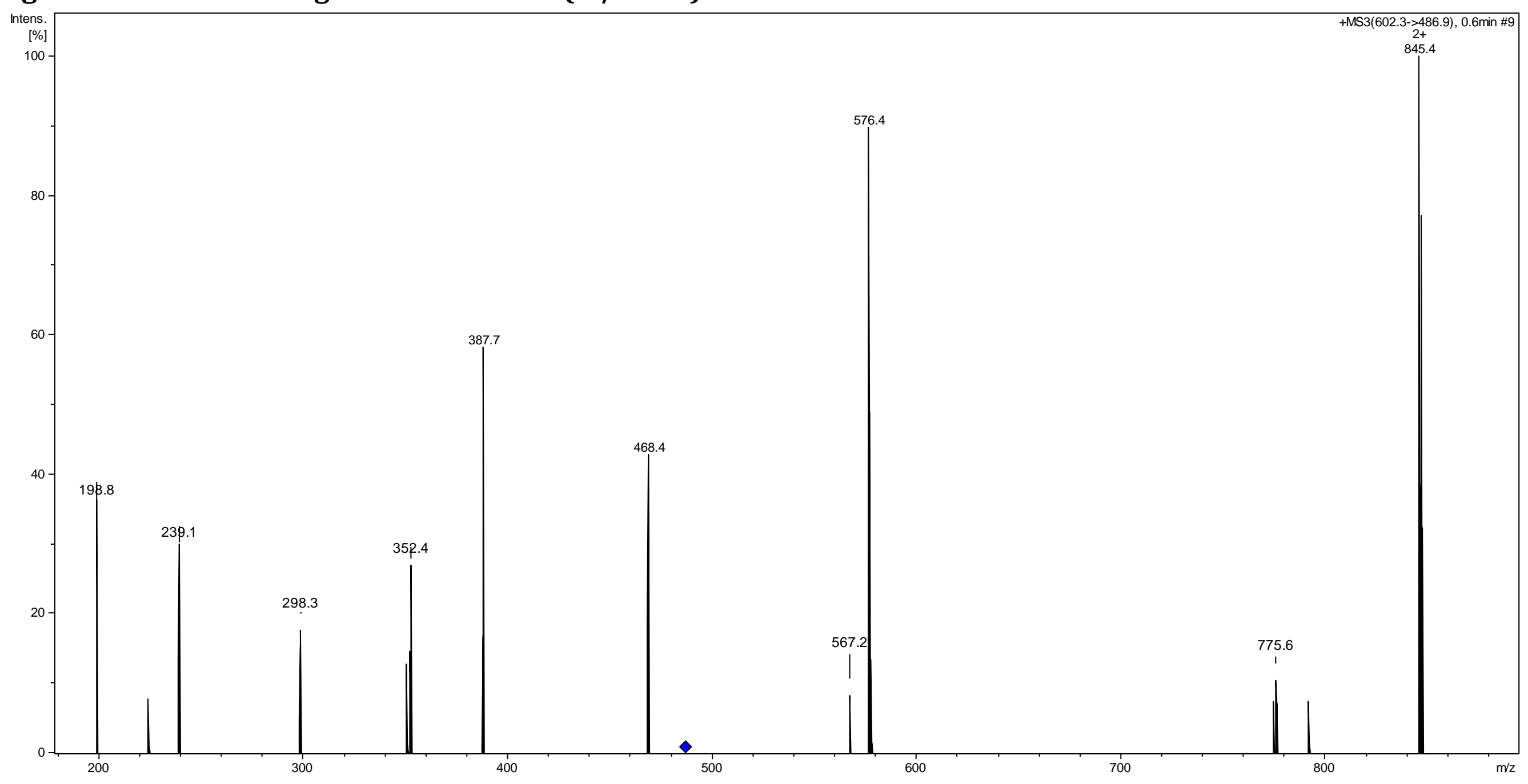

